Elaboração textual via definição de entidades mencionadas e de perguntas relacionadas aos verbos em textos simplificados do português 
SERVIÇO DE PÓS-GRADUAÇÃO DO ICMC-USP

Data de Depósito:

Assinatura:

\section{Elaboração textual via definição de entidades mencionadas e de perguntas relacionadas aos verbos em textos simplificados do português}

\section{Marcelo Adriano Amancio}

Orientadora: Profa. Dra. Sandra Maria Aluísio

Dissertação apresentada ao Instituto de Ciências Matemáticas e de Computação - ICMC-USP, como parte dos requisitos para obtenção do título de Mestre em Ciências - Ciências de Computação e Matemática Computacional. VERSÃO REVISADA.

USP - São Carlos

Agosto/2011 
Ficha catalográfica elaborada pela Biblioteca Prof. Achille Bassi e Seção Técnica de Informática, ICMC/USP, com os dados fornecidos pelo(a) autor(a)

\begin{tabular}{|c|c|}
\hline \multirow[t]{3}{*}{ A $484 \mathrm{e}$} & $\begin{array}{l}\text { Amancio, Marcelo Adriano } \\
\quad \text { Elaboração Textual via Definição de Entidades } \\
\text { Mencionadas e de Perguntas Relacionadas aos Verbos } \\
\text { em Textos Simplificados do Português / Marcelo } \\
\text { Adriano Amancio; orientadora Sandra Maria Aluísio -- } \\
\text { São Carlos, } 2011 . \\
\quad 88 \mathrm{p} \text {. }\end{array}$ \\
\hline & $\begin{array}{l}\text { Dissertação (Mestrado - Programa de Pós-Graduação en } \\
\text { Ciências de Computação e Matemática Computacional) -- } \\
\text { Instituto de Ciências Matemáticas e de Computação, } \\
\text { Universidade de São Paulo, } 2011 \text {. }\end{array}$ \\
\hline & $\begin{array}{l}\text { 1. Elaboração Textual. 2. Atribuição de Papéis } \\
\text { Semânticos. 3. Reconhecimento de Entidades } \\
\text { Mencionadas. 4. Simplificação de Textos. 5. } \\
\text { Processamento de Língua Natural. I. Aluísio, Sandra }\end{array}$ \\
\hline
\end{tabular}




\section{Resumo}

Esta pesquisa aborda o tema da Elaboração Textual para um público alvo que tem letramento nos níveis básicos e rudimentar, de acordo com a classificação do Indicador Nacional de Alfabetismo Funcional (INAF, 2009). A Elaboração Textual é definida como um conjunto de técnicas que acrescentam material redundante em textos, sendo tradicionalmente usadas a adição de definições, sinônimos, antônimos, ou qualquer informação externa com o objetivo de auxiliar na compreensão do texto. O objetivo deste projeto de mestrado foi a proposta de dois métodos originais de elaboração textual: (1) via definição das entidades mencionadas que aparecem em um texto e (2) via definições de perguntas elaboradas direcionadas aos verbos das orações de um texto. Para a primeira tarefa, usou-se um sistema de reconhecimento de entidades mencionadas da literatura, o Rembrandt, e definições curtas da enciclopédia Wikipédia, sendo este método incorporado no sistema Web FACILITA EDUCATIVO, uma das ferramentas desenvolvidas no projeto PorSimples. O método foi avaliado de forma preliminar com um pequeno grupo de leitores com baixo nível de letramento e a avaliação foi positiva, indicando que este auxílio facilitou a leitura dos usuários da avaliação. O método de geração de perguntas elaboradas aos verbos de uma oração é uma tarefa nova que foi definida, estudada, implementada e avaliada neste mestrado. A avaliação não foi realizada junto ao público alvo e sim com especialistas em processamento de língua natural que avaliaram positivamente o método e indicaram quais erros influenciam negativamente na qualidade das perguntas geradas automaticamente. Existem boas indicações de que os métodos de elaboração desenvolvidos podem ser úteis na melhoria da compreensão da leitura para o público alvo em questão, as pessoas com baixo nível de letramento. 


\begin{abstract}
This research addresses the topic of Textual Elaboration for low-literacy readers, i.e. people at the rudimentary and basic literacy levels according to the National Indicator of Functional Literacy (INAF, 2009). Text Elaboration consists of a set of techniques that adds extra material in texts using, traditionally, definitions, synonyms, antonyms, or any external information to assist in text understanding. The main goal of this research was the proposal of two methods of Textual Elaboration: (1) the use of short definitions for Named Entities in texts and (2) assignment of wh-questions related to verbs in text. The first task used the Rembrandt named entity recognition system and short definitions of Wikipedia. It was implemented in PorSimples web Educational Facilita tool. This method was preliminarily evaluated with a small group of low-literacy readers. The evaluation results were positive, what indicates that the tool was useful for improving the text understanding. The assignment of wh-questions related to verbs task was defined, studied, implemented and assessed during this research. Its evaluation was conducted with NLP researches instead of with low-literacy readers. There are good evidences that the text elaboration methods and resources developed here are useful in helping text understanding for low-literacy readers.
\end{abstract}




\section{Agradecimentos}

Primeiramente, gostaria de agradecer a Deus porque sem Ele nada teria sido feito. Também aos meus pais que sempre me apoiaram nos estudos, mesmo eles não tendo o mesmo privilégio que tive, receberam sabedoria divina para reconhecer a importância do estudo e hoje podem se orgulhar de três filhos cursando pós-graduação na Universidade de São Paulo. Agradeço também a meus irmãos.

À minha orientadora, Profa. Sandra Maria Aluísio, envio um agradecimento especial, ao apoio, sugestões de pesquisa, reuniões, revisões de texto, críticas construtivas e amizade. Dela aprendi muitas coisas, principalmente o amor à pesquisa e a dedicação ao trabalho, mesmo em tarefas que parecem pequenas. Realmente são poucos os pesquisadores que apóiam e cuidam de seus alunos como se fossem filhos; a Profa. Sandra é uma delas. Agradeço-a, também, a sugestão do doutorado.

Também agradeço à Magali Duran a sua grande colaboração com este projeto. Seus insights linguísticos, recursos de apoio, anotação de córpus, desenvolvimento de regras, ajudaram imensamente o desenvolvimento deste projeto. Então agradeço a parceria e desejo muito sucesso na continuidade de seu projeto.

Aos meus amigos mais próximos do Nilc, Jefferson Fontinele, Arnaldo Candido Jr e Érick Galani Maziero, agradeço a presença, amizade, e diversas conversas científicas e não científicas que permitiram meu crescimento na área da computação e ampliação de minha visão de mundo em outros temas.

Por fim, gostaria de agradecer à FAPESP o financiamento que permitiu a pesquisa deste mestrado. 


\section{Sumário}

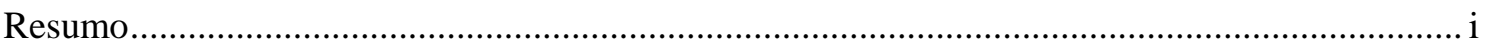

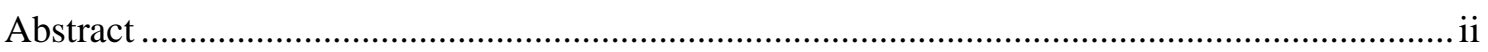

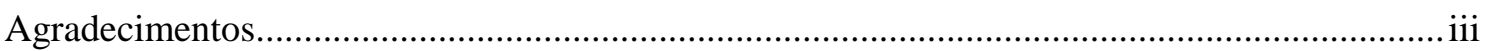

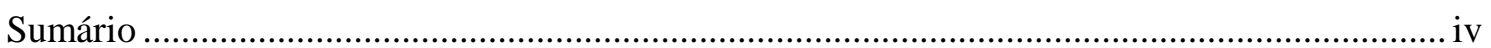

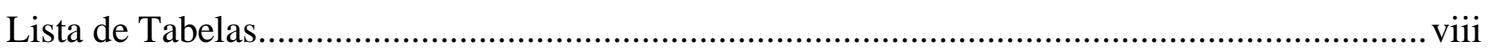

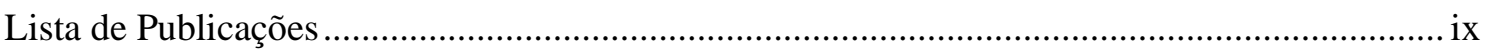

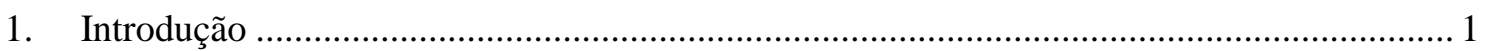

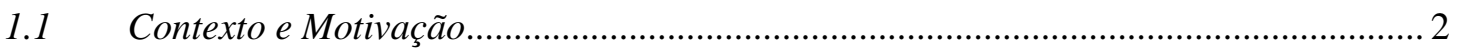

1.2 Objetivos Gerais e Específicos e Questões de Pesquisa ............................................... 4

1.3 A Tarefa de Definição de Entidades Mencionadas ....................................................... 6

1.3.1 A Tarefa de Geração de Perguntas Elaboradas …............................................. 8

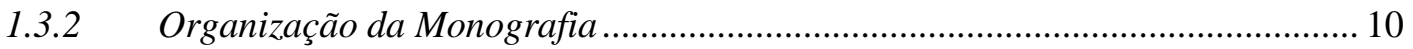

2. Anotação de Papéis Semânticos e de Entidades Mencionadas ............................................. 11

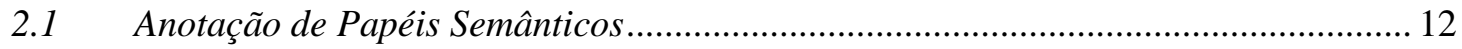

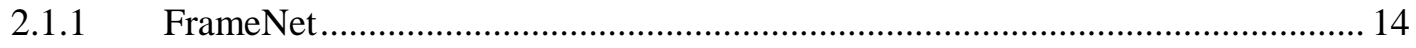

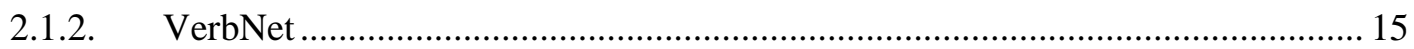

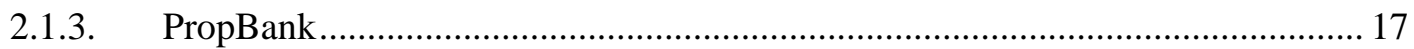

2.1.4. Sistemas de Anotação de Papéis Semânticos ........................................................ 19

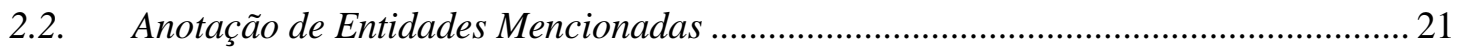

2.2.1. Desafios no Reconhecimento de Entidades Mencionadas ................................... 22

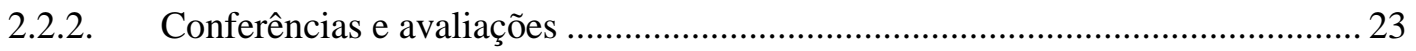

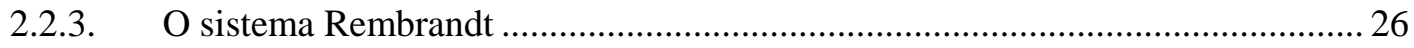

3. Sistema de Elaboração Textual do Português ......................................................................... 29

3.1 Geração de Perguntas Elaboradas em Textos do Português.......................................... 29

3.1.1. Exemplo de elaboração via geração de perguntas elaboradas .................................... 29

3.1.2. Córpus de Trabalho e Etiquetas de Anotação................................................................ 32

3.1.3. Teste da Concordância humana ........................................................................................... 34

3.1.4. O Sistema de Perguntas para a Elaboração Textual (PET) .......................................... 34

3.1.5. A avaliação do sistema PET com juízes humanos ........................................................... 46

3.2. Definições de Entidades Mencionadas para a Elaboração de Textos em Português. 62

3.2.1. Extratos da Wikipedia para o português.................................................................. 62

3.2.2. O sistema Facilita Educacional para a elaboração de textos na Web ................ 63

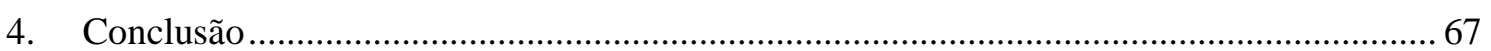

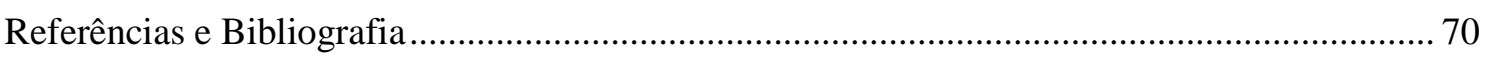


Anexo A: Tabela de Verbos Auxiliares

Apêndice A: Formação de Perguntas .

Apêndice B: Manual de Avaliação do Elatex

80

Apêndice C: Tabelas dos valores de Chi-Quadado para o cálculo da estatística entre as variáveis de qualidade de geração de sentença e os oito tipos de erros 86 


\section{Lista de Figuras}

Figura 1: Níveis de letramento identificados pelo Indicador Nacional de Alfabetismo Funcional (INAF) do Instituto Paulo Montenegro, IBOPE (www.ipm.org.br): rudimentar, básico e avançado/pleno. 2

Figura 2: O Sistema de Elaboração Textual do Português ............................................................. 5

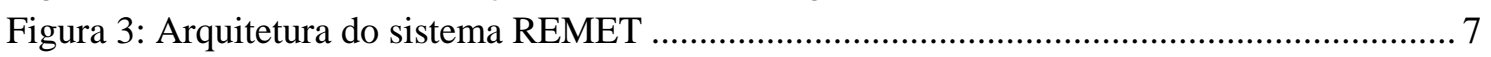

Figura 4: Informações detalhadas sobre a entidade PUC .......................................................... 8

Figura 5: Elaboração levantada a partir da identificação da relação entre o verbo da oração e

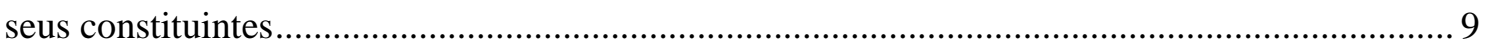

Figura 6: As três tarefas para a geração de perguntas Elaboradas a uma sentença com análise

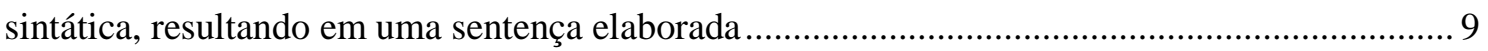

Figura 7: Trecho do sistema Cortex que mostra verbos destacados em verde ............................. 10

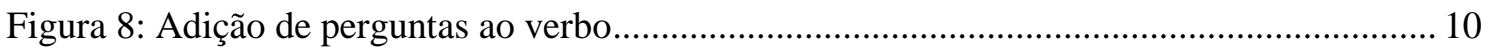

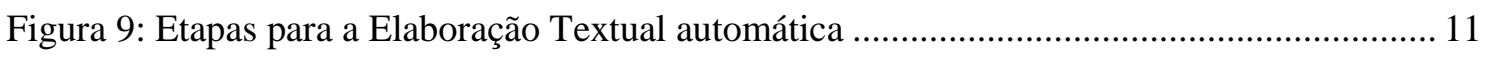

Figura 10: Domínio dos frames e herança especialização de frames........................................... 15

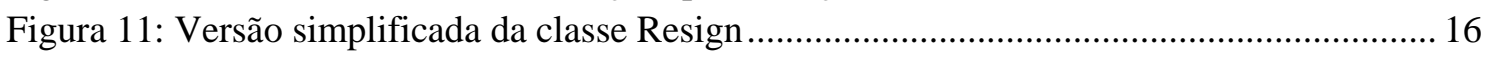

Figura 12: Sentença do córpus Zero Hora (zh023.s17) .......................................................... 30

Figura 13: Árvore sintática gerada pelo parser Palavras para a seguinte sentença: "Ontem,

Nelson Hubner avisou que o governo pensa em elevar a taxa para 3\% de forma autorizada." .. 30

Figura 14: As etiquetas mais frequentes atribuídas às sentenças do córpus................................ 33

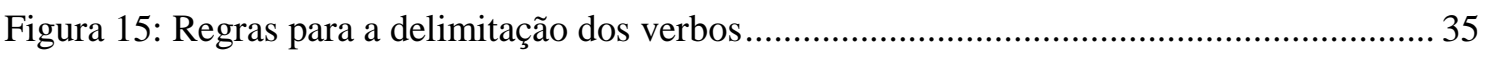

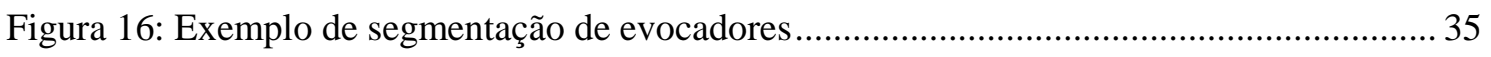

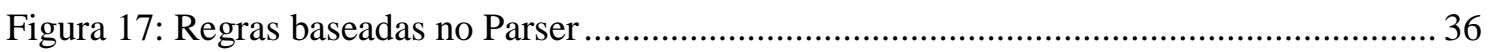

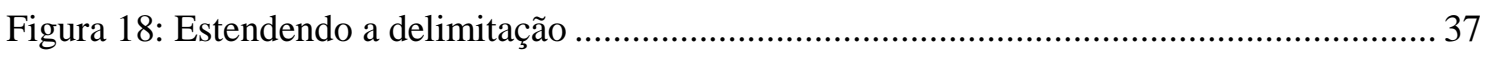

Figura 19: Treinamento e a avaliação do melhor classificador ................................................... 37

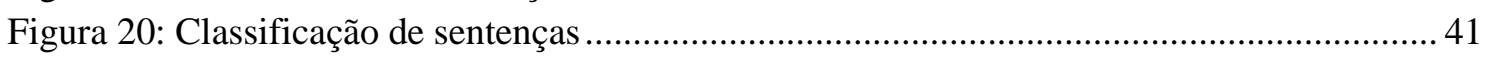

Figura 21: Regras para a elaboração de sentenças .................................................................... 41

Figura 22: Etiquetas do Palavras para indicar que um predicativo é um verbo de ligação......... 42

Figura 23: Regra de geração de perguntas para verbos de ligação............................................... 42

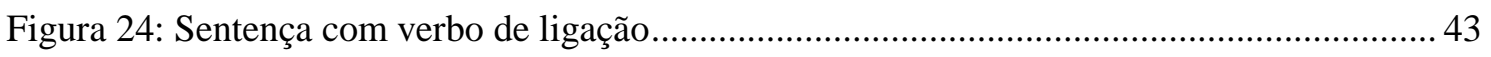

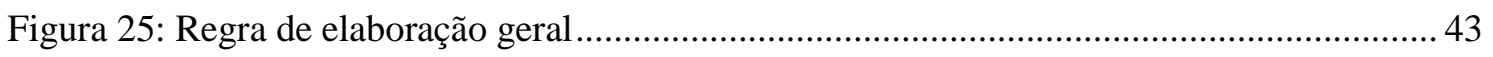

Figura 26: Regra específica para as etiquetas "Qual?-ESQ" e "Quais?-ESQ" ............................ 44

Figura 27: Exemplo de aplicação da regra da etiqueta qual, quais ............................................ 44

Figura 28: Aplicação da regra de inversão do pronome reflexivo em início de frase .................. 44

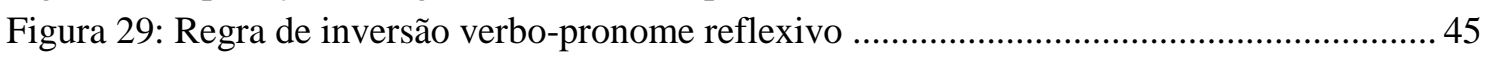

Figura 30: Conjugação do verbo na terceira pessoa do singular ............................................... 45

Figura 31: Conjugação do frame evocador na terceira pessoa do singular ................................. 45

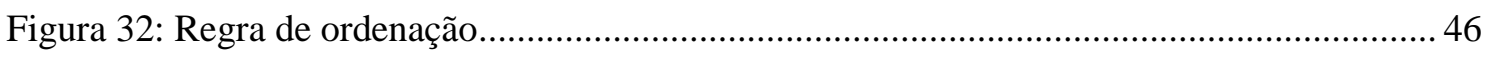

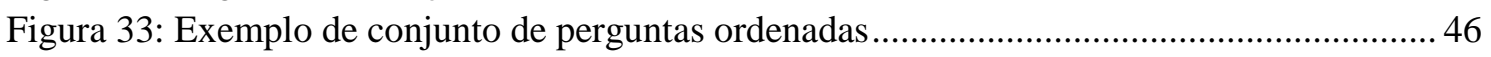

Figura 34: Sentença exemplo da folha de anotação ................................................................. 53

Figura 35: Dados da avaliação do sistema com os juízes selecionados ...................................... 53

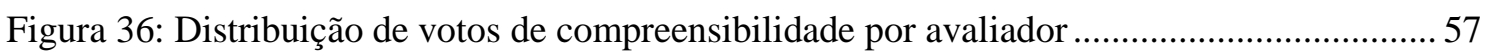

Figura 37: Distribuição de votos de naturalidade por avaliador................................................ 57

Figura 38: Porcentagem da compreensibilidade, naturalidade................................................... 58

Figura 39: Porcentagem dos seis tipos de erros possíveis na pergunta $(\mathrm{P})$ e dois possíveis na

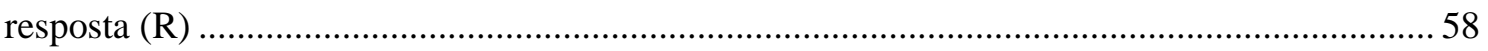

Figura 40: Valores de compreensibilidade e Naturalidade mais votados entre os juízes............. 59 
Figura 41: Calculo de relevância por avaliador.

Figura 42: Elaboração via definição de entidades mencionadas no aplicativo Facilita

Educacional

64

Figura 43:Sinônimo de elaboração da palavra "ligeiramente". 


\section{Lista de Tabelas}

Tabela 1: Simulação das etapas da tarefa de Elaboração via definição de entidades mencionadas

Tabela 2: Resultado da classificação semântica do HAREM I ...................................................... 25

Tabela 3: Resultado da classificação semântica do HAREM II .................................................... 25

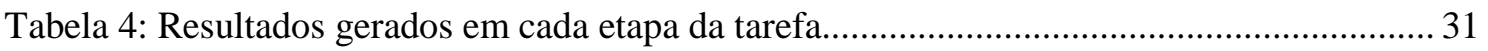

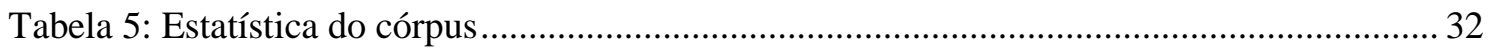

Tabela 6: Valores F-measure para os algoritmos de aprendizado de máquina para a tarefa de

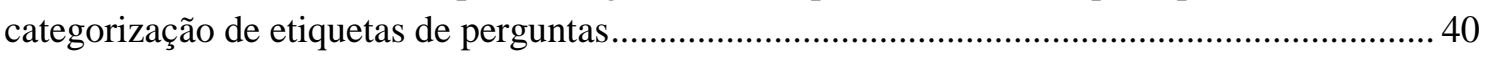

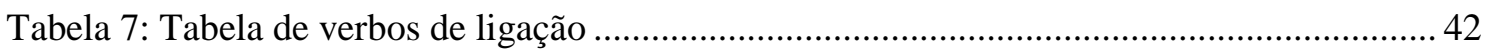

Tabela 8: Descrição dos tipos de valores da variável Compreensibilidade................................... 48

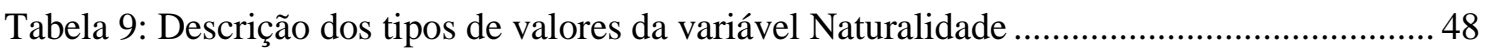

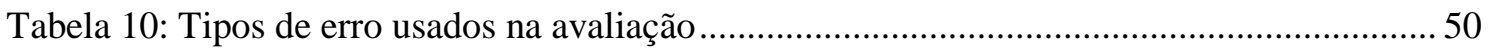

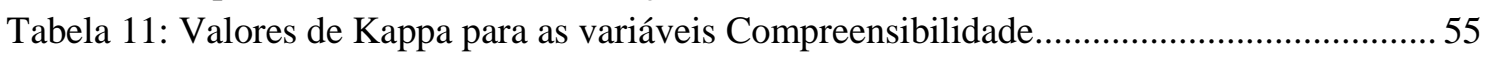

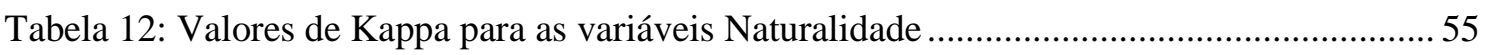

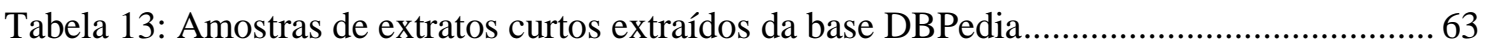

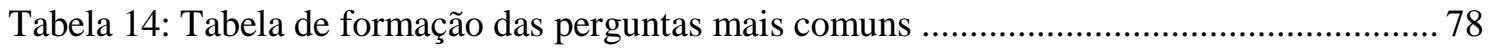

Tabela 15: Etiquetas que possuem sua formação específica e menos previsível ......................... 79

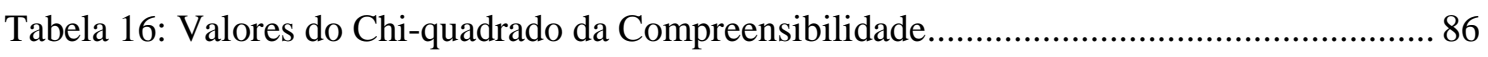

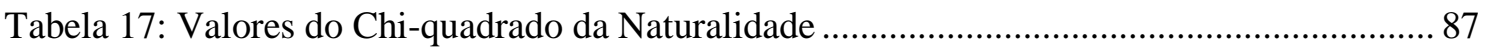




\section{Lista de Publicações}

Amancio, M.A.; Duran, M. S.; Aluísio, S. M. Automatic Question Categorization: a New Approach for Text Elaboration. Procesamiento del Lenguaje Natural, v. 46, p. 43$50,2011$.

Amancio, M.A., Duran, M.S. and Aluisio, S.M. Automatic Question Categorization: a New Approach for Text Elaboration. Proceedings of the Workshop in Natural Language Processing and web-based Technologies 2010, in conjunction with IBERAMIA 2010, p. 21-30.

Watanabe, W. M. ; Cândido, Arnaldo ; Amancio, M.A. ; Oliveira, M. ; Pardo, T. A. S. ; Fortes, R. P. M. ; Aluísio, S. M. . Adapting Web content for low-literacy readers by using lexical elaboration and named entities labeling. New Review of Hypermedia and Multimedia, v. 16, p. 303-327, 2010.

Duran, M. S. ; Amancio, M.A. ; ALUÍSIO, S. M. . Assigning Wh-Questions to Verbal Arguments in a Córpus of Simplified Texts. In: International Conference on Computational Processing of Portuguese Language (PROPOR 2010), 2010, Porto Alegre. PROPOR 2010 Extended Activities Proceedings, 2010. v. 1. p. 1-6.

Duran, M. S. ; Amancio, M.A. ; ALUÍSIO, S. M. . Assigning Wh-Questions to Verbal Arguments: Annotation Tools Evaluation and Córpus. In: The Seventh Conference on International Language Resources and Evaluation (LREC), 2010, Valletta. CALZOLARI, N. et al. (eds) Proceedings of the Seventh conference on International Language Resources and Evaluation (LREC). Paris : ELRA (European Language Resources Association), 2010. v. 1. p. 1445-1451.

Watanabe, W. M. ; Cândido, Arnaldo ; Amancio, M.A. ; Oliveira, M. ; Pardo, T. A. S. ; FORTES, R. P. M. ; ALUÍSIO, S. M. . Adapting web content for low-literacy readers by using lexical elaboration and named entities labeling. In: The 2010 International Cross Disciplinary Conference on Web Accessibility (W4A), 2010, Raleigh. W4A '10: Proceedings of the 2010 International Cross Disciplinary Conference on Web Accessibility (W4A). New York : ACM, 2010. v. 1. p. 1-9. 


\section{Introdução}

O tema de estudo desta pesquisa é a Elaboração Textual (ET) (Urano, 2000; Yano et al., 1994; Burstein et al., 2007; Rahimi, 2011), definida como um conjunto de técnicas para acrescentar material redundante em textos, sendo tradicionalmente usadas a adição de definições, sinônimos, antônimos, ou qualquer informação externa com o objetivo de auxiliar na compreensão do texto por meio dessa informação complementar.

Sabe-se que no processo de leitura, três fatores principais são responsáveis pela compreensão do texto: o texto, o leitor e a atividade na qual o leitor faz parte (Snow, 2002). Se o texto a ser lido contiver material redundante via exemplificações, repetições, paráfrases, definições e sinônimos para termos ou conceitos complexos, ele fornecerá oportunidades aos leitores para processar a informação contida nele e desta forma melhorar a sua compreensão (Rahimi, 2011). É importante notar que a técnica de elaboração mantém palavras não familiares intactas, fornecendo uma oportunidade extra de aumentar o vocabulário do leitor (Urano, 2000). Nesse sentido, a ET, se bem desenvolvida, possibilita um aumento na compreensão do texto uma vez que acrescenta informação útil ao texto. Contudo, a Elaboração Textual é apenas um dos métodos conhecidos da grande área de Adaptação Textual.

A Adaptação Textual (AT) é uma atividade muito comum no meio educacional para facilitar a leitura e compreensão de conteúdos específicos ou para melhorar o aprendizado de línguas (Burstein, 2009). Beneficia tanto aprendizes de língua estrangeira como crianças na fase de alfabetização através de um maior contato com textos de diversos gêneros. A AT também pode beneficiar audiências com necessidades especiais, tais como leitores com baixa escolaridade, adultos na fase de alfabetização ou pessoas cursando educação à distância (uma vez que a compreensibilidade de textos é um fator de importante para esse público), pessoas com problemas auditivos que se comunicam por meio da linguagem de sinais e querem aprender as línguas faladas, tais como Inglês ou Português, dentre outros públicos (Aluísio \& Gasperin, 2010).

Estudos em AT tentam responder duas questões: $O$ que é modificado? e Como é modificado?. Para responder à primeira questão as pesquisas investigam modificações nos diferentes níveis linguísticos: fonológico, lexical, sintático e discursivo. Já para a segunda, existem duas grandes abordagens de adaptações: a Elaboração Textual, definida no início desta Introdução, e a Simplificação Textual. Esta última pode ser 
definida como qualquer tarefa que reduza a complexidade de um texto (por exemplo, no nível lexical ou sintático), enquanto tenta preservar o significado e a informação (Siddharthan, 2003, 2004).

\subsection{Contexto e Motivação}

As motivações para se pesquisar na área de ET vieram do projeto PorSimples ${ }^{1}$ (Simplificação Textual do Português para Inclusão e Acessibilidade Digital) (Aluísio et al., 2008a, 2008b; Caseli et al., 2009, Candido Jr. et al., 2009, Aluísio \& Gasperin, 2010, Watanabe et al., 2010), do qual esta pesquisa fez parte. O PorSimples (proc. Nro. 2007/54565-8) foi aprovado no âmbito do Edital MS Research-Fapesp e teve como objetivo a construção de recursos linguísticos e computacionais para possibilitar o acesso facilitado a textos da Web em português a usuários com dificuldades de leitura. Lacuna encontrada largamente no Brasil devido às deficiências nas bases do ensino, como mostra, por exemplo, o Indicador Nacional de Alfabetismo Funcional (INAF) (INAF, 2009). O INAF vem sendo calculado pelo IBOPE desde 2001 para mensurar os níveis de alfabetismo funcional da população brasileira como pode ser observado na Figura 1.

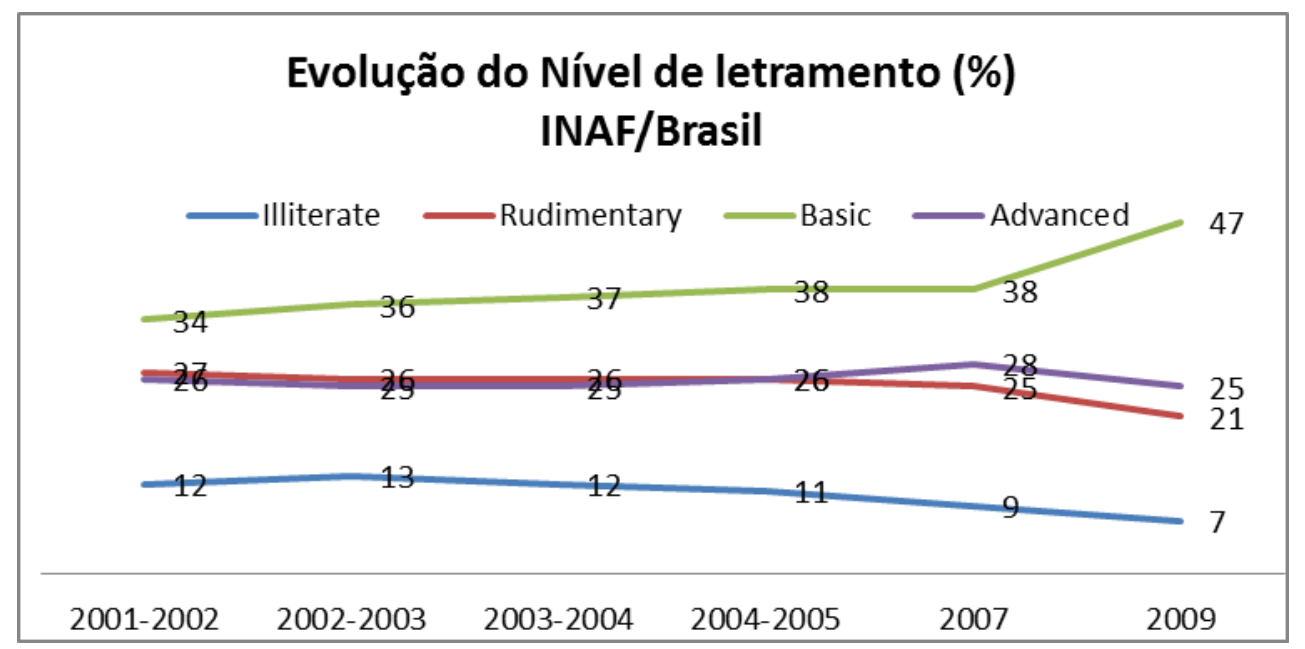

Figura 1: Níveis de letramento identificados pelo Indicador Nacional de Alfabetismo Funcional (INAF) do Instituto Paulo Montenegro, IBOPE (www.ipm.org.br): rudimentar, básico e avançado/pleno

A Figura 1 apresenta uma caracterização mais detalhada destes usuários alvo do projeto PorSimples, o que direcionou a criação de sistemas específicos para atender pessoas com os vários níveis de letramento.

\footnotetext{
${ }^{1}$ http://caravelas.icmc.usp.br/wiki/index.php/Principal
} 
O INAF aponta dois níveis de alfabetismo para melhor capturar os problemas de letramento da população:

i. Alfabetismo em nível rudimentar: pessoas classificadas nesse nível possuem a capacidade de localizar informações explícitas em textos curtos, um anúncio ou pequena carta;

ii. Alfabetismo em nível básico: pessoas classificadas nesse nível possuem capacidade de localizar informações em textos um pouco mais extensos, podendo realizar pequenas inferências.

Na Figura 1 pode-se observar que em 2009 a porcentagem de brasileiros nos níveis de letramento rudimentar e básico totalizou 68\%, um nível preocupante. Para possibilitar o acesso facilitado de textos da Web em português para essas duas classes de letramento, foram propostos no PorSimples métodos e técnicas de duas grandes áreas de pesquisa: o Processamento de Língua Natural (PLN) e a área de pesquisa em Interação Usuário-Computador, e desenvolvidos:

i. Um sistema de autoria (chamado SIMPLIFICA) para apoiar a produção de textos simplificados no qual textos originais recebem simplificação léxica e sintática com possível pós-edição pelos autores. Há possibilidade de escolher o nível de letramento para a simplificação sintática, pois o sistema ativa um sistema baseado em regras para o nível rudimentar (Gasperin et al., 2010) e um baseado em aprendizado de máquina para o nível básico (Gasperin et al., 2009);

ii. Um sistema de suporte à leitura rápida para se obter a informação principal de um texto e possibilitar que analfabetos funcionais tenham fácil acesso ao conteúdo da Web (chamado de FACILITA), composto de ferramentas de simplificação e sumarização (Watanabe et al., 2010);

iii. Um sistema de suporte à leitura detalhada para melhorar o nível de letramento do leitor (FACILITA EDUCATIVO), que usa a elaboração lexical e rotulação de entidades mencionadas, com apresentação de definições curtas da Wikipédia para termos considerados complexos (Watanabe et al., 2009). Esse sistema já inclui o método de elaboração textual via definição de entidades mencionadas desenvolvido nesta pesquisa de mestrado e é o cenário ideal para incluir também a elaboração via geração de perguntas direcionadas aos verbos. 
Quanto aos usuários alvo do projeto PorSimples, consideram-se, principalmente, os analfabetos funcionais, crianças em fase de alfabetização e, até mesmo, pessoas com dificuldades cognitivas como os portadores de dislexia e afasia. Com isso, esta pesquisa de Elaboração Textual herda, automaticamente, o mesmo público alvo do projeto PorSimples.

Vários trabalhos indicam os benefícios da elaboração e simplificação para o público alvo mencionado. Belder \& Moas (2010) adotam a estratégia de simplificação alterando os níveis léxicos e sintáticos das sentenças para o público alvo infantil. Os autores citam que foi possível obter a simplificação, porém não em um nível adequado ao público alvo em questão. Eles citam que os parsers não conseguem trabalhar bem nas partes complexas das sentenças. Uma das alternativas seria a remoção destas partes, com perda de informação. Ou, senão, a adoção de técnicas de elaboração que permitem enriquecer o conteúdo para que ele se torne mais acessível para que possa ser compreendido.

Hauff \& Trieschnigg (2010) também realizam um trabalho voltado ao público infantil. O objetivo é tornar mais acessíveis os textos de literatura infantil clássica do projeto Guttenberg $^{2}$. Para isso, uma das técnicas usadas é a elaboração textual. Os autores trazem definições tanto da Wikipédia ${ }^{3}$ quando da Wikipédia Simplificada ${ }^{4}$ para elaborar palavras que são mais difíceis devido à diferença de épocas.

\subsection{Objetivos Gerais e Específicos e Questões de Pesquisa}

Dados os benefícios da elaboração textual para o público alvo em questão, esta pesquisa teve o objetivo geral de avançar a área computacional de Elaboração Textual através da construção de recursos e sistemas computacionais que também fossem reusáveis para a grande área de PLN. Nessa pesquisa de mestrado, para auxiliar um público alvo que necessita de uma experiência de leitura melhorada, novas técnicas de elaboração foram propostas, para as quais houve a necessidade de construção de recursos de língua. Foram levantadas três questões de pesquisa: (1) a definição de Entidades Mencionadas melhora a compreensão de textos?; (2) a geração automática de Perguntas Elaboradas pode ser realizada de uma forma compreensível e natural?; e (3) os erros cometidos na geração de perguntas impactam negativamente na qualidade desta geração?

\footnotetext{
${ }^{2}$ http://www.gutenberg.org/

${ }^{3} \mathrm{http} / / / \mathrm{www}$.wikipedia.org/

${ }^{4}$ http://simple.wikipedia.org/
} 
Para responder estas questões, foi desenvolvido o projeto de mestrado entitulado Sistema de Elaboração de Textos do Português ${ }^{5}$ (Elatex). O projeto Elatex define duas tarefas de elaboração textual. Estas tarefas são realizadas por dois módulos, chamados aqui de REMET e PET, apresentados na Figura 2. Desta forma, o objetivo específico desta pesquisa foi definir e avaliar duas novas tarefas de PLN, realizadas aqui por dois módulos do projeto Elatex:

(1) O módulo REMET que é responsável por trazer definições da Wikipédia às entidades mencionadas encontradas no texto. Esta tarefa é descrita na Seção 1.2.1.

(2) O módulo PET que prevê o uso de perguntas elaboradas, tarefa introduzida na Seção 1.2.2.

Ambos os módulos recebem o mesmo córpus simplificado de entrada e o enriquecem semanticamente conforme sua especialidade. É importante dizer que a simplificação e elaboração são fortemente relacionadas; enquanto a simplificação aumenta a inteligibilidade de um texto (torna ele mais fácil de ser lido), a elaboração melhora a compreensão do texto, isto é, facilita o entendimento de conceitos nos textos. Com isso, este projeto de pesquisa que trabalha com textos simplificados e elabora as sentenças consegue aproveitar o melhor dessas duas técnicas para o mesmo público alvo em questão.

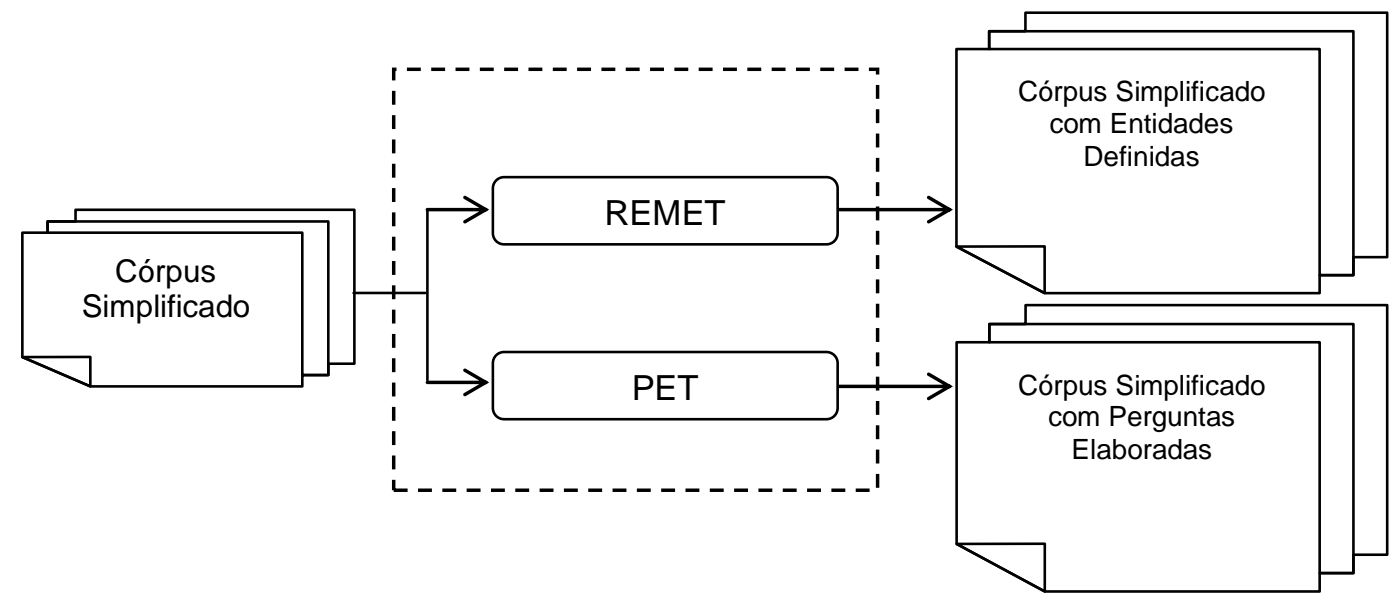

Figura 2: O Sistema de Elaboração Textual do Português

\footnotetext{
${ }^{5}$ http://www.nilc.icmc.usp.br/ marcelo/
} 


\subsection{A Tarefa de Definição de Entidades Mencionadas}

Um cenário comum na atividade de leitura de textos é a busca pela definição das palavras desconhecidas. Novos sentidos para palavras já conhecidas também são o foco da busca de novos significados pelo aluno em dicionários e enciclopédias físicas ou digitais. A elaboração textual via definição de Entidades Mencionadas, visa simular essa atividade sem que o público alvo em questão tenha que interromper sua atividade de leitura para buscar as definições das palavras. Trazê-las no texto com apenas um clique possibilita que eles não percam a fluência da leitura, o que facilita a compreensão do texto.

Entidades Mencionadas (Nadeau at al, 2007) referem-se aos nomes da classes dos substantivos nomeados, por exemplo, nomes de pessoas, lugares, organizações, datas, produtos, moedas, entre outras. A atividade de Reconhecimento de Entidades Mencionadas (REM) em textos é uma tarefa bem estabelecida em PLN, e é dividida em duas etapas principais: a delimitação e a classificação. Considere as sentenças abaixo:

(1) Ronaldo de Assis Moreira nasceu em Porto Alegre em 1980.

(2) $<$ REM $>$ Ronaldo de Assis Moreira $</$ REM $>$ nasceu em $<$ REM $>$ Porto Alegre $</$ REM $>$ em $<$ REM $>1980</$ REM $>$.

(3) $<$ REM Tipo="Pessoa" $>$ Ronaldo de Assis Moreira $</$ REM $>$ nasceu em $<$ REM Tipo="Local" $>$ Porto Alegre $</$ REM $>$ em $<$ REM Tipo="Data" $>1980</$ REM $>$.

As sentenças (2) e (3) correspondem às etapas de delimitação e categorização da sentença (1) por um sistema REM. Sistemas REM, em geral, utilizam etiquetas XML para fazer sua anotação semântica. Na etapa de delimitação, pode ser visto que as etiquetas apenas mostram onde iniciam (etiqueta " $<\mathrm{REM}>$ ") e onde terminam (etiqueta “</REM $>$ ") a entidade. Na etapa de categorização, o sistema atribui uma classe à entidade (etiqueta "Tipo"). Uma tarefa menos comum, mas que também pode ser atribuída ao REM é a associação da entidade mencionada a dicionários ou enciclopédias. Com isso, não somente a classe da entidade é identificada, mas também sua definição. Na Figura 3, pode ser visto o processo de elaboração via definição de entidades mencionadas. Nesse modelo, o sistema realiza o processamento em nível sentencial. Para cada sentença, o sistema REM delimita, classifica e faz a ligação da entidade com alguma enciclopédia ou dicionário e o resultado é a sentença com esses valores semânticos acrescentados. Essas anotações podem ser facilmente lidas pela interface que permite a visualização do resultado. 


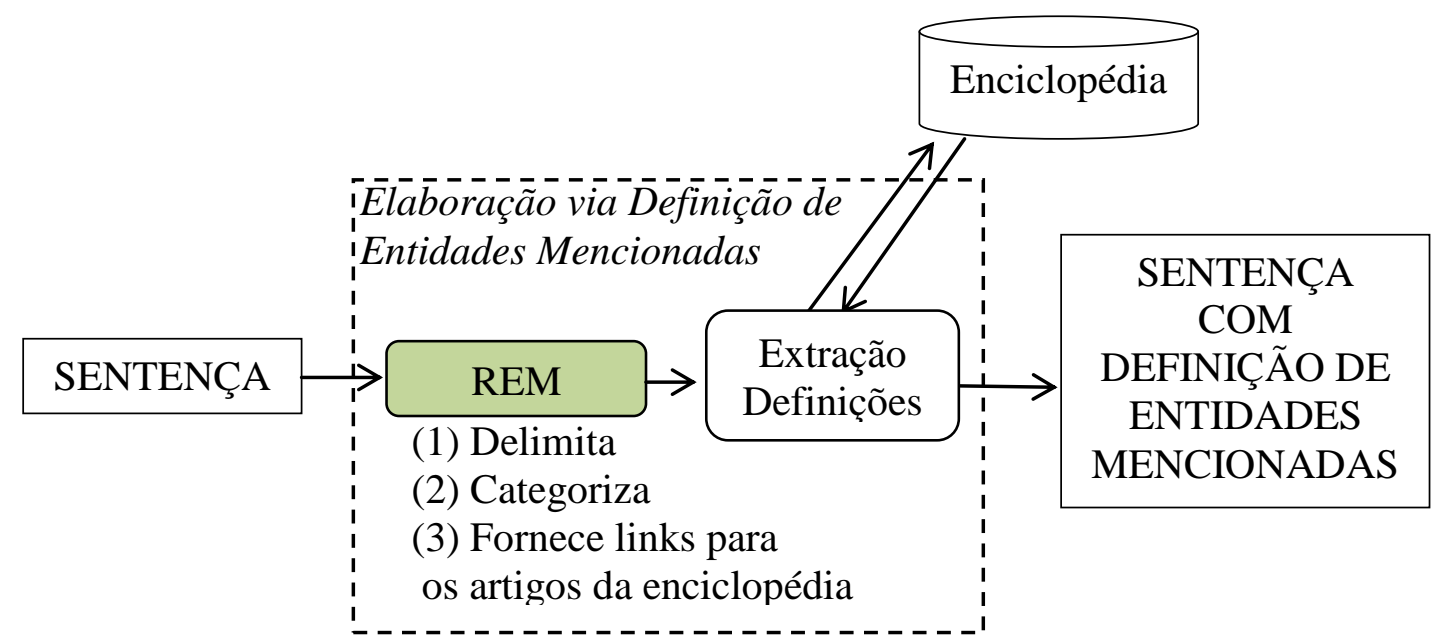

Figura 3: Arquitetura do sistema REMET

O resultado destas etapas para a sentença de exemplo é mostrado em formato tabular na Tabela 1, sendo a primeira coluna a entidade delimitada, a segunda as categorias e a terceira as definições enciclopédicas. Observa-se como as definições podem ser úteis em alguns casos como, por exemplo, definir "Ronaldo de Assis Moreira" como o jogador de futebol Ronaldinho Gaucho, que especifica seu nome mais popular, sua profissão dentre outras informações relevantes.

Tabela 1: Simulação das etapas da tarefa de Elaboração via definição de entidades mencionadas

\begin{tabular}{|l|l|l|}
\hline Delimitação & Categorização & Extração das definições $^{\mathbf{6}}$ \\
\hline Ronaldo de Assis Moreira & Pessoa & $\begin{array}{l}\text { Ronaldo de Assis Moreira, mais conhecido } \\
\text { como Ronaldinho Gaúcho ou Ronaldinho } \\
\text { (Porto Alegre, 21 de março de 1980), é um } \\
\text { futebolista brasileiro que atua como meia } \\
\text { ou atacante. }\end{array}$ \\
\hline Porto Alegre & Local & $\begin{array}{l}\text { Porto Alegre é um município brasileiro e a } \\
\text { capital do estado mais meridional do } \\
\text { Brasil, o Rio Grande do Sul. }\end{array}$ \\
\hline 1980 & Ano & 1980 \\
\hline
\end{tabular}

Sistemas como o da empresa Cortex Intelligence ${ }^{7}$ (Aranha, 2007a) também usam a definição de entidades mencionadas, mas a aplicação é diferente da usada nessa pesquisa de mestrado: um sistema de inteligência de negócios. Na Figura 4, pode ser visto um trecho de texto em que as entidades mencionadas encontram-se realçadas com

\footnotetext{
${ }^{6}$ Definições extraídas da Wikipédia

${ }^{7}$ http://www.cortex-intelligence.com/engine/
} 
cores pelo sistema Cortex Intelligence - diferentes tipos de cores refletem diferentes tipos de entidades. No exemplo da figura, a entidade PUC é classificada como Organização/Universidade e também recebe sua definição enciclopédica.

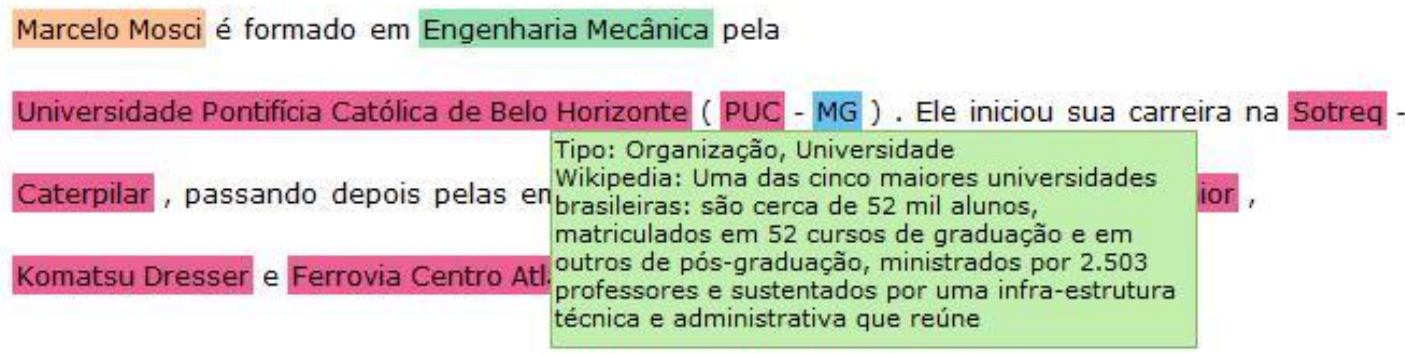

Figura 4: Informações detalhadas sobre a entidade PUC

Dado este exemplo, pode-se perceber que a adição de informações extras em textos pode beneficiar um público bem maior que apenas leitores com necessidades específicas, sendo assim de interesse abrangente na área de PLN. A tarefa de associar textos da Wikipedia em contextos, como do exemplo, também foi explorada em outros trabalhos (Mihalcea \& Csomai, 2007) e (Milne and Witten, 2008).

\subsubsection{A Tarefa de Geração de Perguntas Elaboradas}

A Geração de Perguntas Elaboradas para a Elaboração Textual é a tarefa computacional de levantar perguntas dirigidas aos verbos, seguindo determinadas diretivas. Por exemplo, na oração João acordou às 6 horas da manhã duas perguntas surgem naturalmente:

$$
\begin{aligned}
& 1 \text { - Quem acordou? } \\
& \text { 2-Acordou a que horas? }
\end{aligned}
$$

Relacionar o verbo e seus argumentos por meio de perguntas é um processo que exige interpretação de texto, atividade cujo público alvo deste projeto tem dificuldade de realização. Na Figura 5, é mostrada a ligação do verbo e os argumentos constituintes da oração (que podem ser sujeito, objeto direto, objeto indireto, adjuntos adverbiais de tempo ou lugar e até mesmo Entidades Mencionadas). 


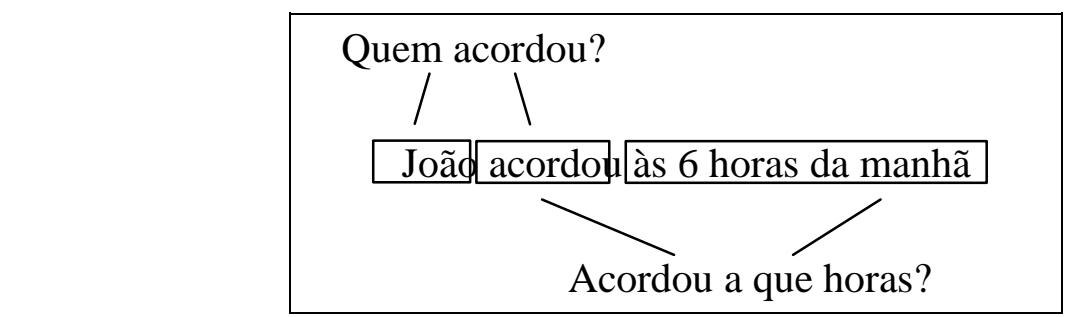

Figura 5: Elaboração levantada a partir da identificação da relação entre o verbo da oração e seus constituintes

A tarefa, portanto, resume-se em três etapas, que podem ser vistas na Figura 6. Primeiramente, para o início da tarefa, é exigido que a sentença de entrada, em (1), receba anotação de algum analisador sintático (parser). Esta sentença passa pelo processo de "Delimitação", em (2), que consiste em Identificar verbos e os constituintes da relação, que são denominados aqui de argumentos do verbo. Em (3), é realizada a "Categorização", em que os argumentos do verbo recebem as etiquetas simples de perguntas (“quem?”, “a que horas?”). A identificação e a categorização dos argumentos dos verbos é uma tarefa conhecida como Etiquetação de Papéis Semânticos (Semantic Role Labeling - SRL) (Palmer et al., 2010), com a diferença de que as categorias semânticas são de papéis semânticos que, por exemplo, no projeto Propbank ${ }^{8}$ são os argumentos numerados (e.g. Arg0, Arg1) ou argumentos modificadores (vários tipos de ArgM).

Em (4), as regras de elaboração são aplicadas para a geração final das perguntas elaboradas, "Quem acordou?” e “Acordou a que horas?”, em (5).

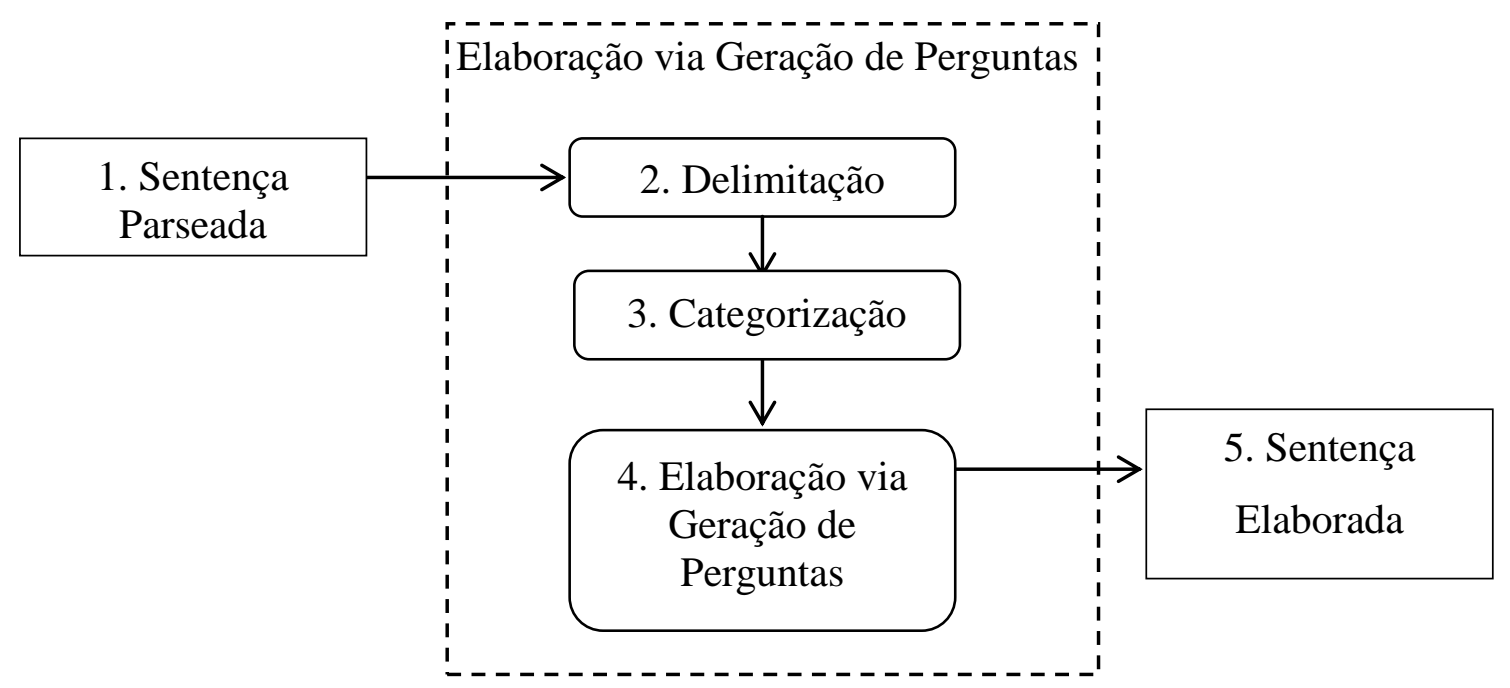

Figura 6: As três tarefas para a geração de perguntas Elaboradas a uma sentença com análise sintática, resultando em uma sentença elaborada

\footnotetext{
${ }^{8}$ http://verbs.colorado.edu/ mpalmer/projects/ace.html
} 
O sistema da empresa Cortex Intelligence também incrementa seus textos com perguntas. Considere o trecho da Figura 7 cujos verbos estão destacados em verde. Desse texto, podem ser observadas perguntas direcionadas ao verbo "anunciou" na Figura 8. Nota-se que “quem anunciou?" e “onde?” são perguntas simples. Seu objetivo apenas é de alimentar o sistema automático de inteligência. A contrário, poderiam ter sido levantadas as perguntas "Quem anunciou que seu lucro líquido caiu para US\$ 19 milhões?" ou "A amazona anunciou quando?”, as quais têm maior foco no usuário humano. O sistema PET prevê essa elaboração voltada para o usuário final humano.

\section{A americana Amazon, maior varejista on-line, anunciou ontem que seu lucro líquido caiu para \\ US\$ 19 milhões, em comparação aos US\$ 30 milhões do terceiro trimestre de 2005 . Ainda assim , 0 \\ resultado bateu as expectativas do mercado e as ações subiram $12 \%$. 0 faturamento da \\ companhia teve aumento de $24 \%$, para US\$2,3 bilhões .}

Figura 7: Trecho do sistema Cortex que mostra verbos destacados em verde

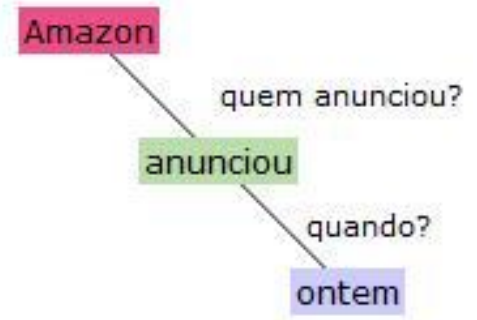

Figura 8: Adição de perguntas ao verbo

\subsubsection{Organização da Monografia}

No Capítulo 2, são apresentados métodos, sistemas e recursos de anotação semântica. Nas Seções 2.1 e 2.2 são apresentados os métodos de anotação de papéis semânticos e de entidades mencionadas, respectivamente. Esta revisão da literatura apoiou o desenvolvimento do Sistema de Elaboração Textual do Português (Elatex), que é descrito no Capítulo 3. No Capítulo 4, são apresentadas as contribuições da pesquisas, as limitações e também os trabalhos futuros. 


\section{Anotação de Papéis Semânticos e de Entidades Mencionadas}

O processo automático de Elaboração Textual depende de várias etapas computacionais que adicionam informação extra relevante para o leitor do texto. $\mathrm{Na}$ Figura 9, podem ser vistas as etapas que podem ser utilizadas na etapa computacional de anotação semântica. O primeiro passo é a análise sintática (1) que é realizada pelo parser. Este passo é tradicional na área de PLN, pois a área computacional de parsing é bem estabelecida, fornecendo atributos em que a próxima etapa, a Análise Semântica (2), se utiliza para determinar a anotação semântica.

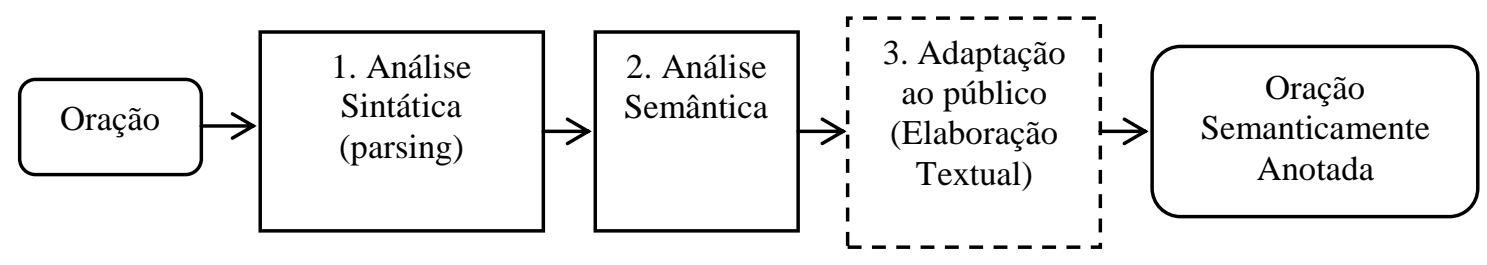

Figura 9: Etapas para a Elaboração Textual automática

A anotação tanto sintática quanto semântica correspondem à atribuição de nomes, categorias, ou seja, qualquer informação adicional que seja útil em seu contexto específico. Essa informação adicional também é conhecida como Metadados. A análise ou anotação semântica tem o objetivo de reduzir a ambiguidade que ocorre naturalmente nos textos através da adição de anotações ou conexões entre unidades de texto em uma representação mais formal para que esta possa ser processada computacionalmente.

A etapa de adaptação ao público (3) é uma etapa de aplicação (sua caixa é representada em linhas tracejadas). Até então, o resultado das etapas (1) e (2) poderia ser adaptado a qualquer aplicação de PLN ou mesmo ser usado dessa forma em sistemas computacionais, como, por exemplo, tradutores ou até mesmo para a web semântica. Esta etapa (3) aplica uma camada de elaboração adaptando o conteúdo ao público específico deste projeto.

Dois tipos de anotação semântica foram estudados neste projeto. O primeiro deles é a Anotação de Papéis Semânticos (APS). A APS, do inglês Semantic Role Labeling, forneceu a base teórica ao desenvolvimento do sistema de Elaboração via Geração de Perguntas Elaboradas, uma vez que o problema de atribuição de perguntas 
pode ser considerado como um tipo de atribuição de papéis semânticos. Ou seja, as perguntas são consideradas como sendo tipos de papéis semânticos, uma vez que foi possível montar um mapeamento entre perguntas e respostas, descrito na Seção 2.1.

O segundo tipo de anotação semântica é o Reconhecimento de Entidades Mencionadas (REM). A área de REM permitiu conectar entidades do texto a definições curtas destas encontradas em artigos da Wikipedia, assim como os links a esses artigos. Esta área é apresentada na Seção 2.2.

\subsection{Anotação de Papéis Semânticos}

Papel semântico é o nome dado ao relacionamento de um argumento em relação ao verbo na sentença em que ele ocorre, ou seja, cada argumento do verbo desempenha um papel semântico no contexto de uma oração. A APS (Palmer et al., 2010) é a tarefa computacional de nomear esses argumentos. Nesse processo, faz-se necessária uma teoria linguística que dê base para a escolha dos nomes dos papéis e regras de anotação utilizadas.

A tarefa de anotação de papéis semânticos tem se tornado uma das principais da área de PLN como pode ser observado pela publicação da edição especial da revista Computational Linguistics em junho de 2008 (Màrquez et al., 2008) e também por sua utilização em outras áreas como a Extração de Informação (Surdeanu et al., 2003), Sistemas de Perguntas e Respostas (Shen \& Lapata, 2007), Sumarização Automática (Narayanan \& Harabagiu, 2004), Web-Semântica (Davies, 2006), entre outras. Em acréscimo, está havendo um resurgimento da área pelo aumento da disponibilidade de grandes recursos linguísticos, principalmente para a língua inglesa, que serão estudados nessa seção, e também, pelo desenvolvimento de métodos de aprendizado de máquina estatístico.

Palmer et al. (2010) observa que os parsers sintáticos tiveram um impacto muito positivo e abrangente na área de PLN, porém que a anotação lexico-sintática está longe de representar o significado completo das sentenças, por exemplo, para responder as perguntas do tipo “Quem fez O que a Quem? “ ou "Como, Quando e Onde?“. O entendimento do tipo semântico permite que seja feito um tratamento mais efetivo da informação computacionalmente. Portanto, há uma lacuna que a APS se propõe a resolver. 
Considere a sentença a seguir:

(1) João quebrou a janela com a vassoura.

Na sentença (1), podem ser identificados os papel de agente em "João", paciente em "a janela" e instrumento em "a vassoura". Agente é todo indivíduo capaz de vontade própria que realiza a ação. Paciente é todo elemento que sofre a ação enquanto instrumento define o objeto usado na ação, no caso em "a vassoura". Neste exemplo simples, pode ser apenas observada a aplicação simples do conceito de APS.

A APS é baseada na Linking Theory (Levin \& Hovav, 1996), teoria que prega que é possível prever os papéis semânticos a partir dos atritutos sintáticos da sentença, e seu objetivo de estudo é descobrir como ocorre essa interação. Por isso, os sistemas de APS são baseados na anotação sintática da oração. Palmer et al. (2010) mostra alguns exemplos de dificuldades na tarefa de APS em relação a sua anotação sintática. Considere um deles:

(1) a. João quebrou a janela.

b. A janela quebrou.

No exemplo (1), nota-se que tanto "João" e "a janela" podem ser considerados sujeitos sintáticos da sentença, como anotado na maioria dos parsers sintáticos. Porém, observa-se que "a janela" tem o mesmo papel semântico (Tema) nas sentenças (a) e (b). Observa-se que não há dicas sintáticas, por exemplo o uso da forma passiva, para indicar a ocorrência da inversão. Com isso, observa-se a importância da anotação dos papéis semânticos para que as informações possam ter seu devido tratamento computacional.

O estudo dos sistemas, recursos e ferramentas da área de APS deram base ao desenvolvimento dos recursos de Geração de Perguntas Elaboradas. Na verdade, as perguntas realizadas aos verbos podem ser consideradas uma etapa auxiliar no levantamento dos papéis semânticos. Essa etapa, realizada neste projeto, forneceu esse subsídio intermediário, um córpus anotado com perguntas, assim como um mapeamento não revisado para papéis similares ao propbank do inglês. Dessa forma, fornecendo subsídios para a construção do projeto Propbank. $\mathrm{Br}$, projeto em andamento no NILC, sendo desenvolvido pela bolsista FAPESP Magali Duran. 
Atualmente, devido ao avanço dos métodos de aprendizado de máquina estatísticos, e também dada a construção de grandes bases de conhecimento, como as dos projetos FrameNet, VerbNet e Propbank, descritos nas Seções 2.1.1, 2.1.2 e 2.1.3, respectivamente, são possíveis o aprendizado da anotação semântica a partir de exemplos. Na Seção 2.1.4 é descrito um sistema de anotação de papeis semânticos.

\subsubsection{FrameNet}

FrameNet ${ }^{9}$ (Baker et. al., 2003) é dos projetos pioneiro para a anotação de papéis semanticos sendo também um dos recursos mais ricos quando comparados aos projetos VerbNet e Propbank. Além disso, vem sendo construída para várias línguas, inclusive para o português (Chishman et al., 2008). Este recurso é baseado na teoria da Semântica de Frames de Filmore (Filmore et al., 1982) sendo composto de 960 evocadores semânticos (frames) que evocam mais de 2.500 papéis semanticos (ou elementos de frame) (Baker et al., 1998; Johnson et al., 2001).

A semântica de frames de Filmore prega a teoria de que não é possível entender a semântica das palavras ou conceitos sem todo o entendimento de todos os conceitos que relacionam estas palavras. Ou seja, entender as situações e contextos em que o termo ocorre, uma espécie de script para descrever estados, objetos ou eventos. Essas situações são denominadas de frames semânticos. Considere o exemplo a seguir:

(1) João visitou seus pais para jantar com eles.

Agente: João

Lugar: o lugar que os pais de João estão

Objetivo: jantar com os pais

No exemplo acima, é apresentado o conceito "Visitar". Esse conceito, em geral, resume-se por um agente chegando a algum lugar com algum objetivo, este objetivo é geralmente social. Logo o frame "Visitar" é composto de três elementos nesse caso simplificado. Logo, cada frame é composto de um nome e de seus elementos do frame (papéis semânticos).

Devido à riqueza e variedade (granulação fina) da base FrameNet, ela é dividida em domínios que definem uma organização lógica de seus frames. O exemplo da Figura

\footnotetext{
${ }^{9} \mathrm{Http}: / / \mathrm{www}$.framenet.icsi.berkeley.edu
} 
10, extraída da base da FrameNet, apresenta dois frames do domínio de "comunicação": "conversação" e "questionamento". Como pode ser visto na Figura 10, o frame de comunicação está conectado a frames especializados. Há vários tipos de relacionamento previstos, tal como herança, especialização, entre outros.

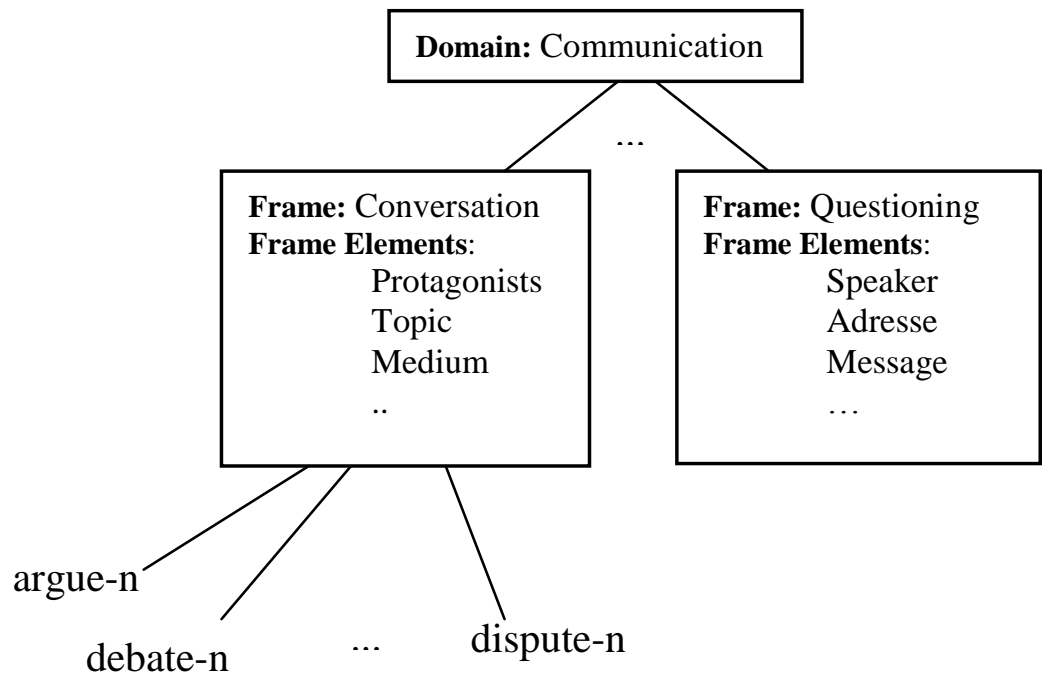

Figura 10: Domínio dos frames e herança especialização de frames

Os elementos de frame podem ser definidos quanto a sua centralidade, tal como "central" (fundamental), periférico (não é necessário, mas ajuda a situar o evento como hora e local, similar aos adjuntos) e extra-temáticos (não específicos ao frame nem similar aos adjuntos, em geral para situar o frame em relação a um contexto maior).

\subsubsection{VerbNet}

A VerbNet (Kipper et al., 2000) é uma base de papéis semânticos compostos de verbos agrupados conforme suas realizações sintático-semânticas. Contém 471 classes que utilizam 24 papéis temáticos (que correspondem aos papéis semânticos) que anotam mais de um milhão de palavras do córpus Treebank do Wall Street Jornal. Sua granulidade lexical é mais fina que do Propbank, mas não mais que dos papéis da FrameNet.

A organização hierárquica de classes verbais foi baseada nas classes de Levin (1996), que inicialmente era constituída de 47 classes de primeiro nível e 193 de segundo e terceiro níveis que agrupam verbos que têm realizações sintáticas 
semelhantes. Cada classe é descrita por seus membros, papéis temáticos, frames sintáticos e predicados semânticos.

Na Figura 11 é apresentada a classe "Resign-10.11" na qual os verbos membros compartilham da mesma estrutura sintático-semântica. Levin afirma que as pequenas variações sintáticas refletem a estrutura semântica adjacente, portanto, o agrupamento de verbos ocorre de acordo com sua estrutura e tipos de inversões nas suas realizações sintáticas permitidas (transitiva, intransitiva, frases preposicionadas, entre outras).

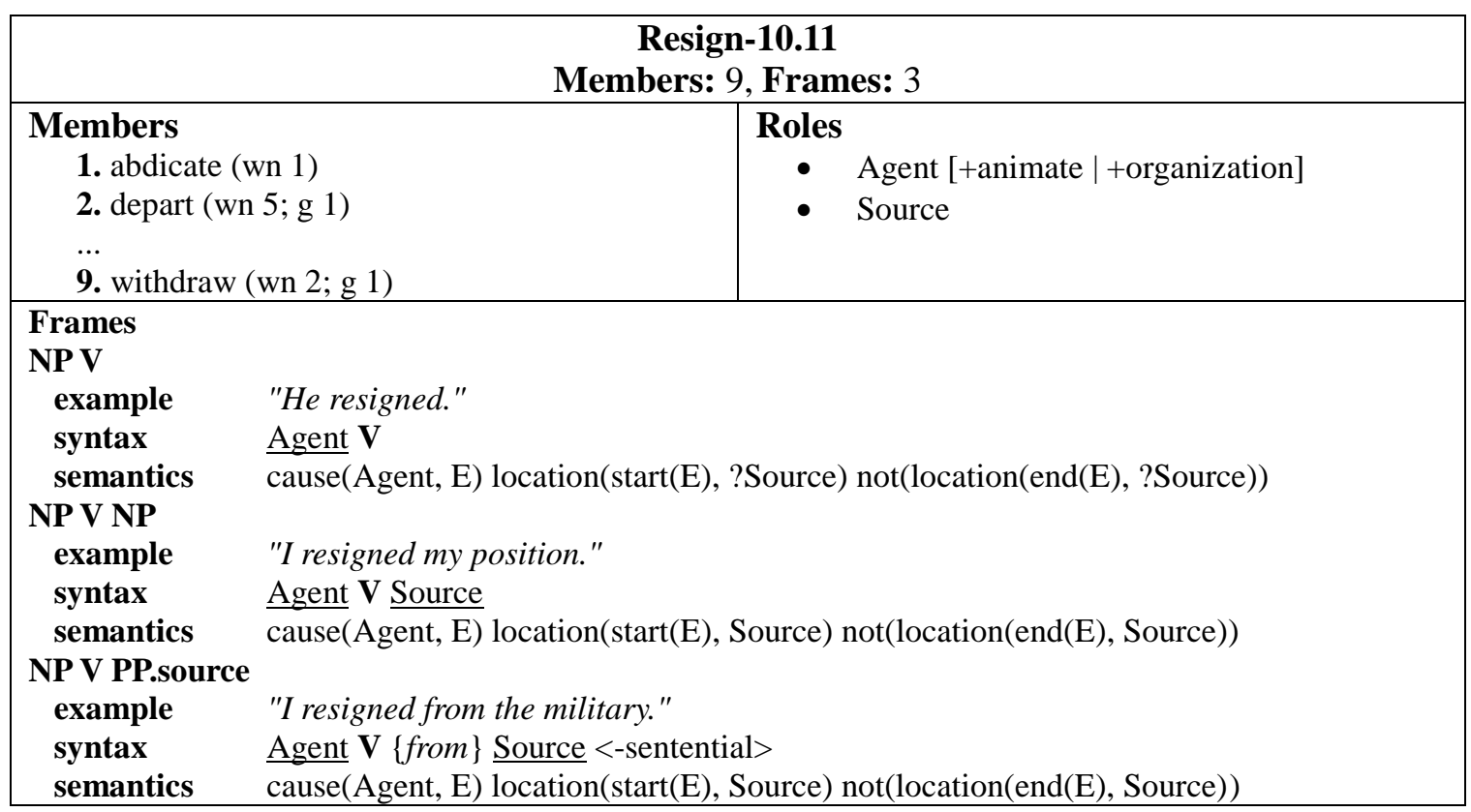
Figura 11: Versão simplificada da classe Resign

No exemplo, são apresentados dois papéis temáticos: "Agent" e "source". No primeiro papel, pode ser observada a adição de restrições semânticas, o agente tem que ser animado (+animado) ou organização (+organização). Essas restrições auxiliam a encontrar um conjunto mais restrito de temas semânticos - apenas 24, por exemplo, Agente, Causa e Beneficiário - similares às classes genéricas da FrameNet, porém, sem perder sua especificidade.

Ainda há a restrição semântica, na figura denominada por "semantics" que relaciona os constituintes temáticos a um sentido que tem que satisfazer a expressão em lógica apresentada. Em relação à FrameNet, a VerbNet apresenta uma alternativa mais simples em que não é necessário ter um papel específico para toda e qualquer situação, mas sim papéis genéricos restringidos pela estrutura sintática, e restrições semânticas. Tal como o Propbank (a ser visto na Seção 2.1.3), a FrameNet é baseada principalmente na análise sintática da sentença. 
A VerbNet.br é um projeto recente, sendo desenvolvido no NILC pela aluna de mestrado Carolina Scarton, que se propõe a construir um recurso similar à VerbNet do inglês. A metodologia adotada se beneficia das conexões entre as classes da VerbNet com os synsets da Wordnet.br de forma indireta, uma vez que a Wordnet do inglês está conectada em ambas as bases.

\subsubsection{PropBank}

O Propbank, ou Proposition Bank, (Kingsbury \& Palmer, 2002) foi um projeto liderado por Palmer et al. (2005) e conduzido no contexto do projeto $\mathrm{ACE}^{10}$, financiado pelo instituto $\mathrm{NIST}^{11}$ e atualmente é disponibilizado pelo $\mathrm{LDC}^{12}$. Inicialmente criado para o inglês, atualmente tem sido construído para outras língua, inclusive para a língua Portuguesa, como comentado na Seção 2.1.

O propósito do projeto Propbank foi construir um córpus com anotação de papéis semânticos para o treinamento de sistemas computacionais usando técnicas de aprendizado de máquina, e não ser apenas um recurso léxico-semântico tal como a FrameNet e a VerbNet. Com isso, o córpus de mais de 1,75 milhões de palavras de textos do Wall Street Jornal do córpus de Penn TreeBank (Kingsbury \& Palmer, 2002), que possui anotação sintática, foi escolhido para receber a anotação resultando no Propbank.

Devido ao seu propósito da construção de ser uma base útil para processamento computacional, optou-se por dar nomes genéricos aos papéis semânticos, chamados de Args Numerados (Arg0, $\operatorname{Arg} 1, . ., \operatorname{Arg5})$. Arg0 e Arg1 são considerados agente e paciente (ou tema) prototípicos (Dowty, 1991); enquanto que Arg2 até Arg5 podem mudar de acordo com o verbo. Também existem os argumentos modificadores (ArgMs) que têm o mesmo sentido em todos os verbos, entre eles o de local (LOC), extensão (Ext), adverbial (ADV), causa (CAU), tempo (TMP), modo (MOD), direção (DIR), entre outros.

A vantagem desta metodologia é não necessitar teoria para o estabelecimento de relações de igualdade entre os temas dos argumentos de dois verbos diferentes (presentes na VerbNet e FrameNet), a desvantagem é reduzir a possibilidade de generalizações úteis ao aprendizado de máquina. De fato, não há consenso geral que defina como o argumento de um verbo se relaciona com o argumento de outro verbo. Problema este que pode ser superado através do estabelecimento de ligações dos papéis semânticos da VerbNet e

\footnotetext{
${ }^{10} \mathrm{http}: / /$ verbs.colorado.edu/ mpalmer/projects/ace.html

${ }^{11}$ National Institute of Standards and Technology [http://www.nist.gov/index.html]

${ }^{12} \mathrm{http} / / / \mathrm{www} .1 \mathrm{dc} . u p e n n . e d u / C a t a l o g /$ CatalogEntry.jsp?catalogId=LDC2004T14
} 
Framenet.

Um exemplo de anotação pode ser visto considerando a anotação da sentença (1) abaixo. Esta sentença exemplo recebe os papéis genéricos do Propbank (Arg0, Arg1 e Arg2) cujos sentidos são apresentados pelos seus equivalentes a base VerbNet.

Sentença:

(1) "John admitted to Mary that he secretly loathed her haircut."

Conjunto de papéis da VerbNet: admit.01 "with hearer"

Papéis Semânticos em relação aos papéis sintáticos da VerbNet:

Arg0: admitter

REL: to admit

Arg2: hearer

Arg1: truth

Sentença (1) Anotada:

"[Arg0 John] [REL admitted] [Arg2 to Mary] that [Arg1 he secretly loathed her haircut]."

O Probank.br é o projeto brasileiro para o desenvolvimento de um córpus similar ao Propbank do inglês. Dadas as dificuldades e experiências relatadas na construção do córpus do inglês, e o projeto do português ser mais reduzido em quantidade de verba e tamanho de equipe, várias atalhos foram tomados para que se pudesse obter qualidade similar em relação ao projeto pioneiro do inglês. Uma delas foi a anotação de perguntas, e seu posterior mapeamento para os papéis de argumento, posteriormente revisados pela própria linguísta que desenvolve o Propbank.br. Outras dos atalhos encontrados foram a utilização de um córpus de textos simplificados, correspondentes a 104 textos do jornal Zero Hora cuja anotação sintática foi realizada pelo parser Palavras.

Magali Duran realizou a anotação das perguntas, a construção do manual de anotação e mapeamento das perguntas para os argumentos numerados. Marcelo Adriano Amancio, por sua vez, colaborou com a construção de um classificador de perguntas e automatizou o mapeamento do córpus, isto é, mapeamento de perguntas para argumentos numerados e modificadores do projeto Propbank. Esse projeto continua seu desenvolvimento computacional com o mestrado de Fernando Alva Manchego, aluno do NILC, na construção semisupervisionada de um etiquetador semântico para o português do 
Brasil.

\subsubsection{Sistemas de Anotação de Papéis Semânticos}

O trabalho de Gildea \& Jurafsky (2002) é referência na área de atribuição de papéis semânticos por ser pioneiro. Eles utilizam a técnica de backoff lattice que extrai probabilidades da contagem de exemplos do córpus de treinamento, no caso, córpus e papéis semânticos da FrameNet. Com isso, eles combinam manualmente os atributos que eles consideram mais importantes e fazem uma interpolação linear na obtenção dos valores das probabilidades na construção do sistema de predição de papéis semânticos. Eles obtêm precisão de $62,9 \%$ na tarefa geral e $78.5 \%$ na tarefa de classificação (dada a segmentação correta). A importância desse trabalho foi principalmente estabelecer um conjunto de atributos que ainda hoje é considerado o núcleo, isto é, o conjunto mais importante, entre a maioria dos sistemas de SRL modernos.

Posteriormente, outros métodos de aprendizado de máquina foram utilizados, como o de árvores de decisão em Surdeanu et al. (2003) e Pradhan et al. (2005), que conseguiram melhora de $2 \%$ na classificação de dados já segmentados em relação ao backoff lattice. Fleischman et al. (2003) usa o algoritmo de regressão logística de máxima entropia com melhora de $3.2 \%$ em relação ao sistema de Gildea \& Jurafsky (2002) e ainda um acréscimo de mais 3\% na precisão com o acréscimo de novos atributos. Contudo, o uso de Support Vector Machine (SVM) em Pradhan et. al (2005) resultou em melhoria de $10 \%$ em relação ao trabalho pioneiro de Gildea. Toutanova et al. (2005), contudo, obteve resultados similares ao de Pradhan et. al (2005) usando um algoritmo de máxima entropia, com a vantagem de ter um custo computacional inferior e desvantagem de ter que fazer a combinação de atributos manualmente, técnica já embutida nos algoritmos de SVM, o que explica seu maior custo computacional.

Vickrey \& Koller (2008) propõem a metodologia de simplificação de sentenças no processo de aprendizado da tarefa de SRL. Eles observam que, devido às árvores sintáticas serem muito esparsas, o desempenho dos sistemas tendem a diminuir, principalmente devido a erros de precisão do parser. O resultado de seu sistema é interessante, pois indica que a simplificação sintática (que também é utilizada como entrada para o sistema de elaboração textual desta pesquisa) pode ajudar no processo de SRL. Eles obtêm melhoria de $1.2 \%$ sobre o melhor sistema participante da avaliação 
conjunta da conferência CoNLL-2005 ${ }^{13}$, o sistema de Punyakanok et al. (2004), que por sua vez tem medida $1 \%$ maior que o sistema de Pradhan et. al (2005).

A seguir, são apresentados alguns dos atributos utilizados no sistema pioneiro de Gildea \& Jurafsky (2002) e uma enumeração de outros atributos comuns nos sistemas que são o estados da arte para esta tarefa:

- Tipo do sintagma: Os diferentes papéis se realizam com probabilidades diferentes em diferentes tipos de sintagmas. Como, por exemplo, na sentença "Maria estudava no quarto" em que o agente ocorre em um sintagma nominal, e o local em um sintagma preposicionado, cujas ocorrências não são aleatórias;

- Categoria governante: Parsers sintáticos de constituintes realizam a anotação de funções gramaticais tais como sujeito, objeto direto e indireto. Essas funções dão dicas quanto aos possíveis papéis. Fillmore (1968) afirma que se há a presença de um agente semântico, então ele representa o agente sintático da sentença;

- Caminho da árvore de parser: O caminho da árvore é a sequencia de categorias sintáticas: Sintagma Verbal, Sintagma Preposicionada, etc., que conectam o constituinte e seu evocador. Seu objetivo é resgatar a relação entre o constituinte e o resto da sentença;

- Posição: O atributo indica se o constituinte ocorre antes ou depois do evocador. Gildea \& Jurafsky (2002) justificam que o atributo posição auxilia o sistema de aprendizado de máquina a resolver alguns problemas de parsing, que confunde posições.

- Voz: A identificação da voz da sentença (ativa ou passiva) auxilia a identificar se os objetos das sentenças podem receber o papel de sujeito, por exemplo.

- Palavra cabeça do sintagma: No frame "Comunicação" da FrameNet as palavras núcleo da sentença como "pai”, “ele", "amigo", entre outras, são as mais prováveis de preencherem o papel de Locutor, por exemplo, do que preencherem o papel de Tópico.

- Subcategorização do verbo: Verbos transitivos podem realizar-se sintaticamente de forma diferente de suas ocorrências intransitivas. Por exemplo, em "João quebrou a janela", há um agente explicito nessa ocorrência transitiva

\footnotetext{
${ }^{13}$ http://www.lsi.upc.edu/ srlconll/
} 
do verbo "quebrar”, enquanto que em “A janela quebrou”, não aparece agente na forma intransitiva do verbo.

- Conjunto de Argumentos: É a estrutura dos papéis ocorrendo na sentença. Como a estrutura depende de todos os papéis associados, este atributo só pode ocorrer em uma etapa de pós-processamento.

Outras features incluídas nos sistemas atuais são (Palmer et al., 2010): ordem dos argumentos; papel anterior; etiquetas de parte de discurso (PoS); entidades nomeadas; clusterização de verbos; preposições; ordem dos constituintes; palavras relacionadas a tempo (por exemplo, hoje, março); entre outras.

\subsection{Anotação de Entidades Mencionadas}

O termo Entidade Mencionada (Nadeau at. al., 2007) se sedimentou em 1996 na conferência Message Understanding Conference (MUC-6) (Grishman e Sundhelm., 1996), apesar da primeira publicação sobre o assunto ter sido feita bem antes, em 1991 (Rau, 1991). Nesta conferência, cujo tema principal era a avaliação de sistemas de Recuperação de Informação, foi identificada a necessidade de se avaliar a tarefa de reconhecimento de entidades mencionadas como tarefa independente.

Entidades Mencionadas (do inglês Name Entities) são palavras da classe dos substantivos próprios que definem nomes de lugares, pessoas, organizações, acontecimentos, coisas, obras e até mesmo dados numéricos como datas, quantidades, moedas, medidas, entre outros. Por exemplo, o termo "Brasil", pode representar um país, nome de uma pessoa, nome de rua, a seleção brasileira de futebol, ou seja, várias entidades mencionadas diferentes. Porém, é interessante buscar seu significado contextual quando este termo ocorre em uma sentença. Resolver qual entidade mencionada é a que representa o termo em um dado texto é a tarefa de Recuperação de Entidades Mencionadas.

As categorias mais estudadas na literatura são "Pessoa", "Local" e "Organização", denominadas de categorias ENAMEX, na conferência MUC-6. Na coleção dourada (Cardoso \& Santos, 2007) um recurso utilizado na conferência de avaliação conjunta de sistemas de entidades mencionadas, a frequência das entidades ENAMEX corresponde a mais de $54 \%$ das entidades totais. Porém, ao contrário dessas entidades genéricas, há sistemas que são especializados em domínios e definem suas 
próprias categorias. Um exemplo é descrito no trabalho de Settles (2004), cuja domínio é da área de medicina.

A Recuperação de Entidades Mencionadas é uma tarefa que pode ser útil tanto para sistemas computacionais em geral, para a resolução de ambiguidades, como também para participar da elaboração semântica de sentenças, visto que muitas vezes podem aparecer nomes que o leitor desconhece na atividade de leitura de textos. Sistemas de REM modernos, como o Rembrandt ${ }^{14}$ (REF) descrito nesta seção, podem estabelecer as relações dessas entidades com dados enciclopédicos, permitindo que o leitor possa ainda obter mais informação sobre uma dada entidade na sua atividade de leitura.

\subsubsection{Desafios no Reconhecimento de Entidades Mencionadas}

Em Aranha (2007a), podem ser encontrados alguns dos tipos de dificuldades de sistemas de REM. Considere as sentenças de exemplo que ele apresenta:

(1) Fernando H. Cardoso

(2) Juiz Nicolau dos Santos Neto

(3) Presidente da Câmara dos Vereadores Alcides Barroso

(4) Hollywood

Em (1) é pode ser observada uma dificuldade, pois embora para um ser humano a identificação seja direta, para o computador se torna difícil, dado que uma abreviação no meio de um nome pode ser entendida como fim de sentença, especialmente se uma frase termina em Fernando H. e a próxima começa em Cardoso, que inicia com letra maiúscula. Este problema pode ser parcialmente resolvido colocando-se uma regra especial, apenas para este caso específico. Como abreviações podem aparecer das formas mais imprevisíveis possíveis, são necessárias, então, várias regras deste tipo.

No exemplo (2) a presença de "dos" (letra inicial em minúscula) pode induzir um sistema de REM a separar os nomes "Juiz Nicolau" e "Santos Neto", os quais, na verdade, fazem parte de um mesmo nome.

Em (3) há exatamente duas entidades. Mas as dicas ortográficas, tais como a presença de maiúsculas, podem confundir o sistema REM, pois a heurística geralmente adotada é o agrupamento de todas palavras que se iniciam em maiúscula em uma mesma entidade. Logo, os nomes "Câmara dos Vereadores" e "Alcides Barroso",

\footnotetext{
${ }^{14}$ http://xldb.di.fc.ul.pt/Rembrandt/
} 
quando adjacentes, são, em geral, confundidos como sendo uma única entidade.

Em (4), tem-se um problema de ambiguidade: não podemos dizer se Hollywood significa lugar ou marca de cigarro. Na maioria dos casos, podemos usar o contexto para desambiguizar essas alternativas.

Outro ponto de dificuldade é o início de frase, que, por padrão, inicia-se sempre com letra maiúscula, o que suprime a evidência de início de entidade mencionada devido a essa ambiguidade. Aranha (2007a) usa a estratégia de identificar a entidade se ela se enquadrar na classe dos substantivos.

\subsubsection{Conferências e avaliações}

O HAREM I (Avaliação de Reconhecimento de Entidades Mencionadas) é a primeira avaliação conjunta de sistemas de reconhecimento de entidades mencionadas para o português e foi desenvolvida no polo de pesquisas Linguateca (Oliveira et. al., 2003). Avaliação conjunta, como definido em Cardoso et. al. (2007c), é uma forma de comparar vários sistemas que concordam na execução de uma determinada tarefa. Os principais objetivos da avaliação conjunta do HAREM foram:

1 - Ajudar a comunidade científica em concordar nos requisitos mínimos da tarefa proposta;

2 - Conhecer a comunidade atuante na área;

3 - Avaliar sistemas de REM, e eventuais opções na sua implementação de forma independente de estrutura;

4 - Obter recursos valiosos para avaliação no futuro, tal como a Coleção Dourada (CD).

A metodologia de avaliação baseia-se na comparação do resultado dos sistemas participantes em relação a um córpus anotado por humanos - a Coleção Dourada. A validação estatística deste formato de avaliação pode ser encontrada em Cardoso et al. (2007b).

Para que houvesse uma padronização na anotação destes sistemas, foi criado um conjunto de diretivas, que podem ser encontradas em Cardoso et. al. (2007a). O conteúdo deste documento trata desde aos formatos das etiquetas a serem usadas até quais entidades devem ser identificadas e quais características devem ser consideradas em sua classificação.

Os sistemas inscritos podiam participar em categorias específicas. Por exemplo, se 
temos um sistema que só reconhece entidades mencionadas geográficas, podemos optar por uma avaliação restrita a este cenário. A nomenclatura usada em Cardoso et. al. (2007) é a de avaliação em cenários seletivos. Até a data de escrita desta monografia, três avaliações conjuntas HAREM foram realizadas. A primeira em 2005 (primeiro HAREM), a segunda em 2006 (MiniHarem) e a última em 2008 (segundo HAREM).

Entre os principais sistemas participantes do HAREM I, destacam-se o sistemas Palavras e o Siemês, primeiro e segundo colocados, respectivamente. O sistema Palavras de Bick (2000) é baseado em gramática de restrições (GR) (Karlsson 1990; Karlsson et al., 1995), parsing sintático e gazetteer. Sua gramática é sensível a morfologia, pois busca evidências internas nas palavras, por exemplo, identifica a presença do token indicativo de pessoa, por exemplo o token "Dra." na entidade "Dra. Paula". Além destas dicas internas, esta gramática também faz a análise do contexto das entidades. Este, em geral, está relacionado às palavras da vizinhança das entidades. Por exemplo, o token "rua" pode indicar que a entidade "Santa Luzia" é local na sentença "rua de Santa Luzia". Seu gazetteer, recurso linguístico complementar, é composto por mais de 17 mil entradas.

O sistema Siemês (Sarmento, 2006), segundo colocado na avaliação conjunta do HAREM I, é um sistema de três etapas: Identificação, Classificação e Desambiguação. A Identificação é realizada através do conceito de sementes alfabéticas, na qual sua identificação depende de dica ortográfica: presença de maiúscula. Essas sementes, quando ligadas por conectores, por exemplo "da", "de", "dos", são conectadas, o que gera uma semente maior. A etapa de classificação especifica cinco tipo de regras que permitem obter a proximidade da entidade do texto em relação a uma entidade do gazetteer. Obtida a entidade mais próxima, então, a classe da entidade do texto é definida como a mesma classe da entidade do gazetteer. Por fim, a etapa de desambiguação estabelece algumas regras que permitem filtrar etiquetas alternativas para cada entidade. Essas regras são similares às do sistema Palavras.

O HAREM II (Mota \& Santos, 2009) foi a segunda edição do HAREM, porém há algumas diferenças relevantes. Houve a introdução da tarefa ReRelEM (Mota e Santos, 2009) que objetiva encontrar relações entre entidades mencionadas. Os sistemas vencedores foram o Priberam (Mota \& Santos, 2009) e o Rembrandt (Cardoso, 2009), primeiro e segundo colocados, respectivamente. 
O XIP, REM da Xerox ${ }^{15}$ (Mota \& Santos, 2009) foi o sistema que obteve a melhor pontuação para as entidades de valor e tempo. Este sistema é baseado em regras e análise sintática. Nele, é estabelecido um formalismo rico que permite expressar um leque importante de regras em relação à desambiguação, construção de dependências e delimitação de sintagmas nucleares.

O Priberam (Mota \& Santos, 2009) é um sistema de reconhecimento de entidades mencionadas comercial. O produto mais importante em que o Priberam está inserido é o Flip ${ }^{16}$, corretor ortográfico, sintático, analisador morfológico e conjugador de verbos. Sua etapa de categorização é dividida em dois estágios. Para cada entidade são levantadas sua classificação morfológica e semântica para valores registrados em uma base. Logo em seguida, um conjunto de regras de contexto melhoram a classificação anterior.

Na Tabela 2, é mostrado o resultado da classificação semântica dos sistemas vencedores do HAREM I, enquanto na Tabela 3 o resultado dos sistemas vencedores do HAREM II. A diferença de resultado dessas avaliações conjuntas refletem as dificuldades impostas naquele cenário. $\mathrm{O}$ fato do sistema Palavras ter uma medida $\mathrm{F}$ no HAREM I maior que o sistema Priberam no HAREM II não indica necessariamente que o sistema Palavras seja superior. Supõe-se que o cenário encontrado no HAREM II seja mais difícil que o cenário do HAREM I.

Tabela 2: Resultado da classificação semântica do HAREM I

\begin{tabular}{|l|l|l|l|}
\hline & Precisão (\%) & Abrangência (\%) & Medida F \\
\hline Palavras & $56.30 \%$ & $60.42 \%$ & $63.00 \%$ \\
\hline Siemês & $57.28 \%$ & $49.85 \%$ & $56.30 \%$ \\
\hline
\end{tabular}

Tabela 3: Resultado da classificação semântica do HAREM II

\begin{tabular}{|l|l|l|l|}
\hline & Precisão (\%) & Abrangência (\%) & Medida F \\
\hline Priberam & $64.17 \%$ & $51.46 \%$ & $57.11 \%$ \\
\hline Rembradt & $64.97 \%$ & $50.30 \%$ & $56.74 \%$ \\
\hline XIP & $65.66 \%$ & $46.52 \%$ & $54.45 \%$ \\
\hline
\end{tabular}

\footnotetext{
${ }^{15}$ Desenvolvido em colaboração com a L2F (INESC-ID Lisboa) e o XRCE (Xerox Research Centre Europe, Grenoble, France)

${ }^{16}$ http://www.flip.pt
} 


\subsubsection{O sistema Rembrandt}

O Rembrandt (Cardoso, 2009) é um sistema REM desenvolvido por Nuno Cardoso em seu projeto de doutorado no laboratório LaSIGE $^{17}$, na Universidade de Lisboa. Esse sistema depende de língua uma vez que não faz uso do paradigma estatístico, mas sim de bases de conhecimento como a Wikipedia e também de regras de detecção de relações entre entidades que aparecem no texto (DRE).

O Rembrandt utiliza duas estratégias principais. A primeira, mais atual, é a utilização da enciclopédia Wikipedia, recurso abrangente em temas, criado manualmente, e que, estudado para a tarefa de REM, comprova aumentar a precisão dos melhores sistemas REMs da literatura (Kazama \& Torisawa, 2007). A segunda estratégia é bem conhecida, ela refere-se à utilização de regras gramaticais durante a fase de identificação e classificação das EMs. Esta estratégia foi adotada no PALAVRAS_NER (Bick, 2007), sistema vencedor da avaliação conjunta de EMs do HAREM I. O diferencial do Rembrandt é a utilização da Wikipédia em contraste ao uso de um dicionário de EMs (gazetteer) adotado pelo PALAVRAS_NER ou pelo Siêmes. O uso da base da Wikipédia, além de melhorar a qualidade da identificação das EMs, também disponibiliza um link de cada entidade para cada artigo da Wikipedia, possibilitando assim obter mais informações sobre a entidade para o leitor.

O uso da base Wikipedia na tarefa de recuperação de informação é uma técnica recente. As possibilidades de extração de conhecimento dela são imensas (Wu et. al., 2007). Vários trabalhos estão sendo publicados, cujos objetivos são mostrar a forma de exploração desse recurso. Um exemplo é o trabalho de Auer \& Lehmann (2007), que usam o atributo caixas de informação (infoboxes) da Wikipedia, na extração de tuplas no formato RDF, as quais podem ser usadas em outras aplicações.

As categorias do Rembrandt são dez, nove delas herdadas do Harem I (Santos \& Cardoso, 2006): Pessoa; Lugar; Organização; Obra; Acontecimento; Abstração; Valor; Tempo e Coisa, que possuem ainda 47 classes internas. A categoria "número", a décima do Rembrandt, contém quatro subcategorias.

A identificação das entidades e sua classificação são efetuadas em três etapas. Na primeira etapa (i) são reconhecidas expressões de tempo, número ou valor, entidades que são codificadas via expressões regulares. A seguir, as categorias das outras entidades mais comuns são encontradas por meio do sistema Saskia que procura estes

\footnotetext{
${ }^{17}$ http://lasige.di.fc.ul.pt/Main_Page
} 
valores usando a base da Wikipedia (ii). Por fim, é feita a detecção entre as entidades para melhorar o resultado da etapa anterior (iii). Essas etapas são descritas mais detalhadamente abaixo:

\section{i. Reconhecimento e expressões numéricas e geração de EM candidatas}

Cada texto é sentenciado e tokenizado com o uso de um atomizador disponível no módulo Perl Lingua::PT::PLN em search.cpan.org. Após isso, um conjunto de regras reconhece as entidades numéricas, por exemplo, algarismos ou valores escritos por extenso, valores ordinais, cardinais, ou até mesmo expressões temporais de datas, horas, entre outros. Após essa primeira etapa, é feita a identificação das entidades resultantes. Entre elas: palavras com ao menos uma maiúscula e/ou um algarismo, dos quais podem estar ligados pelos seguintes conectivos: "de", "da", "do", "das", "dos" e "e". Estes, também são referidos pelo termo daoese, devido a sua expressão regular "d[aoe]s?e".

\section{ii. Classificação semântica de EM}

A classificação semântica das EMs é composta pelo sistema Saskia, que realiza sua classificação semântica baseado na Wikipedia, e aplica seu conjunto de regras de revisão. Porém, o conjunto de etiquetas para uma entidade é abrangente, o qual será refinado pelo segundo conjunto de regras. Esse conjunto usa evidências sintático-morfológicas na melhoria da classificação. Por exemplo, a sentença "moro na avenida Getúlio Vargas", em que "Getúlio Vargas" que pode ser classificado como PESSOA/INDIVIDUAL pelo primeiro conjunto de regras, é corrigido pelo segundo conjunto de regras. Nesta etapa, também são levantadas as etiquetas alternativas ("<ALT>"), que indicam que há dois tipos de identificação possível. Isso pode ocorrer na presença de um conectivo daeose, os quais podem fazer parte de uma entidade como em "João da Silva" ou estar entre duas "Fiat do João".

\section{iii. Repescagem de EM sem classificação}

Esta etapa três é composta pelo detector de relações entre as entidades e por sua repescagem. A detecção de relações é feita através de um conjunto de regras específicas para esta tarefa. Esta técnica permite detectar algumas EMs ainda não classificadas. Etiquetas não classificadas até este ponto serão eliminadas. 


\subsubsection{O módulo Saskia para acesso a Wikipedia}

A classificação semântica do Saskia envolve três etapas. A primeira associa uma EM a uma página da Wikipedia. Nessa etapa, busca-se um artigo da Wikipédia cujo título contenha o mesmo valor do texto da EM. Caso não haja resultado, o artigo mais próximo a essa entidade é procurado. Seu conteúdo deverá ter texto idêntico ao conteúdo da entidade: indício de proximidade. Também, é realizado o emparelhamento de EMs. Por exemplo, para a entidade "Estados Unidos", há vários links (âncoras), que ligam as mesmas formas de se referênciar a esta entidade: EUA, Estados Unidos, América do Norte, etc.

A segunda etapa consiste na coleta de categorias, a qual, para cada uma das categorias das entidades emparelhadas anteriormente tem seu tipo analisado e, na ausência de informação suficiente, mais páginas relacionadas são visitadas, as quais têm suas categorias extraídas e adicionadas a uma lista. Dentre as várias categorias adicionadas, estão aquelas de acrônimos e de desambiguação.

Por fim, a terceira etapa é responsável por aplicar uma lista de regras gramaticais para cada tipo de categoria para fazer uma filtragem dos melhores resultados. Essa última etapa encerra a etapa de classificação de EMs do sistema Saskia. As operações disponíveis pelo Saskia, além da opção da navegação, incluem a extração de categorias, armazenamento e filtragem de links, a normalização do título das páginas, entre outros.

\subsubsection{O módulo de Detecção de Relações entre Entidades (DRE)}

A proposta deste módulo é a detecção das relações entre as entidades mencionadas. Essa deteccção permite o auxilio da desambiguação das entidades, pois, por exemplo, se for identificado que a entidade "Lula" corresponde a entidade "Luís Inácio Lula da Silva", presente no mesmo texto, então, a primeira que poderia ser classificada como molusco, será, agora, classificada como pessoa.

Outro exemplo são as entidades "Festival de Dança de Joinville" e "Joinville", relacionadas pela regra ocorre_em, que estabelece relação entre uma categoria que define acontecimento e outra que define lugar. Ainda mais complexo é o estabelecimento da relação entre "Brasília" e "Juscelino Kubitschek", a qual pode ser identificada através do link para o artigo do ex-presidente Juscelino, encontrado na artigo da página de Brasília na Wikipédia. 


\section{Sistema de Elaboração Textual do Português}

O sistema de Elaboração Textual do Português (Elatex) implementa dois módulos de elaboração textual para o público alvo do projeto PorSimples, projeto maior no qual esta pesquisa de mestrado se insere.

O primeiro módulo gera perguntas elaboradas que explicitam a ligação existente entre o conjunto verbal da sentença (evocador) e seu constituinte ou argumento. Esse sistema foi avaliado com especialistas da área de PLN o que permitiu levantar os erros de geração e avaliar o seu impacto, além de avaliar as perguntas com as medidas de compreensibilidade e naturalidade.

O sistema e sua avaliação são descritos na Seção 3.1. O segundo módulo de elaboração, a elaboração via definições curtas da Wikipedia para entidades mencionadas, foi implementado no sistema FACILITA EDUCATIVO (Watanabe et al., 2010) e avaliado junto a usuários com grau de escolaridade baixo. O sistema e o resultado da avaliação são apresentados na Seção 3.2.

\subsection{Geração de Perguntas Elaboradas em Textos do Português}

A Geração de Perguntas Elaboradas em textos do português foi implementada no sistema PET (Perguntas para a Elaboração Textual). Na Seção 3.1.1 é mostrado um exemplo de elaboração considerando-se poucas exceções ao problema, com o objetivo introduzir os conceitos e formas de resoluções gerais da tarefa de geração de perguntas. $\mathrm{Na}$ Seção 3.1.2 são apresentados valores quantitativos e qualitativos do córpus simplificado que foi utilizado para o treinamento e testes desta tarefa de elaboração. Também foi realizado um teste de concordância quanto à reprodutibilidade da tarefa da atribuição de etiquetas de perguntas que é apresentado na Seção 3.1.3. Enfim, na Seção 3.1.4 é mostrado o sistema de Elaboração Textual do Português, o sistema Elatex. Sua avaliação é apresentada na Seção 3.1.5.

\subsubsection{Exemplo de elaboração via geração de perguntas elaboradas}

Para exemplificar mais detalhadamente cada etapa da tarefa de elaboração textual via geração de perguntas elaboradas, e também para indicar as escolhas por recursos e ferramentas neste mestrado, tomou-se como exemplo a sentença da Figura 12. Esta sentença é composta por três verbos evocadores de perguntas, sublinhados. Com auxílio 
desses verbos, as perguntas elaboradas serão construídas, e suas respostas são os argumentos dos verbos encontrados na sentença. Neste momento, ainda não são tratadas questões específicas do problema, tais como o tratamento de verbo composto, argumentos que não permitem gerar perguntas ao verbo, entre outros que serão tratados em outras seções específicas.

Ontem, Nelson Hubner avisou que o governo pensa em elevar a taxa para 3\% de forma autorizada.

Figura 12: Sentença do córpus Zero Hora (zh023.s17)

Na Figura 13, a sentença de exemplo recebe a anotação do parser Palavras (Bick, 2000). Nesta figura, pode ser vista a estrutura de árvore sintática gerada. Nesse exemplo, a árvore origina-se de um nó único, o nó raiz que recebe o valor "UTT" ("Utterance" do inglês que pode ser traduzido como "enunciado" em português).

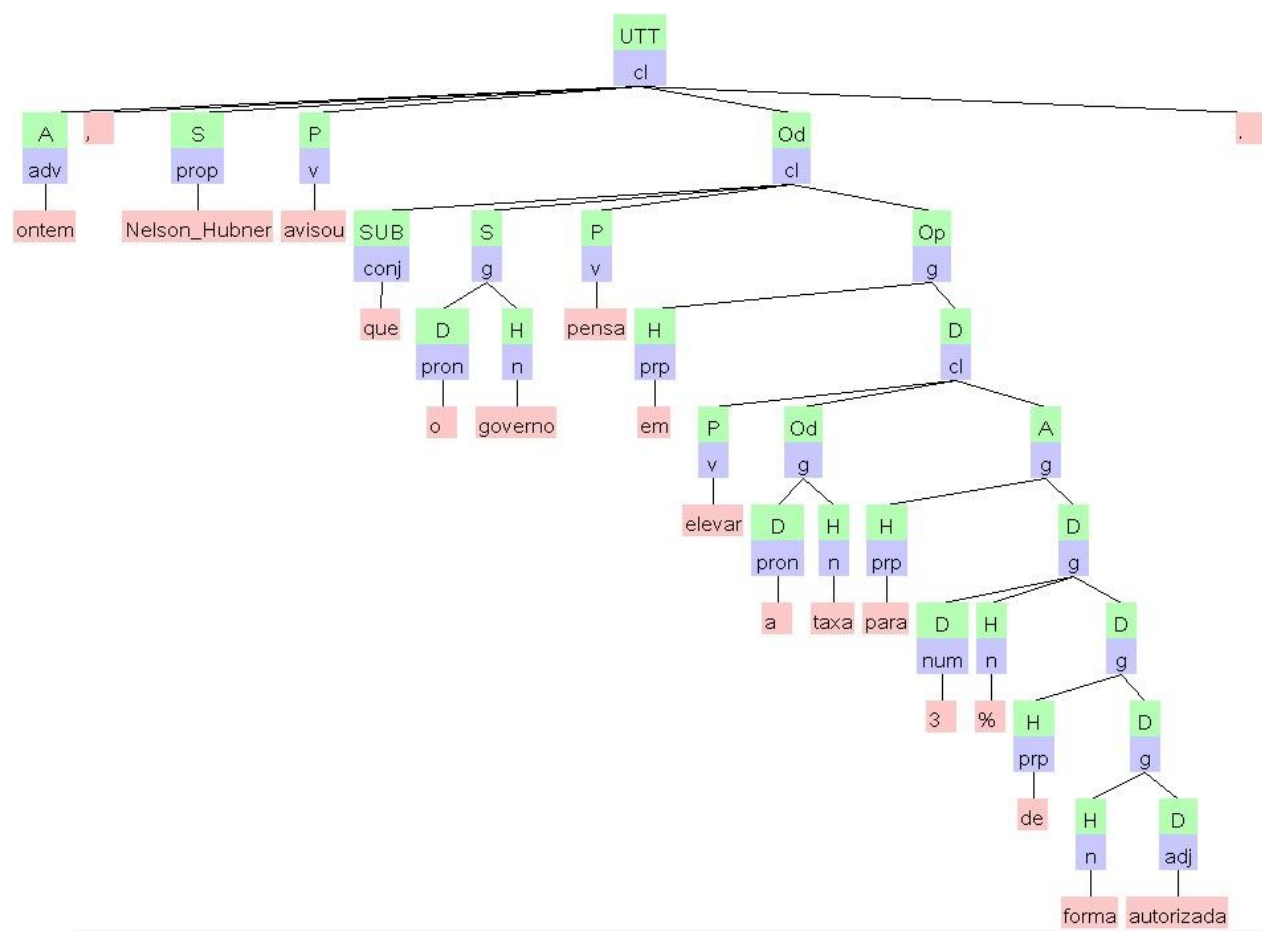

Figura 13: Árvore sintática gerada pelo parser Palavras para a seguinte sentença: "Ontem, Nelson Hubner avisou que o governo pensa em elevar a taxa para $3 \%$ de forma autorizada."

$\mathrm{Na}$ sentença exemplo, encontram-se os três verbos evocadores de perguntas, o verbo "avisar", "pensar" e "elevar", organizados em forma hierárquica, sendo o verbo “avisar" o de maior nível e o "pensar" o de segundo maior nível na hierarquia, uma vez que o verbo "elevar" está contido na sub-árvore classificada como objeto preposicionado (Op) do verbo "pensar", e o verbo "pensar" está contido sub-árvore classificada como objeto direto do verbo "avisar". 
Na Tabela 4, podem ser vistos os resultados gerados nas três etapas da tarefa de elaboração via geração de perguntas aos verbos de uma sentença: delimitação, categorização e elaboração. As duas primeiras colunas à esquerda da tabela correspondem à delimitação dos verbos e dos segmentos de resposta do verbo, a coluna seguinte corresponde à etiqueta de perguntas que esses segmentos recebem, enquanto que a última coluna corresponde às perguntas elaboradas para as etiquetas.

Tabela 4: Resultados gerados em cada etapa da tarefa

\begin{tabular}{|l|l|l|l|}
\hline \multicolumn{2}{|c|}{ Delimitação } & Categorização & Elaboração \\
\hline Verbo & Segmentos de Resposta & Categorias & Pergunta Elaborada \\
\hline Avisou & "Nelson Hubner" & Quem? & Quem avisou? \\
\cline { 2 - 4 } & $\begin{array}{l}\text { "Que o governo pensa em elevar a } \\
\text { taxa para 3\% de forma autorizada." }\end{array}$ & O que? & Avisou o que? \\
\cline { 2 - 4 } & "Ontem" & Quando? & Avisou quando? \\
\hline Pensa & $\begin{array}{l}\text { "Em elevar a taxa para 3 \% de } \\
\text { Elevar }\end{array}$ & "A taxa" que? & Pensa em que? \\
\cline { 2 - 5 } & "Para 3 \%." & & \\
\cline { 2 - 5 } & "Ainda em 2008." & O que? & Elevar o que? \\
\cline { 2 - 4 } & $\begin{array}{l}\text { "De forma autorizada, isto é, não } \\
\text { obrigatória." }\end{array}$ & Como? & Elevar como? \\
\hline
\end{tabular}

Para segmentar os verbos, foi necessária apenas a informação " $\mathrm{P} / \mathrm{v}$ " de verbo, encontrada na árvore sintática. Para a identificação dos argumentos dos verbos, foram encontradas as sub-árvores que estavam no mesmo nível do verbo. Por exemplo, o verbo "avisou" tem no seu mesmo nível três elementos sintáticos: um advérbio, representado por "A/Adv", um nome próprio "S/prop" e uma sentença que é o objeto direto do verbo "Od/cl". Fazendo-se as mesmas etapas para os outros verbos, as duas primeiras colunas da Tabela 4, correspondentes à delimitação, podem ser preenchidas.

A próxima etapa é a categorização dos segmentos encontrados em relação ao verbo. Esta etapa se dá através da extração dos atributos para o aprendizado de máquina, dos segmentos de resposta em relação ao verbo. No sistema desenvolvido foram utilizados 23 atributos/features que podem ser encontrados na Seção 3.1.4.1.2. A última etapa consiste na geração das perguntas elaboradas. A geração é composta por vários tipos de 
regras. Essas regras estabelecem relações entre o verbo e as etiquetas, na tarefa de geração de perguntas elaboradas. As regras do sistema desenvolvido podem ser encontradas na Seção 3.1.4.3.2. Estas regras foram elaboradas conjuntamente com a pós-doutoranda do NILC Magali Sanches Duran.

\subsubsection{Córpus de Trabalho e Etiquetas de Anotação}

O córpus de trabalho da tarefa de geração de perguntas elaboradas é composto de 104 artigos do jornal Zero Hora (ZH). Este córpus foi simplificado manualmente no projeto PorSimples (Caseli et al., 2009). Duas versões estão disponíveis no site do PorSimples $^{18}$, as versões de simplificação natural e forte. Neste projeto, foi usada a simplificação forte.

As razões de se usar um córpus simplificado foram: (i) textos simplificados consistem de sentenças em voz ativa, não têm cláusulas relativas (ou as tem em número mínimo), não têm aposição (ou as tem em número mínimo), e poucas sentenças coordenadas e subordinadas. Essas características diminuem a exposição do texto a erros do parser, e (ii) as regras manuais de simplificação usadas para gerar os textos do córpus não produzem mudanças em relação aos adjuntos.

O córpus recebeu anotação prévia do parser Palavras (Bick, 2000), porém sua anotação sintática não foi revisada, mas somente as orações sem problemas de parsing foram retidas. Depois da anotação sintática, 9820 etiquetas de perguntas foram atribuídas a suas sentenças usando o sistema SALTO (Burchardt et al., 2006) e o conjunto de etiquetas é composto de 68 tipos diferentes de perguntas possíveis. A Tabela 5, mostra algumas das estatísticas sobre o córpus original e o de simplificação forte.

Tabela 5: Estatística do córpus

\begin{tabular}{|c|c|c|}
\hline Córpus & ZH original & $\begin{array}{c}\text { ZH com } \\
\text { simplificação forte }\end{array}$ \\
\hline Textos & 104 & $\mathbf{1 0 4}$ \\
\hline Sentenças & 2.184 & $\mathbf{3 . 3 2 9}$ \\
\hline Palavras & 46.190 & $\mathbf{4 3 . 4 0 6}$ \\
\hline Palavras media por texto & 444.1 & $\mathbf{4 1 7 , 3}$ \\
\hline Palavras media por sentença & 21.1 & $\mathbf{1 3 . 0}$ \\
\hline
\end{tabular}

\footnotetext{
${ }^{18}$ http://caravelas.icmc.usp.br/wiki/index.php/Tools
} 
De um total de 3329 sentenças anotadas, 334 (9,1\%) foram anotadas como "Wrong subcórpus" (córpus errado). Essas sentenças tinham uma anotação sintática errada, por exemplo, árvores desconexas, visualizadas pela ferramenta SALTO. Outras razões para se descartar orações no córpus errado foram: erro de segmentação de sentenças, títulos de textos (não eram o foco do trabalho), erros de tokenização.

No córpus, o número de sentenças corretas são 2995, sendo anotados 4771 verbos (4151 verbos simples e 620 verbos compostos) e 9820 argumentos anotados com etiquetas de perguntas.

Na Figura 14, observa-se que 3295 (33,55\%) dos argumentos anotados são relacionados com o papel sintático de sujeito (“O que?-DIR" e "Quem?-DIR") e 2996 (30,20\%) estão relacionados com o papel sintático de objeto direto (“Quem?-ESQ" e "O que?-ESQ”). Estes valores eram esperados, pois sujeitos e objetos diretos são os argumentos verbais mais frequentes. Os adjuntos de lugar, tempo e modo são os mais frequentes (“Onde?”, “Quando?” e “Como?”). Objetos diretos são bem distribuídos, uma vez que as etiquetas atribuídas são introduzidas por vários tipos diferentes de preposições. Eles estão incluídos em “Other labels”, mostrados na Figura 14.

É válido mencionar que "Quem?" é a pergunta mais frequentemente respondida pelos sujeitos (2120 “quem?” contra 1175 “o que?”) e “O que?” é a pergunta mais frequentemente respondida pelos objetos diretos (2753 “O que?” contra 213 “Quem?”). O conjunto total das etiquetas usadas na anotação pode ser encontrado no Apêndice A.
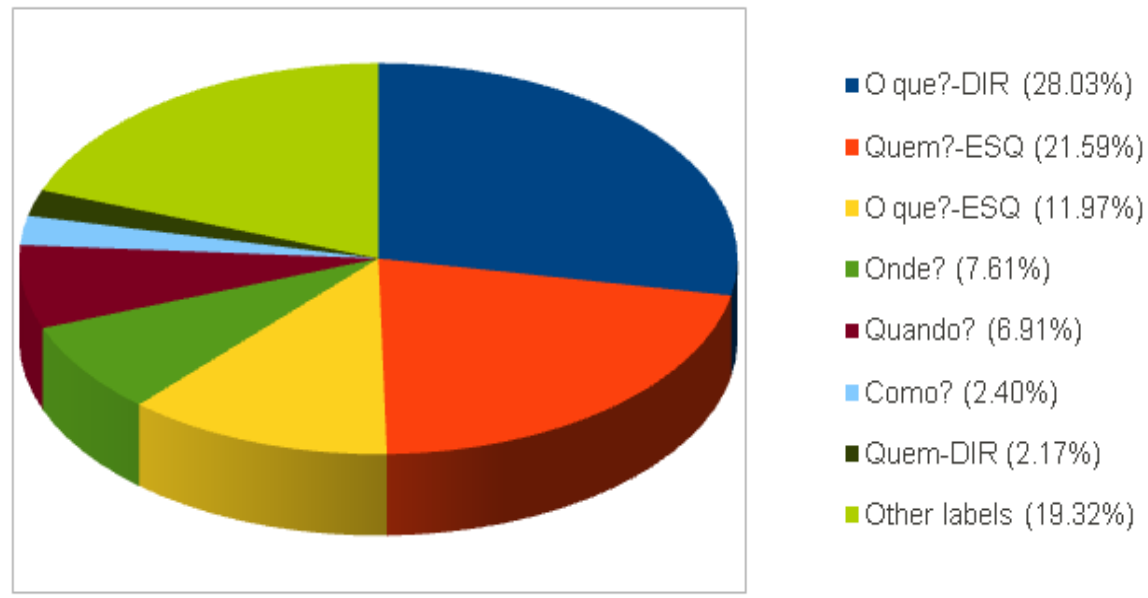

Figura 14: As etiquetas mais frequentes atribuídas às sentenças do córpus 


\subsubsection{Teste da Concordância humana}

Foi realizado um experimento piloto com o objetivo estudar a reprodutibilidade da tarefa de atribuição de perguntas entre etiquetadores humanos (Duran et. al., 2010a). Para isso, utilizou-se a estatística de concordância Kappa (Carletta, 1996).

Sete avaliadores realizaram a tarefa, sendo todos eles alunos de pós graduação da área de PLN. A tarefa era composta por um conjunto de 43 etiquetas de perguntas em que os avaliadores poderiam utilizar para categorizar 75 argumentos presentes em 25 sentenças. Os anotadores contaram com um manual de anotação e tiveram um tempo de 30 minutos para a avaliação, após uma exposição e exemplificação da tarefa.

O resultado da tarefa foi um Kappa de 0.78 . Esse resultado representa uma alta concordância para a tarefa, demonstrando que a tarefa é reprodutível.

\subsubsection{O Sistema de Perguntas para a Elaboração Textual (PET)}

O módulo de Perguntas para a Elaboração Textual divide o problema de geração de perguntas elaboradas em três módulos: Delimitação, Categorização e Elaboração, os quais são descritos nas Seções 3.1.4.1, 3.1.4.2 e 3.1.4.3, respectivamente. A avaliação da tarefa com juízes humanos pode ser vista na Seção 3.1.5.

\subsubsection{Delimitação}

O objetivo da tarefa da delimitação é a identificação de elementos das sentenças que participam do processo de construção de perguntas e de suas respostas. $\mathrm{O}$ primeiro elemento deste processo é o evocador de perguntas. Esse evocador é composto de pelo menos um verbo principal e elementos auxiliares na evocação que podem ser verbos auxiliares assim como a negação "não", pronomes reflexivos, por exemplo, o elemento "se". A tarefa de delimitação é composta de duas etapas, a (i) segmentação do evocador e a (ii) delimitação das respostas do evocador (espécie de argumento do verbo).

\subsection{Segmentação do Evocador}

No português, muitas perguntas podem ser geradas em referência a uma oração ou frase qualquer. Por exemplo, para a frase "Caixa azul", pode-se fazer a pergunta “Que cor é a caixa?", e a resposta é “azul”. Ou até perguntas que não podem ser 
respondidas à priori: “De quem era a caixa azul?", que depende do conhecimento do texto de origem da sentença. Neste projeto, optou-se por limitar o escopo de perguntas a apenas evocadores de origem verbal, uma vez que seguimos a linha de anotação do projeto Propbank (Palmer et al., 2005).

A identificação dos evocadores consiste em identificar o verbo principal ou o conjunto verbal principal e, em seguida, adicionar elementos que têm alguma conexão lógica com o verbo, e que unidos geram o próprio evocador de perguntas. No estudo realizado no córpus de trabalho, os elementos que se agregam ao verbo na geração de perguntas são os pronomes oblíquos átonos e a negação não. São três regras específicas para a delimitação do evocador, elas podem ser vistas na Figura 15.

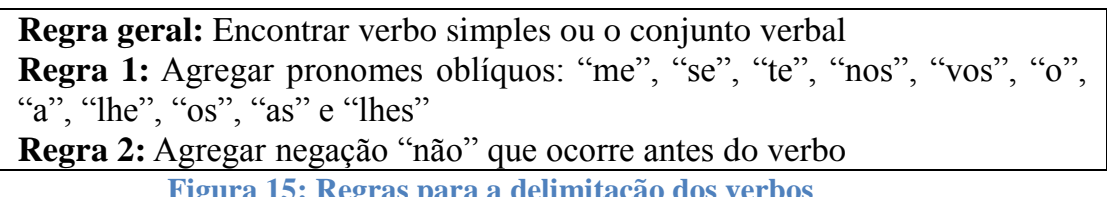

Exemplos de aplicação dessas regras:

- Ele não foi à escola ontem. (Regra geral e Regra 2)

- Ele não se cortou no arame farpado. (Regra geral, Regra 1 e Regra 2)

\section{Lista de verbos auxiliares para melhorar a identificação do Palavras}

No estudo realizado, notou-se que o Palavras, parser baseado em regras, não tem uma tabela abrangente de verbos auxiliares. Por isso, foi usada uma tabela de verbos auxiliares criada pela pesquisadora Magali Sanches Duran, durante a sua pesquisa de pós-doutorado, na criação do córpus anotado do projeto Propbank.Br. A tabela pode ser encontrada no Anexo A. Esta tabela permite que o conjunto verbal identificado pelo Palavras seja melhorado, via pós-processamento. Na Figura 16, pode ser visto um exemplo de aplicação dos verbos auxiliares do Anexo A, a "Regra i" permite a junção "tinha" e "começado", resultando em "tinha começado" e a "Regra ii" permite a junção "tinha começado" e "a aprender", resultando em "tinha começado a aprender".

Sentença: "Ele tinha começado a aprender a andar"

Regra i (Anexo A): ter + <verbo no particípio>

Regra ii (Anexo A): começar + a $+<$ verbo no infinitivo >

Sentença ev. delimitado: "Ele tinha começado a aprender a andar"

Figura 16: Exemplo de segmentação de evocadores 
Uma observação é feita ao verbo "andar", que não possui sujeito nem objetos que permitem que perguntas futuras sejam criadas. Logo, este verbo não é delimitado.

\subsection{Segmentação das respostas do evocador}

A identificação dos segmentos que serão as respostas das perguntas levantadas ao evocador é realizada em duas etapas: (a) Regras baseadas em parser e (b) Regras baseadas em categorização.

\section{Regras baseadas em Parser}

A principal dica de quem são os segmentos que estabelecem relação lógica com o verbo para o levantamento de pergunta está na árvore sintática, pois é nela que podem ser encontradas as relações sintáticas. Na Figura 17 são encontradas duas regras, a primeira é relativa aos nós vizinhos de mesmo nível e filhos de um mesmo pai da subárvore em que está presente o evocador, e a segunda regra é relativa à subárvore do verbo de elocução.

Regra 1: Para cada verbo, encontre as árvores vizinhas que não sejam raiz, exceto quando a raiz é um nome.

Regra 2: Se o verbo é de elocução (mostrado pelo parser), segmente a subárvore originária deste verbo de elocução.

Figura 17: Regras baseadas no Parser

\section{Regras baseadas em categorização}

Há segmentos de resposta cuja delimitação pode ser aglutinada com o próximo segmento, desde que os mesmos tenham a mesma categoria. Por exemplo, na sentença:

\section{"Ele morou vários anos em Viçosa, $M G$."}

O parser Palavras segmentará corretamente a palavra "Viçosa" e "MG" separadamente. Porém, para o propósito deste projeto é mais interessante identificar estes dois elementos como um apenas, cuja segmentação seria "Viçosa, MG". Portanto, a regra de delimitação da Figura 18 foi criada. 
Regra: Transforme em um segmento novo C, todo semento A e B que satisfaça os dois critérios a seguir:

i. $\quad$ A e B são segmentos contíguos

ii. $\quad$ A e B têm a mesma categoria de pergunta (porém a etiqueta não pode ser do tipo esquerda “-Esq")

Figura 18: Estendendo a delimitação

\subsubsection{Categorização}

A categorização é a parte do processo de elaboração responsável por atribuir etiquetas de perguntas aos segmentos identificados durante a delimitação. A categorização é dividida em duas etapas: (i) o treinamento de um classificador, mostrado na Figura 19, e (ii) o uso do classificador treinado para a classificação de uma sentença, na Figura 20.

\subsection{Treinamento do classificador}

Na Figura 19, pode ser vista a arquitetura usada no treinamento do classificador e também na sua avaliação. Em (1), pode ser visto o córpus Zero Hora anotado manualmente, que encontra-se no formato da ferramenta SALTO. A anotação manual consiste nas etapas de delimitação e atribuição manual de etiquetas.

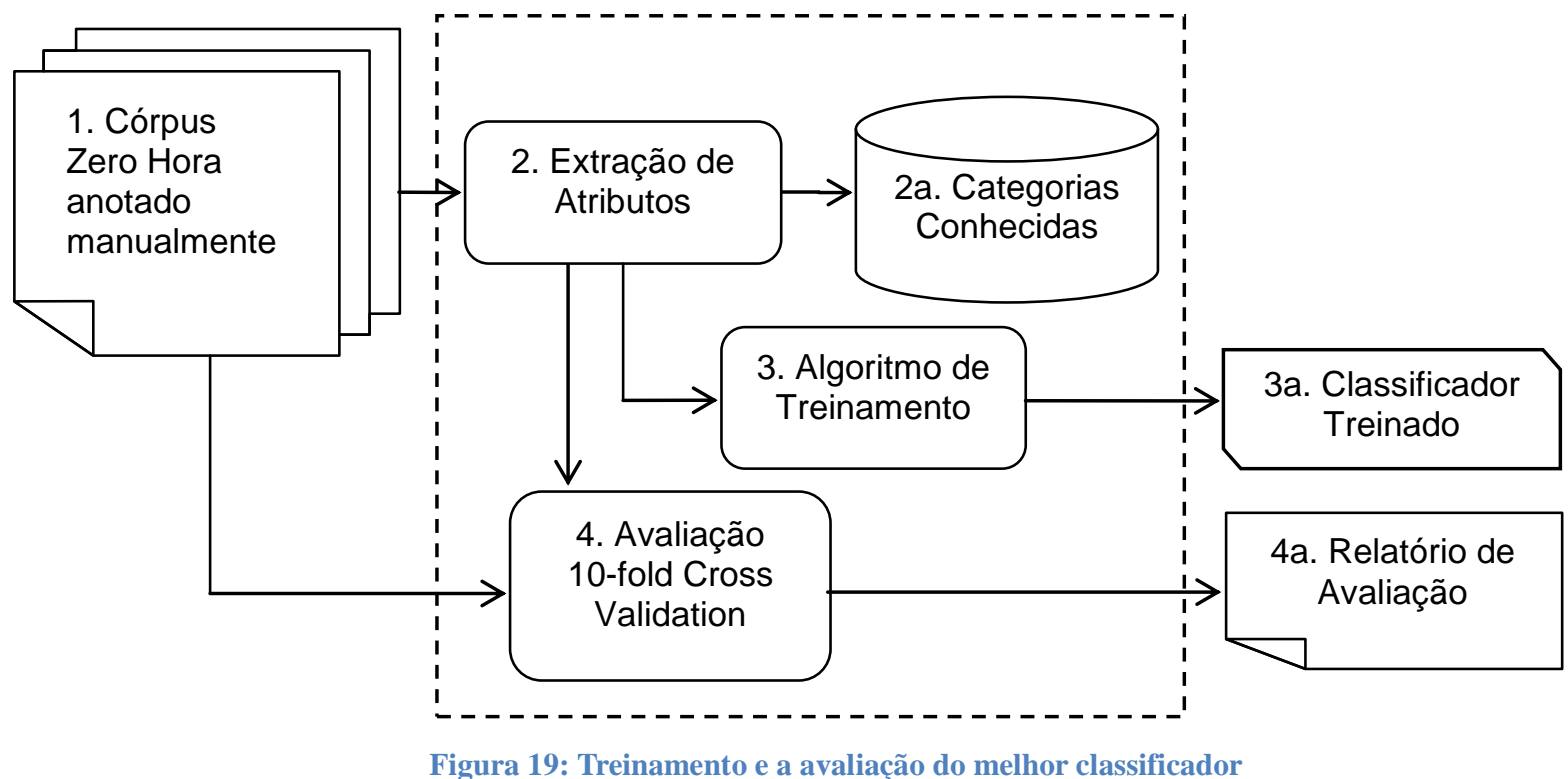


O extrator de atributos (2) extrai 14 atributos dos 23 testados. Esses 14 atributos foram selecionados entre os 23 que foram levantados inicialmente. Os 23 atributos são apresentados na Seção 3.1.4.1.2 e a seleção dos atributos na Seção 3.1.4.1.3.

Há várias categorias encontradas, por exemplo, os tokens que introduzem o segmento. Estas categorias encontradas têm de ser salvas em (2a), porque na etapa de classificação, o classificador consegue se beneficiar somente dos valores conhecidos. Os valores desconhecidos que não estão armazenados na base (2a) receberão o valor da categoria "outros".

Em (3), o algoritmo de treinamento utilizado é o SMO, do WEKA (Hall et al., 2009), pois ele teve a melhor F-measure na avaliação 10-fold cross validation em (4), como mostrado na Seção 3.1.4.1.4. Foram considerados vários algoritmos de aprendizado de máquina diferentes, que foram avaliados e comparados para a escolha do melhor.

\subsection{Atributos utilizados}

Foram utilizadas 23 features divididas em 13 tipos que são apresentados abaixo. Estes atributos são geralmente utilizados em sistemas de rotulação de papéis semânticos (Semantic role labeling) (Palmer et al., 2010).

- Tipo da frase (sintagma): Diferentes tipos de questões tendem em ser realizadas por diferentes tipos de categorias sintáticas. Em geral, frases nominais (NP - Noun Phrases do Palavras) tendem a responder as questões “o que?" ou “quem?" enquanto as frases preposicionadas (PP - Prepositional Phrases do Palavras) tendem a responder as perguntas "para que?", “de que?", "para onde?", “em que?", “com quem?”, entre outros. O parser Palavras, que foi usado na anotação do córpus, tem um grande conjunto de etiquetas sintáticas das quais 12 categorias de alto nível foram usadas; além das NP e PP foram usadas frases adverbiais, cláusulas, entre outras.

- Lado da ocorrência: Este atributo indica se o constituinte a ser categorizado ocorre antes (à esquerda) ou depois (à direita) do verbo em foco. Os valores possíveis para este atributo são "ESQ" para os constituintes à esquerda e "DIR" para constituintes à direita. 
- Posição do argumento: Este atributo é um número inteiro que indica a posição do constituinte em relação ao verbo. A posição é a contagem do número de constituintes entre o verbo e o constituinte atual.

- Funções sintáticas: Este atributo se refere ao conjunto de etiquetas de argumentos sintáticos do verbo. Para o córpus em estudo, 26 etiquetas do Palavras foram usadas. Entre elas: objeto direto, objeto indireto, objetos preposicionados, sujeito, predicadores, complemento do sujeito, complemento do objeto, entre outras.

- Funções sintáticas específicas: Este atributo corresponde à subcategorização do atributo de número 4. Por exemplo, no Palavras existem dois tipos de objetos diretos, dois tipos de verbos (verbo principal, verbo auxiliar), entre outros.

- Existe atributo no lado esquerdo do verbo?: Este atributo booleano permite a identificação de sentenças sem sujeito ou com sujeito no lado direto do verbo.

- Número de argumentos: Indica o número de argumento da sentença.

- Forma infinitiva do verbo principal: Todo evocador de pergunta anotado possui um verbo principal. Sua forma infinitiva é o valor deste atributo.

- Etiquetas POS do último e dois primeiros tokens do argumento: Estes três atributos ajudam a refinar o tipo de NP envolvido, uma vez que as etiquetas POS ajudam a distinguir nomes próprios e nomes comuns, a forma singular, e a forma plural.

- Primeiro e segundo tokens do argumento: Este atributo é usado quando o primeiro e segundo tokens pertencem a classes fechadas, por exemplo, os artigos ou as preposições. Para classes gramaticais abertas, por exemplo, os nomes, o atributo é deixado em branco.

- Valores semânticos do argumento: São oito features semânticas extraídas dos tokens de cada argumento divididos em classes e subclasses encontradas no parser Palavras.

- Verbos simples e compostos: O número de tokens dos verbos de cada evocador.

- Número de tokens dos argumentos: Número inteiro indicando o número de tokens de cada argumento.

\subsection{Seleção de Atributos}

Para reduzir a dimensionalidade do problema, etapa necessária para que o algoritmo SMO e SimpleLogistic pudessem ser aplicados, foi utilizado o algoritmo 
Information Gain do Weka, o qual ranqueou os atributos levantados. Dos 23 atributos, selecionamos os 14 primeiros encontrados na lista dos mais influentes: Eles são: (1) Tipo da frase, (2) Lado da ocorrência, (5) Funções sintáticas específicas, (4) Funções sintáticas, (3) Posição do argumento, (8) Forma infinitiva do verbo principal, (9) Etiquetas POS do último e dois primeiros tokens do argumento , (10) Primeiro tokens do argumento, (10) Segundo tokens do argumento , (11) Valores semânticos do argumento do primeiro token, (11) Valores semânticos do argumento do segundo token. Os valores destes atributos tinham pelo menos o valor de 0.34 no ranking geral, sendo que o maior valor tinha 1,39 .

\subsection{Avaliação algoritmos de categorização}

Usando os 14 melhores atributos levantados, foram conduzidos experimentos com seis tipos diferentes de algoritmos de aprendizado de máquina, utilizando o método 10-fold cross validation. Seus resultados para a F-measure podem ser observados na Tabela 6.

Tabela 6: Valores F-measure para os algoritmos de aprendizado de máquina para a tarefa de categorização de etiquetas de perguntas

\begin{tabular}{|c|c|}
\hline Algoritmos & F-measure \\
\hline SMO & 0.79 \\
\hline SimpleLogistic & 0.78 \\
\hline J48 & 0.74 \\
\hline KNN (K=1) & 0.73 \\
\hline JRIP & 0.72 \\
\hline Naive Bayes & 0.71 \\
\hline Classe Majoritária & 0.42 \\
\hline
\end{tabular}

Na Tabela 6, os dois melhores algoritmos foram o SMO e o Simple Logistic com os valores de 0.79 e 0.78 , respectivamente. Os algoritmos $\mathrm{J} 48$ e $\mathrm{KNN}$ (com k=1, que resultou no melhor F) com os valores de 0.74 e 0.73 , respectivamente. JRIP com $F=0.72$ e NB com $\mathrm{F}=0.71$ obtiveram os piores resultados. Todos os algoritmos superaram a medida $\mathrm{F}$ da classe majoritária (etiqueta mais frequente à direita e a esquerda), cujo valor é de 0.42 . Dado o algoritmo SMO ser o melhor algoritmo encontrado, este foi usado em todas as etapas posteriores neste projeto.

\subsection{Classificação de sentenças}

A classificação de sentenças utiliza algumas tarefas usadas na etapa de treinamento, mostradas na Figura 20. Em (1), uma sentença analisada e com delimitação automática entra no sistema. O mesmo algoritmo de extração de atributos usado no treinamento é usado em (2) 
para a obtenção dos atributos da sentença de entrada. Categorias dos atributos que não estão na base "Categorias conhecidas", ou seja, categorias novas recebem o valore de "outros", para que o atributo possa ser processado pelo classificador treinado. Para cada segmento da sentença, o classificador escolherá uma categoria com base nos atributos selecionados. O resultado é a "Sentença Categorizada", em (4).

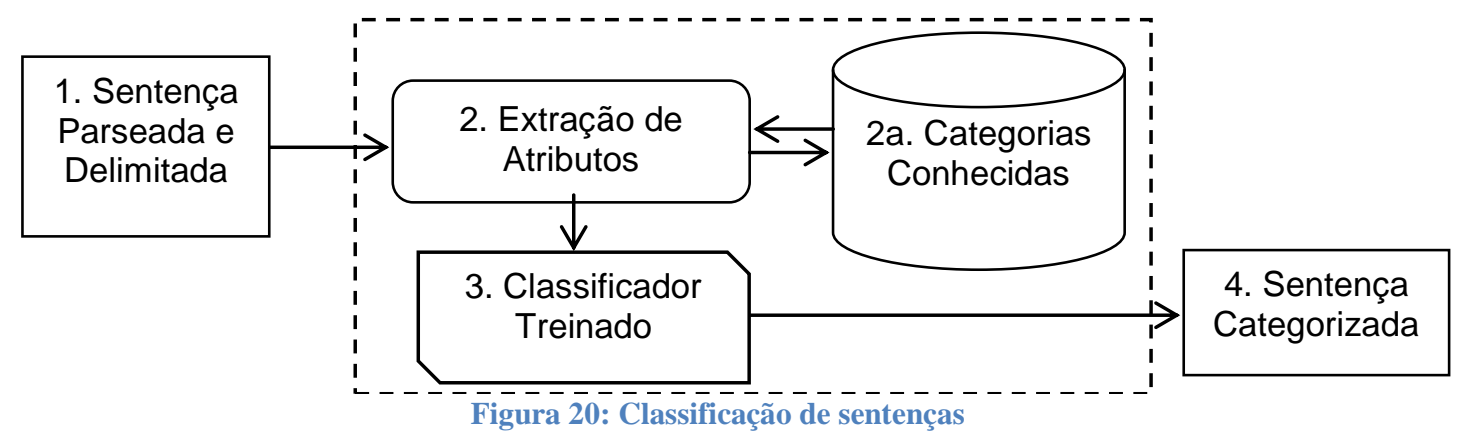

\subsubsection{Elaboração}

A Geração de Perguntas Elaboradas consiste em um conjunto de regras que, a partir das etiquetas de perguntas, geram sentenças completas. As regras são detalhadas abaixo, sendo a Figura 11 uma ilustração do processo pelo qual uma oração delimitada e categorizada passa para se transformar em uma oração elaborada. As Seções 3.1.4.3.1 a 3.1.4.3.6 descrevem o processo.

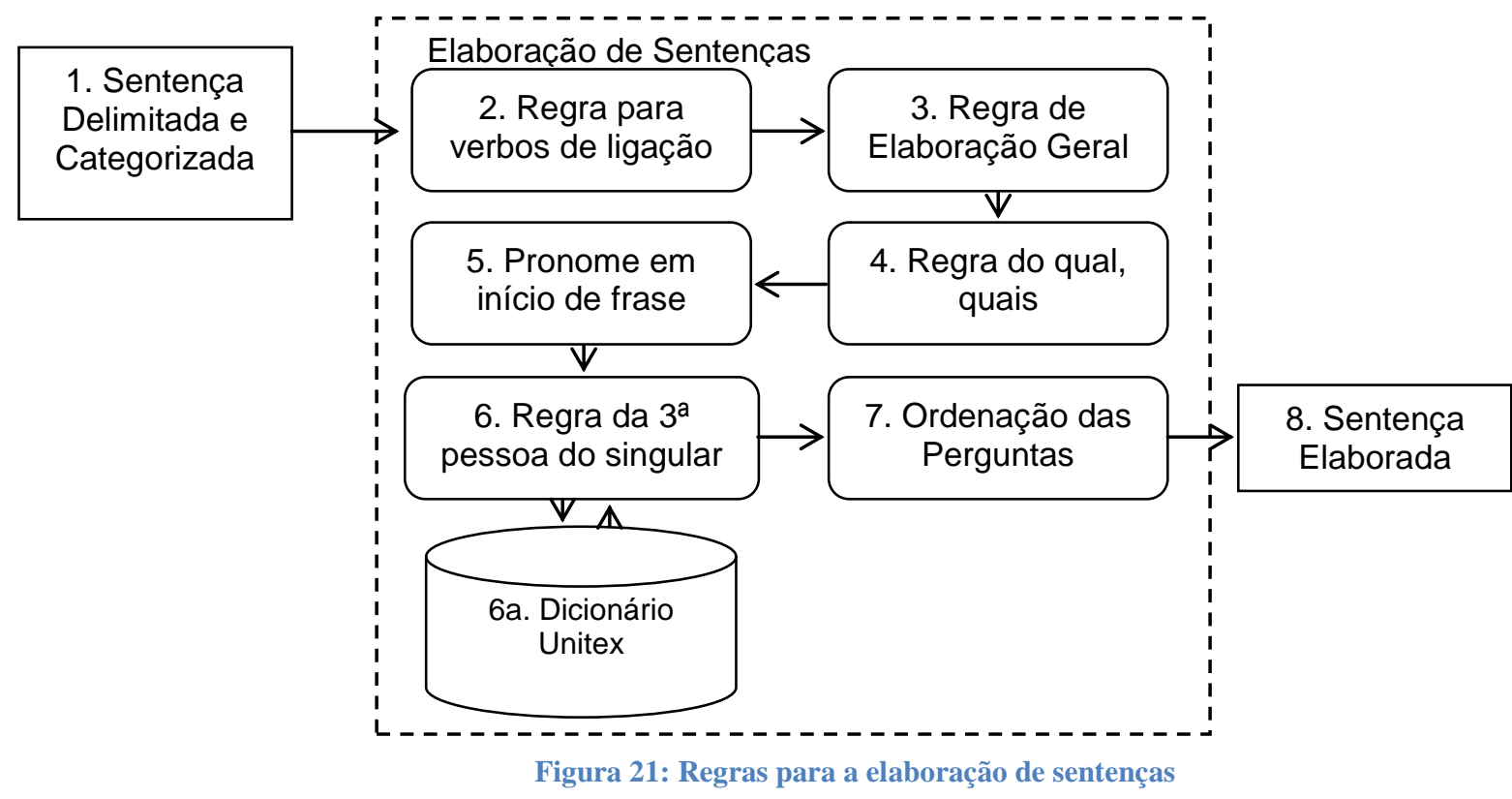

\subsection{Regras para o verbo de ligação}

Verbos de ligação são verbos frequentes e, devido a isso, são os verbos que podem assumir mais sentidos dentro de uma oração. Portanto, para que a pergunta 
criada não fique vaga no caso de somente usar-se o verbo de ligação e o segmento de resposta, decidiu-se a construção de regras especiais para os verbos de ligação. Essas regras tentam incorporar na pergunta os elementos do sujeito ou objeto, elementos do verbo evocador e a etiqueta de pergunta. Na Tabela 7 podem ser vistos os sete verbos de ligação usados neste projeto.

Tabela 7: Tabela de verbos de ligação

\begin{tabular}{|l|l|}
\hline Ser & Estar \\
\hline Ficar & Permanecer \\
\hline Continuar & Parecer \\
\hline Andar (só quando acompanhado de predicativo) & \\
\hline
\end{tabular}

Os verbos de ligação são aqueles que ligam um sujeito a um verbo (predicativo). No parser Palavras, o predicativo pode ter duas etiquetas que demonstram que ele é um verbo de ligação; essas etiquetas podem ser encontradas na Figura 22.

@PRED> 'forward' free predicative (refers to the following @SUBJ, even when this is incorporated in the VP)

@ < PRED `backward' free predicative (refers to the nearest NP-head to the left, or to the nearest @ SUBJ to the left)

Figura 22: Etiquetas do Palavras para indicar que um predicativo é um verbo de ligação.

Dado que um elemento de pergunta é composto de:

(i) EVOCADOR: Elemento evocador da pergunta (verbo e componentes auxiliares).

(ii) RÓTULO: Rótulo da pergunta atribuído ao segmento da resposta.

considere a regra da Figura 23.

Regra: Se encontrado um verbo de ligação, faça:

- A pergunta à esquerda deve incorporar o segmento marcado com "o quê" ou "quem" ou "como-verbal" ou "que idade" à direita, se este existir.

Pergunta: [EVOCADOR] [RÓTULO] [SEGMENTO_DA_DIREITA]?

- A pergunta à direita deve incorporar o segmento marcado com "o quê" ou "quem" à esquerda, se este existir.

Pergunta: [SEGMENTO_DA_ESQUERDA] [EVOCADOR] [RÓTULO] ?

Figura 23: Regra de geração de perguntas para verbos de ligação

Por exemplo, na sentença da Figura 24, todas as variáveis da regra são levantadas, e com a aplicação regras anteriores, as perguntas à esquerda e à direita podem ser levantadas. 


\begin{tabular}{|l|}
\hline Sentença: "Maria tem 10 anos." \\
EVOCADOR: tem \\
SEGMENTO_DA_ESQUERDA: Maria \\
SEGMENTO_DA_DIREITA: 10 anos \\
RÓTULO ESQUERDA: Quem?-esq \\
RÓTULO DIREITA: Quem?-dir \\
Pergunta da esquerda: Quem tem 10 anos? \\
Pergunta da direita: Maria tem que idade?
\end{tabular}

Figura 24: Sentença com verbo de ligação

No caso do predicativo ser um adjetivo, este deve ser lematizado (transformado em masculino singular). Por exemplo, a sentença:

"A lua está luminosa."

A pergunta com o adjetivo lematizado fica assim: "O que está luminoso?"

\subsection{Regras de Elaboração Geral}

A regra de elaboração geral é a regra mais utilizada e mais simples. Ela é a regra de geração de orações mais comum, e é utilizada quando nenhuma outra regra se aplica. Dado que um elemento de pergunta é composto de:

(i) EVOCADOR: Elemento evocador da pergunta (verbo e componentes auxiliares).

(ii) RÓTULO: Rótulo da pergunta atribuído ao segmento da resposta.

A Regra geral de evocação geral pode ser vista na Figura 25. Esta regra é composta de dois componentes, um para o caso do tratamento do Agente ou Sujeito, e o outro componente para o caso do tratamento do objeto do verbo.

Regra 1: Se a etiqueta rótulo tem a terminação "-ESQ" (Agente ou sujeito) então a pergunta será composta da seguinte forma:

[RÓTULO $]+[$ EVOCADOR] ?

Regra 2: Caso contrário, a pergunta será da seguinte forma:

$[$ EVOCADOR $]+[$ RÓTULO $]$ ?

Figura 25: Regra de elaboração geral

Seja a sentença exemplo: “Amanhã eles não tomarão chuva."

i. Quem não tomarão? (Regra 1)

ii. Não tomarão quando? (Regra 2)

iii. Não tomarão o que? (Regra 2) 


\subsection{Regra do qual, quais}

Sentenças que contém a etiqueta "Qual?-ESQ" não devem gerar perguntas para o argumento marcado com "O que?-DIR", porém, este deve incluir o segmento de resposta em sua pergunta, esta regra pode ser vista na Figura 26.

Regra: Se encontrado as etiquetas "Qual?-ESQ" ou "Quais?-ESQ" e "O que?-DIR" em uma sentença:

- A pergunta gerada com "O que?-DIR", não deve ser levantada.

-A pergunta a esquerda ficará do seguinte modo: [RÓTULO] [EVOCADOR] [SEGMENTO_DA_ESQUERDA]

Figura 26: Regra específica para as etiquetas "Qual?-ESQ" e "Quais?-ESQ"

Na Figura 27, pode ser visto um exemplo de aplicação da regra. Para a sentença em questão, somente a pergunta “Qual era o objetivo?” será gerada.

Sentença: "O objetivo era protestar contra o ataque de cães durante o exercício de as atividades."

EVOCADOR: era

SEGMENTO_DA_ESQUERDA: O objetivo

SEGMENTO_DA_DIREITA: protestar contra o ataque de cães durante o exercício de as atividades

RÓTULO ESQUERDA: Qual?-ESQ

RÓTULO DIREITA: O que?-DIR

Pergunta da esquerda: Qual era o objetivo?

Pergunta a direita (não será gerada): Protestar contra o ataque de cães durante o exercício de as atividades era o que?

Figura 27: Exemplo de aplicação da regra da etiqueta qual, quais

\subsection{Inversão verbo-pronome reflexivo em início de frase}

$\mathrm{Na}$ língua portuguesa, pronomes reflexivos oblíquos átonos são proibidos de iniciarem frase. Durante a geração, para evitar este tipo de erro, foi criada uma regra que toda vez que um pronome reflexivo apresenta-se no início de frase, ele sofre inversão com seu verbo. A Figura 28 mostra a geração das perguntas com ou sem a regra de inversão do pronome reflexivo do verbo "se tornaram" sublinhado na sentença. Na Figura 29, esta regra é detalhada.

Sentença: "Os ataques se tornaram mais freqüentes"

Pergunta sem a regra: Se tornaram o que? Mais freqüentes. (Errado)

Pergunta com a regra: Tornaram-se o quê? (Correto)

Figura 28: Aplicação da regra de inversão do pronome reflexivo em início de frase 
Se o evocador tiver pronome reflexivo (se, me, te, nos, vos) então:

1. Este deverá ser posposto ao verbo na pergunta

2. Deverá ser apresentado na terceira pessoa do singular "se" nas perguntas quem?-esq, o que?-esq e qual?-esq

Figura 29: Regra de inversão verbo-pronome reflexivo

\subsection{Regra da terceira pessoa do singular}

Considere a seguinte sentença "Eles chegaram tarde à escola." Quando se deseja obter o sujeito da sentença acima, o interlocutor usualmente fará a pergunta "Quem chegou tarde à escola?". Observa-se que a conjugação do verbo "chegar" concorda em nome e número com o pronome interrogativo "Quem" ao invés de concordar com o sujeito "Eles".

Dado o fenômeno observado, foi criada uma regra para toda vez que fosse encontrado um sujeito, identificado pelas etiquetas "Quem-Esq", "O quê-Esq" e "QualEsq", manter-se o modo do verbo (particípio, infinitivo, etc.) e conjugar-se o verbo na terceira pessoa do singular.

Se o verbo for composto e possuir uma das formas do particípio, então este deverá ir para a 3a pessoa do singular também. Os passos para a conjugação correta podem ser encontrados na Figura 30. Um exemplo do córpus pode ser encontrado na Figura 31, com o segmento evocador da oração em negrito e o verbo conjugado na resposta destacado em amarelo. Para a realização das conjugações, foi utilizado o recurso Unitex (Muniz, 2004).

\footnotetext{
Se encontradas as etiquetas "Quem-Esq", "O quê-Esq" ou "Qual-Esq" faça

Se o verbo está na terceira pessoa do singular não faça nada

Senão

Armazene modo do verbo principal

Lematize verbo

Conjugue o verbo lematizado na 3 a do singular no modo armazenado

Repita as três etapas acima a forma do particípio do verbo composto, caso ela exista

Figura 30: Conjugação do verbo na terceira pessoa do singular
}

"Os buquês de macela são encontrados por o preço médio de $R \$ 1$ em o centro de

Porto Alegre ."

O que é encontrado? Os buquês de macela.

Figura 31: Conjugação do frame evocador na terceira pessoa do singular 


\subsection{Ordem das Perguntas}

Na geração de perguntas, observou-se que a ordem das sentenças geradas é um fator importante para o usuário do sistema. Em geral, é mais urgente obter a informação sobre quem é o sujeito antes de saber qualquer ação, ou mudança de estado que o agente fez ou sofreu. Na Figura 32, é mostrado um conjunto de regras de prioridade na escolha de qual pergunta dever ser levantada primeiro. Em (1) dá-se prioridade aos verbos de mais alto nível na árvore sintática, e em (2) são dadas quatro regras de prioridade de cada tipo de pergunta de cada verbo, por exemplo, a seleção de perguntas de descoberta do sujeito.

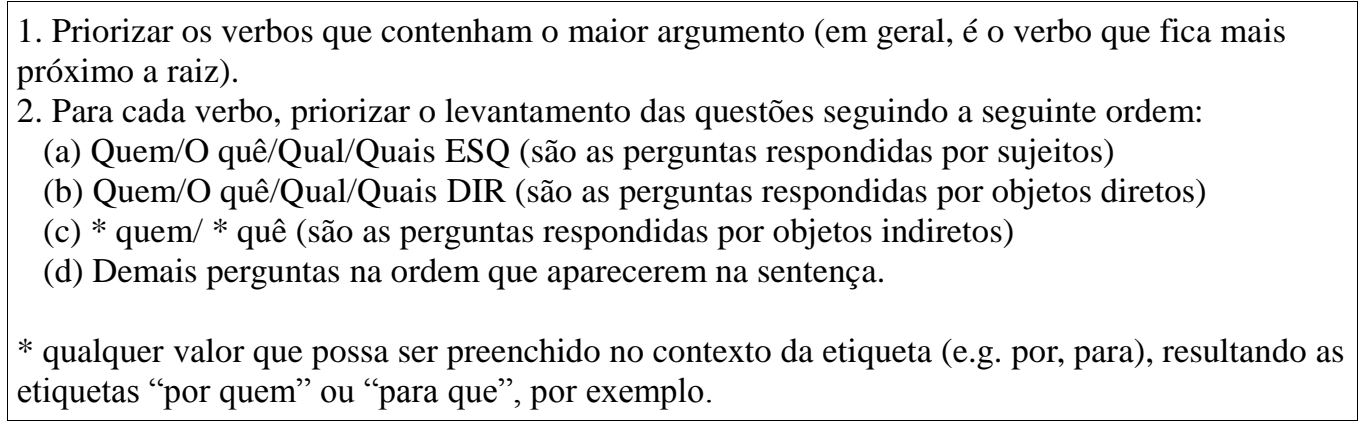

Figura 32: Regra de ordenação

Na sentença da Figura 33, pode ser vista a aplicação das regras descritas anteriormente.

Sentença: "Quem participa há quatro anos chegou a $93 \%$ de melhoria - diz ele."

Pergunta A: Quem diz? Ele.

Pergunta B: Diz o quê? Quem participa há quatro anos chegou a $93 \%$ de melhoria.

Pergunta C: Quem chegou? Quem participa há quatro anos.

Pergunta D: Chegou a quê? A $93 \%$ de melhoria.

Pergunta E: Quem participa? Quem.

Pergunta F: Participa há quanto tempo? Há quatro anos.

Figura 33: Exemplo de conjunto de perguntas ordenadas

\subsubsection{A avaliação do sistema PET com juizes humanos}

Nesta seção, são apresentados os detalhes da avaliação dos três módulos do sistema PET, ativados em sequência. O sistema recebeu avaliação de sete juízes que não são os usuários finais previstos pelo sistema, mas foram escolhidos por serem pesquisadores da área de PLN e assim são classificados como especialistas em tarefas como a em foco. Com base em um manual de anotação, no qual foram descritas as variáveis de avaliação e foram dados exemplos para cada uma delas, julgaram a qualidade da geração de sentenças com base nas variáveis Compreensibilidade e Naturalidade. Também requisitou-se que os avaliadores apontassem problemas na geração das sentenças. Esses problemas foram codificados em oito variáveis de erro. 
Os objetivos da avaliação são apresentados na Seção 3.1.5.1, assim como a definição adotada para as variáveis de Compreensibilidade e Naturalidade. Na Seção 3.1.5.2, é apresentado o planejamento da avaliação: o córpus escolhido, o manual de descrição da tarefa, e a escolha dos juízes e o tempo médio previsto. A Seção 3.1.5.3 traz os resultados da avaliação: a concordância entre anotadores, assim como os valores obtidos na avaliação usando as medidas estatísticas de porcentagem e moda. Também é mostrado um estudo de correlação entre as variáveis de erro e a qualidade de geração da sentença (Compreensibilidade e Naturalidade).

\subsubsection{Objetivos e variáveis de avaliação do sistema Elatex com juízes}

O objetivo da avaliação do sistema foi o de obter, de forma criteriosa, valores que pudessem determinar a qualidade da tarefa de geração de sentenças que foi o tema central deste projeto de mestrado. Critérios comuns na literatura da área de geração texto-a-texto monolíngüe, que engloba as tarefas de fusão de sentenças, compressão de sentenças, visando sumarização, geração de paráfrases no nível de sentenças, geração de respostas (Question answering) e simplificação de sentenças (Flanagan, 2009; Saggion \& Lapalme, 2000; Siddharthan, 2004) são as de Compreensibilidade e Naturalidade, além da avaliação da gramaticalidade. Uma forma prática e eficiente de obter esses resultados é através da avaliação com juízes humanos de acordo com critérios préestabelecidos. Na avaliação, foram selecionados juízes que avaliaram o sistema de acordo com critérios pré-estabelecidos.

Para que se evitasse ao máximo divergências na avaliação, as variáveis Compreensibilidades e Naturalidades foram definidas segundos os critérios estabelecidos no manual apresentado no Apêndice B, e também apresentadas a seguir. Além disse, o manual traz os critérios pelos quais as perguntas foram geradas pelo sistema de forma que a avaliação também usasse as mesmas regras, principalmente a última abaixo que pede para que as perguntas sejam avaliadas individualmente, mesmo que os pares perguntas e respostas criem um contexto responsável por suprir dúvidas da pergunta atual, dadas as anteriores:

\footnotetext{
(1) a resposta está contida na sentença;

(2) as perguntas são evocadas por verbos ou sintagmas verbais presentes na sentença; e

(3) as várias perguntas de uma sentença devem ser avaliadas isoladamente, sem considerar o contexto criado pela sequência de perguntas.
} 
A variável Compreensibilidade estabelece a facilidade que o avaliador tem de recuperar a resposta da pergunta. Pois a resposta pode ser direta, ou seja, estar presente na sentença a qual a pergunta foi gerada, depender do contexto de onde a sentença veio, ou não possuir resposta. Portanto, três valores para a variável Compreensibilidade são definidos. No formulário de avaliação essas variáveis são referenciadas por números (1, 2 e 3). Sua definição é apresentada na Tabela 8.

Tabela 8: Descrição dos tipos de valores da variável Compreensibilidade

\begin{tabular}{|l|l|l|}
\hline $\begin{array}{l}\text { Referência } \\
\text { Numérica }\end{array}$ & Significado & Descrição \\
\hline 1 & $\begin{array}{l}\text { Claramente } \\
\text { Compreensível } \\
\text { (CC) }\end{array}$ & $\begin{array}{l}\text { É possível saber com facilidade o tipo de resposta que está sendo } \\
\text { esperada. }\end{array}$ \\
\hline 2 & Compreensível (C) & $\begin{array}{l}\text { É possível inferir o tipo de resposta esperada desde que se conheça } \\
\text { o contexto da sentença, i.e., o texto de onde a sentença veio. }\end{array}$ \\
\hline 3 & $\begin{array}{l}\text { Não } \\
\text { Compreensível } \\
\text { (NC) }\end{array}$ & $\begin{array}{l}\text { Mesmo conhecendo o contexto da sentença (texto de onde veio), } \\
\text { não é possível inferir com certeza a resposta esperada. }\end{array}$ \\
\hline
\end{tabular}

A variável Naturalidade determina a proximidade da geração da sentença da geração humana. A pergunta que pode ser confundida com a geração humana é a "Fortemente Natural", enquanto a "Pouco Natural" é geração aceitável para um humano enquanto a "Não Natural" é não aceitável. Tais valores podem ser vistos na Tabela 9.

Tabela 9: Descrição dos tipos de valores da variável Naturalidade

\begin{tabular}{|l|l|l|}
\hline $\begin{array}{l}\text { Referência } \\
\text { Numérica }\end{array}$ & Significado & Descrição \\
\hline 1 & Fortemente Natural (FN) & Como se um humano tivesse elaborado. \\
\hline 2 & Pouco Natural (PN) & Possível de ocorrer em uma interação humana. \\
\hline 3 & Não Natural (NN) & Ninguém perguntaria dessa forma. \\
\hline
\end{tabular}

Observa-se a similaridade do valor da variável Naturalidade com o Teste de Turing (Turing, 1950). O Teste de Turing propõe a avaliar a "inteligência" de sistemas computacionais através de um teste de um interlocutor humano "H" com um interlocutor "I" que pode ser humano ou máquina. O interlocutor humano " $\mathrm{H}$ " tem de decidir se "I" é homem ou máquina através de uma interação comunicativa através de um terminal de texto. No caso dos avaliadores do sistema Elatex, eles conhecem a proveniência da geração da pergunta que é a máquina. Porém, eles decidem se a geração pode ser confundida com a de um humano. 
Além das variáveis de qualidade de geração de perguntas, foram criadas oito variáveis que possibilitaram apontar problemas na geração das perguntas. Além da observação direta da porcentagem dos tipos de problemas, foram realizados teste de correlação, o que permitiu analisar que tipos de problemas influenciam as variáveis Compreensibilidade e Naturalidade. Essas variáveis são denominadas variáveis de erro.

A variável do tipo "erro" permite registrar os tipos de problemas que ocorrem na geração da pergunta. Seis tipos de erro estão ligados diretamente à pergunta e dois tipos à resposta obtida. Na Tabela 10, são mostrados os oito tipos de erro, assim como sua proveniência, valores usados na avaliação, siglas usadas nesse texto e sua descrição. Exemplos para os oito tipos de erro podem ser encontrados no manual de anotação no Apêndice B. 


\begin{tabular}{|l|l|l|l|l|}
\hline $\begin{array}{l}\text { Classes de } \\
\text { erro }\end{array}$ & Origem & $\begin{array}{l}\text { Erros usados } \\
\text { na avaliação }\end{array}$ & Abreviações & Descriçãa \\
\hline $\begin{array}{l}\text { Erro de } \\
\text { delimitação }\end{array}$ & Pergunta & Falta & Falta_P & $\begin{array}{l}\text { Falta informação na pergunta. Tanto } \\
\text { a falta quanto o excesso na pergunta } \\
\text { ou resposta podem ter origens no } \\
\text { módulo de delimitação. }\end{array}$ \\
\cline { 2 - 6 } & Resposta & Falta & Falta_R & Excesso de informação na pergunta. \\
\cline { 3 - 6 } & Excesso & Excesso_R & Falta informação na resposta. \\
\hline inadequado & Pergunta & $\begin{array}{l}\text { Núcleo } \\
\text { Inadequado }\end{array}$ & ENúcleo_P & $\begin{array}{l}\text { O núcleo da pergunta e.g. o que, } \\
\text { quem) está incorreto pode ser } \\
\text { substituído por outro melhor. Erro } \\
\text { de origem provável do módulo de } \\
\text { categorirização ou ser uma } \\
\text { conjunção de erros. }\end{array}$ \\
\hline $\begin{array}{l}\text { Pergunta } \\
\text { Descabida }\end{array}$ & Pergunta & $\begin{array}{l}\text { Pergunta } \\
\text { Descabida }\end{array}$ & Descabida_P & $\begin{array}{l}\text { Não há relação entre a resposta } \\
\text { encontrada o verbo evocador para } \\
\text { que possa ser levantada algum tipo } \\
\text { de pergunta. Erro de origem } \\
\text { provável do módulo de delimitação. }\end{array}$ \\
\hline $\begin{array}{l}\text { Ordem } \\
\text { Invertida }\end{array}$ & Pergunta & Ordem Invertida & Invertida_P & $\begin{array}{l}\text { Erro que indica se a posição dos } \\
\text { elementos presentes na pergunta } \\
\text { gerada não estão corretos. Este erro } \\
\text { é de origem provável do módulo de } \\
\text { elaboração ou pode ser derivado de } \\
\text { uma sequencia de erros nos módulos } \\
\text { anteriores. }\end{array}$ \\
\hline $\begin{array}{l}\text { Erro } \\
\text { gramatical }\end{array}$ & Pergunta & Erro Gramatical & EGramatical_P & $\begin{array}{l}\text { A pergunta gerada tem erros de } \\
\text { concordância ou outros tipos de } \\
\text { erros gramaticais. Erro de origem } \\
\text { provável do módulo de elaboração. }\end{array}$ \\
\hline
\end{tabular}

\subsubsection{Planejamento da Avaliação}

Abaixo são descritos o córpus usado, o processo de criação do manual de avaliação, as características dos avaliadores e também o tempo de avaliação.

\section{Córpus para a avaliação}

O córpus usado na avaliação é composto dos 104 textos simplificados (simplificação forte) do jornal Zero Hora, que é um resultado do projeto PorSimples. Foram selecionadas 44 sentenças, sendo que cada sentença passou pelas etapas de delimitação, categorização e elaboração. Para o treinamento do classificador, o córpus Zero Hora, exceto as 44 sentenças que receberam a classificação foi utilizado. É importante reforçar aqui que durante o projeto PorSimples foram simplificados dois córpus (textos do Zero Hora e também textos do caderno Ciência da Folha de São 
Paulo), mas somente o córpus Zero Hora recebeu anotação de perguntas, por isto que o treinamento da classificação foi feito com este último córpus somente.

Na Figura 34, é mostrada uma unidade da folha de avaliação que os juízes receberam. Nesse exemplo, pode ser visto a sentença "Eu sei que a administração Bush não controla esse microfone - descontrai Kerry.", suas quatro perguntas elaboradas (pergunta "A" até a "D"), respostas para estas quatro perguntas e o formulário de avaliação para as perguntas e respostas, com os valores de "Compreensibilidade", "Naturalidade", "Erros" e uma entrada prevista aos comentários. No manual de avaliação também pode ser encontrado um exemplo de sentença que os avaliadores tomaram como referência na sua avaliação. 
Sentença 43: "Eu sei que a administração Bush não controla esse microfone descontrai Kerry."

Pergunta A: Sei o que?

Compreensibilidade ( ) 1-claramente compreensível 2-compreensível 3-não compreensível natural

Naturalidade ( ) 1-fortemente natural 2-pouco natural 3-não
Erros
( ) inversão da ordem
( ) núcleo inadequado
( ) pergunta descabida
( ) erro gramatical
( ) falta parte
( ) parte em excesso

\section{Comentários:}

Resposta: Que a administração Bush não controla esse microfone.

Erros ( ) falta parte ( ) parte em excesso

Comentários:

Pergunta_B: Quem não controla?

Compreensibilidade ( ) 1-claramente compreensível 2-compreensível 3-não compreensível natural

Naturalidade ( ) 1-fortemente natural 2-pouco natural 3-não

Erros ( ) inversão da ordem ( ) núcleo inadequado ( ) pergunta descabida
( ) erro gramatical
( ) falta parte
( ) parte em excesso

Comentários:

Resposta: A administração Bush.

Erros ( ) falta parte ( ) parte em excesso

Comentários:

Pergunta_C: Não controla o que?

Compreensibilidade ( ) 1-claramente compreensível 2-compreensível 3-não compreensível

Naturalidade ( ) 1-fortemente natural 2-pouco natural 3-não natural

Erros ( ) inversão da ordem ( ) núcleo inadequado ( ) pergunta descabida

Comentários:

Resposta: Esse microfone.

Erros ( ) falta parte ( ) parte em excesso

Comentários:

Pergunta_D: Quem descontrai?

Compreensibilidade ( ) 1-claramente compreensível 2-compreensível 3-não compreensível

Naturalidade ( ) 1-fortemente natural 2-pouco natural 3-não natural
Erros
( ) inversão da ordem
( ) núcleo inadequado
( ) pergunta descabida
( ) erro gramatical
( ) falta parte
( ) parte em excesso 


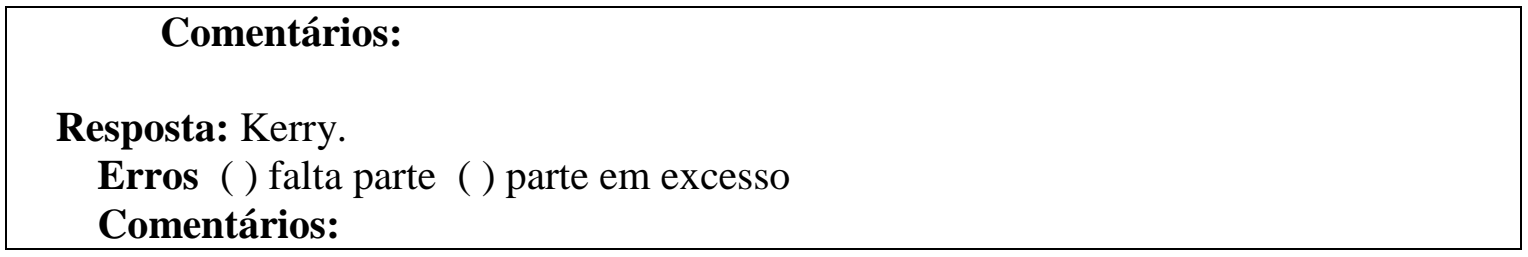

Figura 34: Sentença exemplo da folha de anotação

\section{Manual de Avaliação}

Foram realizadas cinco versões diferentes do manual antes que ele pudesse ser disponibilizado aos avaliadores. Este manual foi entregue três dias antes da avaliação junto com duas sentenças exemplo para que os avaliadores pudessem se familiarizar com a anotação. O manual, que contém quatro páginas, faz uma descrição sucinta do sistema, dos tipos de erro, entradas da avaliação assim como disponibiliza exemplos e diretivas de avaliação. O manual pode ser encontrado no Apêndice B.

\section{Avaliadores e Tempo de Duração da Avaliação}

Foram selecionados sete avaliadores, todos satisfaziam o seguinte critério: eram alunos envolvidos com a área de PLN em seus mestrados e doutorados, e possuíam disponibilidade para fazer a avaliação, além do interesse em avaliar o sistema. Cada avaliador recebeu 44 sentenças, cada sentença continha perguntas e respostas criadas pelo sistema, no total de 129 perguntas e respostas. Cada pergunta e resposta continham as seguintes variáveis de avaliação: compreensibilidade, naturalidade e erros. O tempo médio da avaliação foi de 2 horas e 10 minutos. Para uma melhor visualização, estes dados também são mostrados na Figura 35.

\begin{tabular}{|lc|}
\hline N. de avaliadores & 7 \\
N. de sentenças & 44 \\
N. de perguntas e respostas & 129 \\
Tempo médio da avaliação & $\sim 150 \mathrm{~min}$. \\
\hline \multicolumn{2}{|c|}{ Figura 35: Dados da avaliação do sistema com os juízes selecionados } \\
\hline
\end{tabular}

No formulário de avaliação, foi previsto um campo denominado "Comentários" para que o avaliador pudesse adicionar alguma informação útil que ele achou necessária durante a avaliação. Em geral, o avaliador apenas justificou sua anotação ou realizou a correção da pergunta ou resposta da forma que ele considerou ser a mais apropriada. 
Alguns avaliadores comentaram o valor "resposta descabida". Este é um tipo de erro que mostra erro do sistema durante fase de segmentação. Para exemplificar, a seguinte sentença será considerada:

"Porém, ele resolveu voltar."

Nela, o sistema poderia ter identificado erroneamente o seguimento "Porém". Qualquer pergunta ao verbo, relacionada à conjunção segmentada gerará o erro de "resposta descabida", porque o "Porém" não possui ligação lógica com o verbo, mas sim entre sentenças.

\subsubsection{Resultados}

Abaixo, trazemos o primeiro resultado da avaliação que é o valor da estatística Kappa entre os avaliadores para informar o quanto os avaliadores concordam entre si (Seção 3.1.5.3.1). Na Seção 3.1.5.3.2, é apresentado um estudo da distribuição de frequência por avaliador. Esta distribuição permite identificar as diferenças quantitativas entre os diferentes tipos de avaliadores. Na Seção 3.1.5.3.3, são mostrados os valores das porcentagens, considerando todo o conjunto de avaliadores os quais são comparados com a medida moda, além de apresentar resultados das correlações entre os erros e as medidas de naturalidade e compreensibilidade.

\subsection{Concordância entre avaliadores (Cohen Kappa)}

A estatística Kappa (Carletta, 1996) é uma medida muito utilizada para medir a concordância entre diferentes anotadores. Portanto, adotamos essa medida para calcularmos a concordância entre os avaliadores para as variáveis Naturalidade e Compreensibilidade. Nesse exercício, também foram feitas aglomerações de classes. Na Tabela 11 e Tabela 12, a primeira linha corresponde ao Kappa sem qualquer aglomeração de classes, enquanto que na segunda linha foram juntadas as classes de melhor pontuação CC com C e FN com PN que são as classes perfeitas ou aceitáveis pelo humano. Na terceira linha, aglomera-se C com CN e PN com NN. 


\begin{tabular}{|l|c|}
\hline & Compreensibilidade \\
\hline CC C NC & 0.20 \\
\hline (CC-C) NC & 0.33 \\
\hline CC (C-NC) & 0.33 \\
\hline
\end{tabular}

\begin{tabular}{|l|c|}
\hline & Naturalidade \\
\hline FN PN NN & 0.22 \\
\hline (FN-PN) NN & 0.28 \\
\hline FN (PN-NN) & 0.31 \\
\hline
\end{tabular}

Como pode ser visto na Tabela 11, tanto os valores das variáveis aglutinadas, quanto elas consideradas independentemente, enquadravam-se no intervalo de concordância "Razoável”. Esse é um valor baixo de concordância entre os avaliadores.

Tabela 11: Classificação de valores Kappa

\begin{tabular}{|l|l|}
\hline Intervalo Kappa & $\begin{array}{l}\text { Classificação de } \\
\text { concordância }\end{array}$ \\
\hline$<0.20$ & Pequena \\
\hline$[0.20 ; 0.40)^{19}$ & Razoável \\
\hline$[0.40 ; 0.60)$ & Moderada \\
\hline$[0.60 ; 0.80)$ & Boa \\
\hline$[0.80 ; 1.00]$ & Muito Boa \\
\hline
\end{tabular}

Os principais fatores gerais que podem gerar um Kappa baixo são:

1 - Tarefa não foi muito bem definida

2 - A tarefa é difícil de ser avaliada, pois depende muito de conhecimento inerente do avaliador.

Os seguintes fatores relacionados à tarefa em questão também são levantados:

3 - Problema na decisão de projeto que elaborava melhor as perguntas com os verbos de ligação e deixava as perguntas com os verbos plenos com menos informação. Isto pode ter afetado a decisão dos avaliadores.

4 - O manual indicava que as várias perguntas de uma sentença não deveriam ser consideradas como um contexto de diálogo, assim cada pergunta seria avaliada independentemente. Entretanto, os avaliadores podem ter desconsiderado esta indicação e avaliado de forma diferente do pedido.

\footnotetext{
${ }^{19}$ Nesses intervalos foi usado o símbolo matemático parênteses para denotar intervalo aberto e colchetes para intervalo fechado.
} 
No manual desenvolvido (Apêndice B), foi tomada a máxima precaução para que a tarefa fosse bem definida. Foram cinco versões desenvolvidas até sua versão final. Na avaliação, não houve muitas dúvidas quanto à anotação. Apesar de a tarefa estar bem definida, nosso trabalho está enquadrado na área semântica de PLN. Nessa área, é difícil tanto a construção de sistemas devido à necessidade de conhecimento de mundo, por exemplo, quanto a sua avaliação. Logo, o Kappa baixo pode ser resultado da opção de número dois e também das características particulares deste sistema levantadas (3) e (4).

\section{Análise dos votos por avaliador}

Para poder visualizar melhor o resultado da avaliação, foram criados os gráficos da Figura 36 e da Figura 37. Estes gráficos mostram a votação das variáveis de Compreensibilidade e Naturalidade para cada um dos sete avaliadores. Este gráfico permite verificar como vários anotadores, apesar de serem estudantes da mesma área, podem fazer uma anotação totalmente diferente.

Cada coluna do gráfico, de A1 a A7, representa um avaliador. Suas notas de Compreensibilidade (NC, C e CC) e Naturalidade (NN, PN e FN) apresentam-se distribuídas conforme a porcentagem apresentada. Cada categoria é representada em cores, as quais podem ser recuperadas na legenda. $\mathrm{O}$ valor das porcentagens de cada classe por avaliador pode ser obtido através de projeção ao eixo vertical do gráfico. Os gráficos foram arranjados pelo valor de $\mathrm{CC}$ do gráfico de Compreensibilidade. Este arranjo estabelece a ordenação dos avaliadores que são representados pelos valores de A1 a A7. No gráfico de Compreensibilidade, A1 representa o avaliador mais crítico do sistema enquanto A7 o avaliador mais benevolente. 

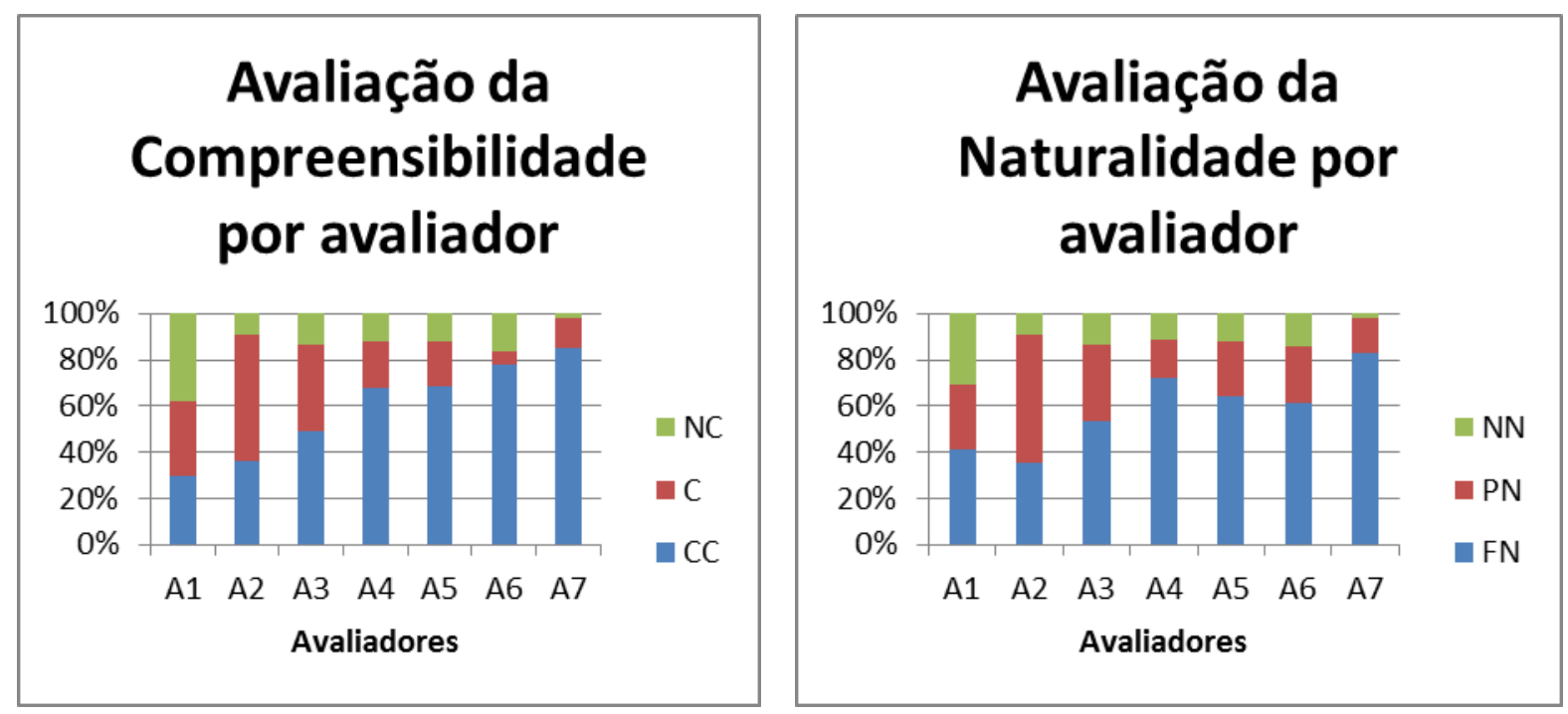

Figura 36: Distribuição de votos de compreensibilidade Figura 37: Distribuição de votos de naturalidade por avaliador por avaliador

Uma observação é a similaridade entre estes os dois gráficos. Se compararmos um a um o valor das barras dos dois gráficos por avaliador, podemos verificar que apenas o avaliador A6 tem um valor mais discrepante entre os valores de compreensibilidade e naturalidade, apesar destes valores não destoarem muito. Outro ponto interessante é a discrepância entre anotadores. O avaliador A1 seguiu critério totalmente diferente do avaliador A7. Esta diferença de uso de critérios e a abstração da tarefa são os principais fatores que resultaram em Kappa baixo.

\subsection{Análise da Distribuição de Frequências}

Compreensibilidade e naturalidades são variáveis nominais que podem assumir três valores diferentes. Por isso, foi possível levantar na Figura 38 o gráfico de suas porcentagens. Este gráfico foi montado considerando as porcentagens dos sete avaliadores em conjunto. As colunas azuis representam os valores de compreensibilidade enquanto as vermelhas da naturalidade. Observa-se uma semelhança entre o comportamento dessas duas variáveis.

Dos valores Claramente Compreensível e Compreensível e Fortemente Natural e Pouco Natural para Compreensibilidade, obtém-se a soma de 87,2\% e 83,72\% para os valores de porcentagens nessas variáveis que são consideradas aceitáveis ao ser humano. 


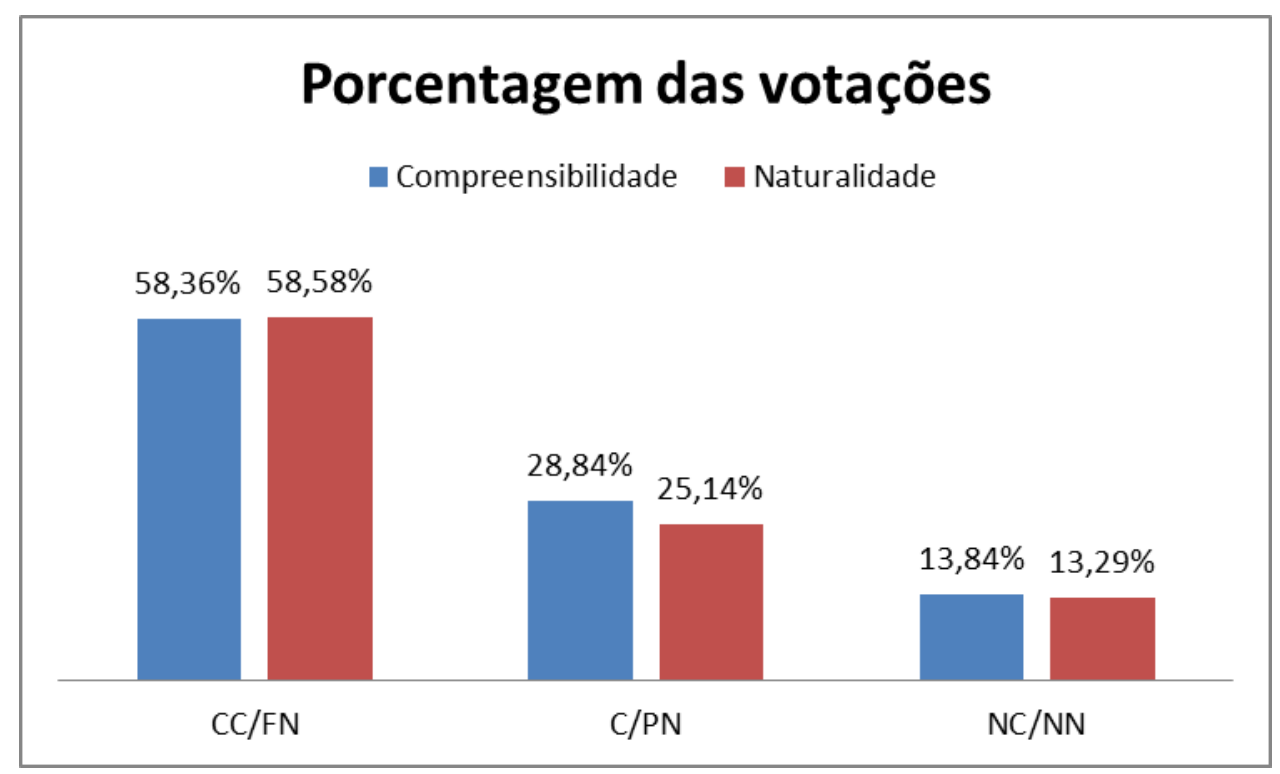

Figura 38: Porcentagem da compreensibilidade, naturalidade.

A Figura 38 traz as porcentagens para cada um dos oito erros possíveis. O maior tipo de problema encontrado é a falta de informação nas perguntas, com 34,11\% de frequência. Esse fato ocorreu principalmente devido à estratégia adotada pelo sistema de não elaborar ao máximo as perguntas com verbos completos.

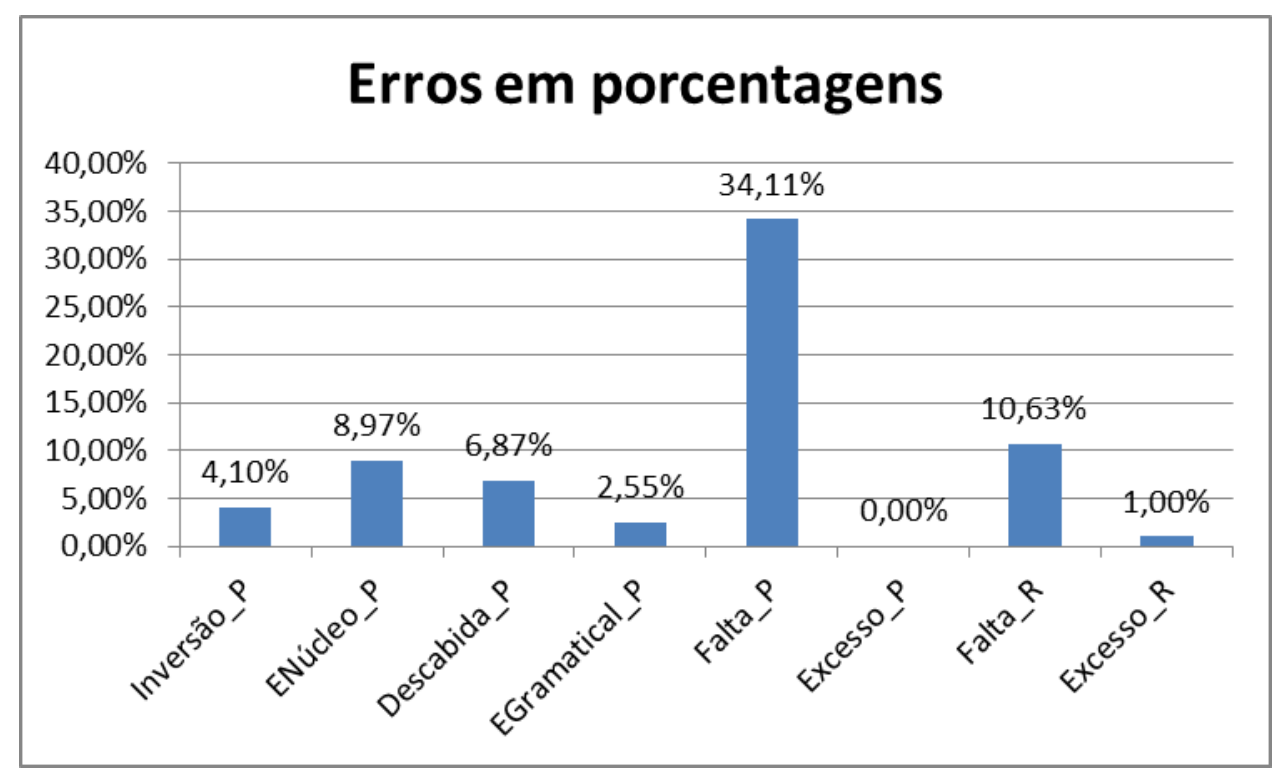

Figura 39: Porcentagem dos seis tipos de erros possíveis na pergunta $(\mathbf{P})$ e dois possíveis na resposta $(\mathbf{R})$

\subsection{Análise da Distribuição da moda}

Além dos valores das porcentagens, considerando a alta discordância dos avaliadores, resolveu-se também calcular o valor estatístico da moda dos resultados. 
Essa variável considera o valor mais frequente entre os sete juízes, uma espécie de votação. A Figura 40 mostra a porcentagem do valor da moda entre os sete avaliadores para as variáveis de compreensibilidade e naturalidade. Como há três classes e sete votos por instância, é possível que haja empate nas votações. Quando isso ocorre, cada classe recebe meio ponto.

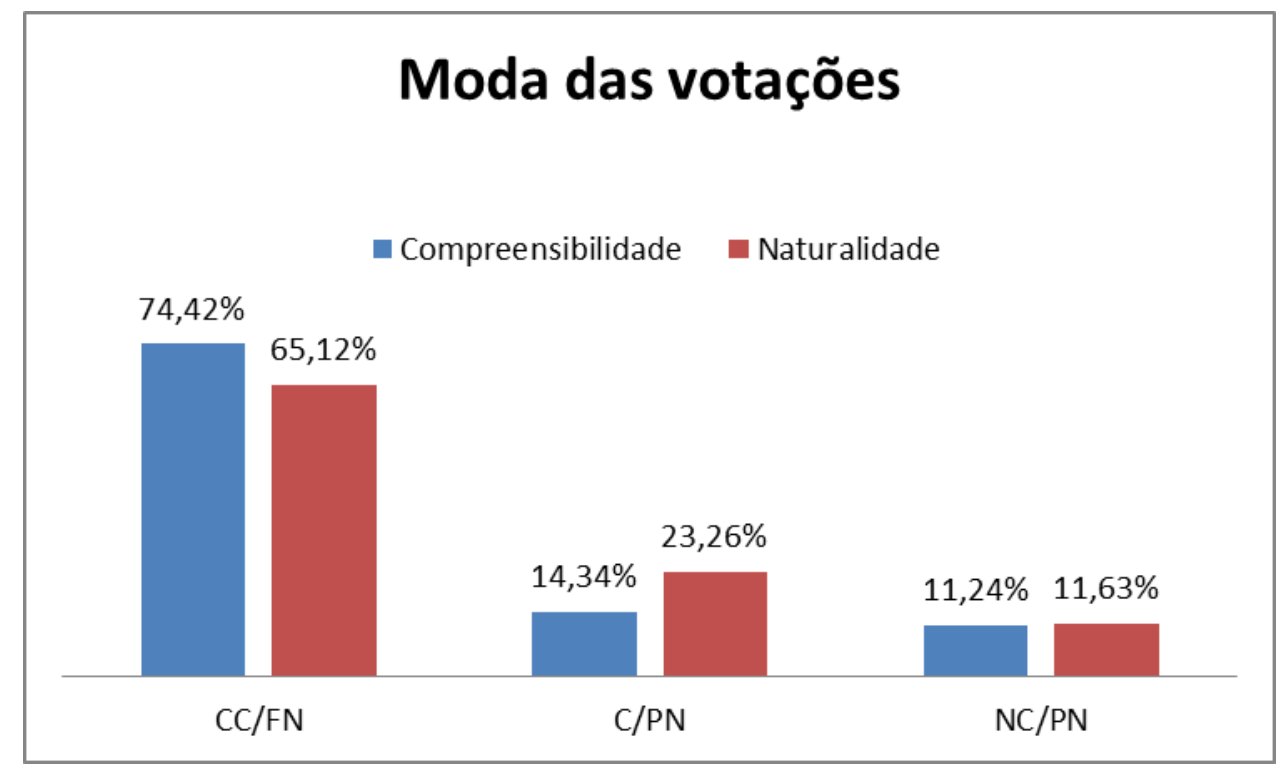

Figura 40: Valores de compreensibilidade e Naturalidade mais votados entre os juízes

$\mathrm{Na}$ porcentagem da moda é importante observar que os resultados são considerados melhores que o da porcentagem simples. O valor da variável CC aumentou 16,06\% enquanto o valor de $\mathrm{FN} \mathrm{6,57 \% ,} \mathrm{valores} \mathrm{provindos} \mathrm{principalmente} \mathrm{das}$ variáveis $\mathrm{C}$ e PN. Houve diminuição também das variáveis $\mathrm{NC}$ e $\mathrm{PN}$ em pouco mais de $2 \%$. A conclusão das diferenças é a de que as votações negativas do sistema ocorreram individualmente, enquanto o grupo é mais otimista na pontuação do sistema, principalmente dos melhores resultados do sistema, os valores de CC e FN. Para os valores aceitáveis pelo humano, obtém-se $\mathrm{CC}+\mathrm{C}=88,76 \%$ e $\mathrm{FN}+\mathrm{PN}=88,38 \%$.

\subsection{Análise de Correlações entre os Erros e a Compreensibilidade e Naturalidade}

$\mathrm{Na}$ avaliação foi possível estabelecer uma correlação estatística entre as variáveis de erro e as de qualidade da geração de texto, a Compreensibilidade e a Naturalidade. 
A seleção do cálculo de correlação depende dos tipos de variáveis do problema. No caso da avaliação realizada, as variáveis Compreensibilidade e Naturalidade trabalham com valores nominais (ou categóricos) ( $\mathrm{CC}, \mathrm{C}, \mathrm{NC}$ ou $\mathrm{FN}, \mathrm{PN}$ e $\mathrm{NN}$ ) assim como as variáveis de erro com valores nominais ("possui erro" ou "não possui erro"). Dadas estas características, escolheu-se o teste Chi-quadrado para o cálculo da correlação estatística.

\subsection{Correlação estatística entre avaliador e os oito tipos de erros.}

Considerando-se a divergência entre os critérios adotados pelos avaliadores, foi observado que seria mais eficiente obter as correlações por avaliador e depois somar o resultado de cada pessoa do que tentar achar correlação do grupo apenas.

Portanto, para cada avaliador foi calculado o teste de correlação Chi-quadrado (a fórmula do Chi-Quadrado pode ser encontrada no Apêndice C. Portanto, são ao todo oito tipos de erros contra as variáveis de compreensibilidade, e naturalidade por avaliador.

O teste Chi-quadrado estabelece um teste de hipóteses. Neste teste, a hipótese nula foi considerada que as duas variáveis em estudo são independentes. Com isso, calcula-se a probabilidade da observação ocorrer caso a hipótese nula seja verdadeira, dentro de um limite de confiança. Se essa probabilidade de ocorrência for muito baixa, então, pode-se dizer que há evidências suficientes para rejeitar a hipótese nula. Logo, as variáveis estão correlacionadas.

O fator de confiança adotado nesta avaliação é de 0.01 , valor mais rígido que o valor de 0.05 comumente adotados nos testes de hipótese. Porém, este valor já permite a obtenção dos valores de correlação desejados. Neste fator de confiança, os valores das tabelas do Apêndice C que ultrapassam um Chi-quadrado de 9.21, são valores que permitem que a hipótese nula seja rejeitada e que possa ser determinada a correlação. $\mathrm{O}$ valor de 9.21 foi obtido de uma tabela Chi-quadrado considerando-se o grau de liberdade dois. 


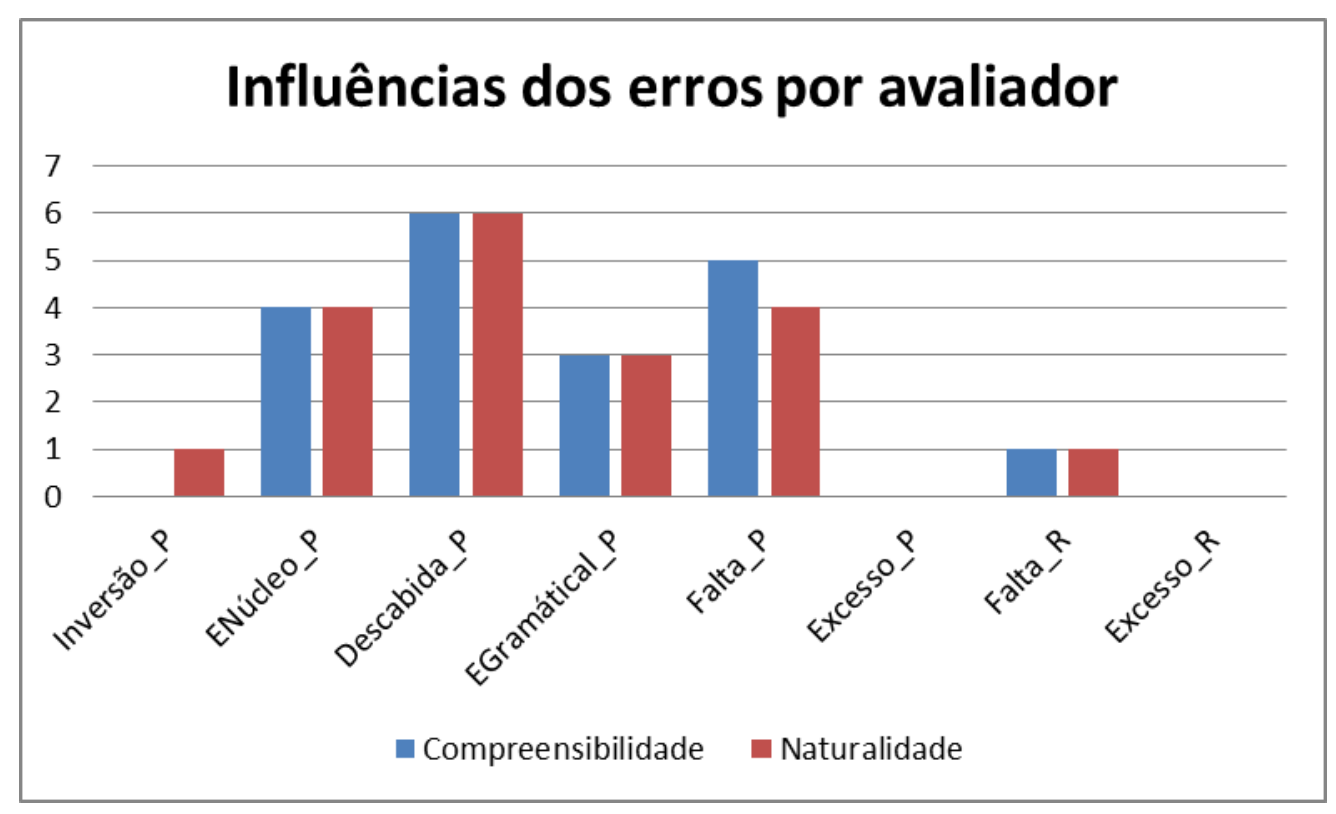

Figura 41: Calculo de relevância por avaliador

O resultado do teste de correlação para os sete avaliadores pode ser visto na Figura 41. Uma observação direta é a similaridade entre as correlações dos tipos de erros da variável compreensibilidade e da variável naturalidade. Exceto pela pequena diferença de um valor para os erros de inversão e falta na pergunta (Inversão_P e Falta_P), os gráficos podem ser considerados idênticos. De fato, compreensibilidade e naturalidade são influenciadas de forma idêntica pelos tipos de erros pré-determinados.

Para quase a totalidade dos juízes, o teste de correlação de pergunta descabida (Descabida_P) foi positivo. Este erro pode ocorrer na fase da delimitação, quando um elemento é identificado, porém não há pergunta cabível ao verbo tal que esse elemento seja sua reposta, ou ocorrer também na fase de classificação, quando é possível fazer a pergunta, mas o classificador escolhe o tipo de pergunta errônea. Estes fatores influenciam diretamente a qualidade da compreensão e naturalidade.

Os erros de núcleo ou o de falta (ENúcleo_P, Falta_P), são os próximos fatores mais relevantes na influência da qualidade da geração das sentenças. A falta de informação em uma pergunta pode gerar incerteza quanto à especificidade dela. A maioria das regras que foi desenvolvida para o sistema Elatex não tentava resgatar todo o conteúdo da informação na geração das perguntas quando o verbo era forte, apenas quando o verbo era fraco (os verbos de ligação). Por esse motivo, parece que os avaliadores pontuaram melhor os verbos de ligação do que a elaboração efetuada para os verbos fortes. 
Sobre o erro de núcleo, este pode provocar a geração de uma pergunta descabida ou ainda gerar, por acaso, porém em menor frequência, uma pergunta que ainda faça sentido no contexto estabelecido. Por esse motivo, ele não influenciou tantos avaliadores quanto ao valor pergunta descabida. A baixa influência da variável inversão (Inversão_P), pode indicar que inversão nas frases não influencia de forma grave na qualidade dos resultados.

\subsection{Definições de Entidades Mencionadas para a Elaboração de Textos em Português}

Um estudo sobre as definições extraídas da Wikipédia pode ser encontrado na Seção 3.2.1, enquanto a implementação Web e sua avaliação na Seção 3.2.2.

\subsubsection{Extratos da Wikipedia para o português}

A Wikipédia é uma enciclopédia online considerada a maior do mundo. São mais de três milhões e meio de artigos do inglês contra 120 mil artigos da enciclopédia Britânica e 45 mil da enciclopédia Encarta, recurso que pode ser muito bem aproveitado no meio educacional. Para o português, são mais de 680 mil artigos que podem ser utilizados.

Neste projeto, seu uso ocorre com a extração da primeira sentença. A heurística visa encontrar um texto que defina a entidade, ou ajude de alguma forma o leitor a ter uma melhor compreensão da entidade mencionada através desse acréscimo de informação (elaboração).

Considere a extração aleatória de dez artigos da base DBPedia ${ }^{20}$ (Auer et. al., 2007) da Tabela 13 que apresentam informações quanto ao título do artigo, o extrato curto (possível definição) o número de palavras e o campo que diz se a sentença pode ser usada como definição. A primeira observação que pode ser feita é o alto índice sentenças que podem ser usadas como definição. De fato, apesar de a amostra ser pequena, seja $X$ a variável aleatória que determina se a sentença pode ser usada como definição, cuja soma pode ser aproximada a distribuição normal (Peizer e Pratt, 1968), poderia ser inferido que ao menos $73,5 \%$ dos extratos podem ser considerados como definições. Entretanto, acredita-se que esse valor possa ser maior, pois o acesso a Wikipédia não é uniforme, como considerado na análise.

\footnotetext{
${ }^{20}$ http://wiki.dbpedia.org
} 


\begin{tabular}{|c|c|c|c|}
\hline Título Artigo & Extrato Curto & $\begin{array}{l}\text { Número de } \\
\text { palavras }\end{array}$ & $\begin{array}{l}\text { Pode ser usado } \\
\text { como definição? }\end{array}$ \\
\hline 8485 Satoru & $\begin{array}{l}\text { Satoru (asteróide 8485) é um asteróide da } \\
\text { cintura principal, a 2,3132023 UA. }\end{array}$ & 12 & $\operatorname{sim}$ \\
\hline $\begin{array}{l}\text { A Posteriori } \\
\text { (álbum) }\end{array}$ & $\begin{array}{l}\text { Em 2006, o Enigma lança o seu sexto disco A } \\
\text { Posteriori que contém uma versão nova para } \\
\text { "Hello and Welcome". Destaque para "Eppur } \\
\text { Si Muove" e "Goodbye Milk Way". }\end{array}$ & 29 & não \\
\hline Chaussan & $\begin{array}{l}\text { Chaussan é uma comuna francesa na região } \\
\text { administrativa de Ródano-Alpes, no } \\
\text { departamento de Ródano. }\end{array}$ & 14 & $\operatorname{sim}$ \\
\hline Curitibanos & $\begin{array}{l}\text { Curitibanos é um município brasileiro do } \\
\text { Estado de Santa Catarina. }\end{array}$ & 10 & $\operatorname{sim}$ \\
\hline Hillsboro (Iowa) & $\begin{array}{l}\text { Hillsboro é uma cidade localizada no Estado } \\
\text { americano de Iowa, no Condado de Henry. }\end{array}$ & 14 & $\operatorname{sim}$ \\
\hline $\begin{array}{l}\text { Helianthus } \\
\text { paradoxus }\end{array}$ & $\begin{array}{l}\text { Helianthus paradoxus é uma espécie do } \\
\text { gênero botânico Helianthus, da família das } \\
\text { Asteraceae. }\end{array}$ & 12 & $\operatorname{sim}$ \\
\hline Schwobsheim & $\begin{array}{l}\text { Schwobsheim é uma comuna francesa na } \\
\text { região administrativa da Alsácia, no } \\
\text { departamento Baixo Reno. }\end{array}$ & 14 & $\operatorname{sim}$ \\
\hline Nepogomphoides & $\begin{array}{l}\text { Nepogomphoides é um género de libelinha da } \\
\text { família Gomphidae. Este género contém as } \\
\text { seguintes espécies: }\end{array}$ & 15 & $\operatorname{sim}$ \\
\hline $\begin{array}{l}\text { Poligny (Altos- } \\
\text { Alpes) }\end{array}$ & $\begin{array}{l}\text { Poligny é uma comuna francesa na região } \\
\text { administrativa da Provença-Alpes-Costa } \\
\text { Azul, no departamento de Altos-Alpes. }\end{array}$ & 16 & $\operatorname{sim}$ \\
\hline Tiruvethipuram & $\begin{array}{l}\text { Tiruvethipuram é uma cidade e um município } \\
\text { no distrito de Tiruvanamalai, no estado } \\
\text { indiano de Tamil Nadu. }\end{array}$ & 17 & $\operatorname{sim}$ \\
\hline
\end{tabular}

Outro fator que pode ser observado é o alto índice de palavras infrequentes, tais como "8485 Satoru“, "Helianthus paradoxus“, cujas definições ajudam até mesmo a aumentar a compreensão para pessoas cultas/plenamente alfabetizadas na língua portuguesa. A média de palavras destes extratos é 14, usando a distribuição normal pode considerar-se $95 \%$ das sentenças não passam de 17 palavras, número razoável de sentenças a um público que necessita de sentenças curtas tais como os analfabetos em níveis rudimentar e básico.

\subsubsection{O sistema Facilita Educacional para a elaboração de textos na Web}

O sistema Facilita Educacional (Watanabe et al., 2010) é um sistema Web que auxilia o leitor via métodos de elaboração em quaisquer tipos de texto Web através da 
implementação de um plugin no navegador Mozila Firefox ${ }^{21}$ durante o desafio JetPack $^{22}$. Watanabe et al. (2010) observa que a área de acessibilidade web prega que é importante fornecer mecanismos que permitam que os clientes de páginas web possam entender os textos Web. Esse sistema implementa o módulo de definição de entidades mencionadas (REMET) e também um sistema de elaboração léxica. O sistema de perguntas elaboradas ainda não está agregado a essa ferramenta.

A elaboração via definição de entidades mencionadas usa o software de Reconhecimento de Entidades Mencionadas Rembrandt, descrito na Seção 2.2.3 e recupera a primeira sentença do artigo. Para alguns artigos, ainda podem ser encontradas figuras. Na Figura 42, pode ser vista a tela que exibe a elaboração da entidade "Roger Federer".

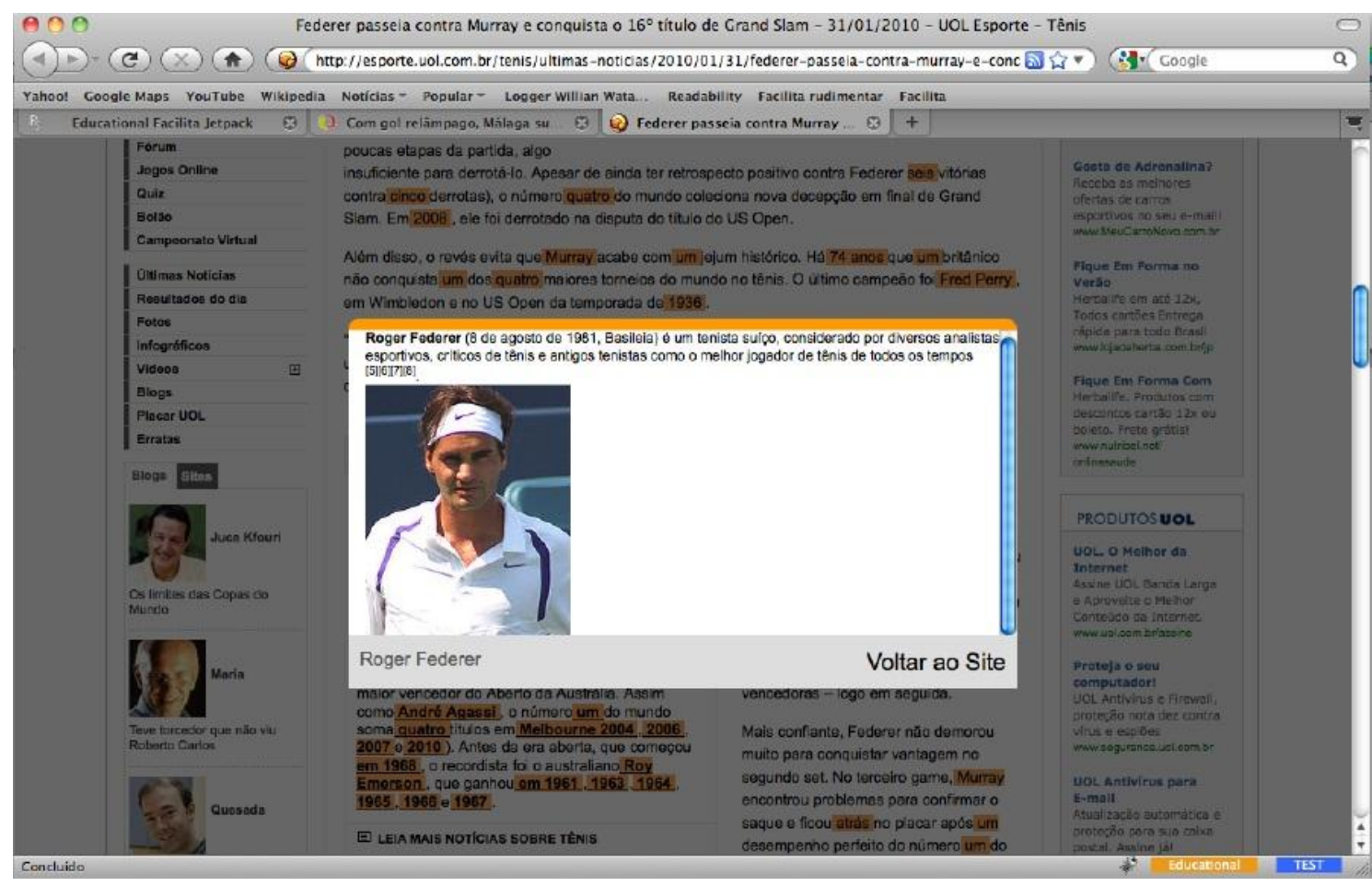

Figura 42: Elaboração via definição de entidades mencionadas no aplicativo Facilita Educacional

A elaboração léxica consiste em identificar as palavras complexas do texto e trazer seus sinonimos. A busca das palavras complexas ocorre por exclusão, cada palavra do texto que não seja preposição, artigo, nomes próprios, entre outras, são procuradas em três dicionários, cada dicionário conjuntos de palavras simples, como a usadas por crianças, palavras frequentes ou palavras concretas, respectivamente.

21 Website do Mozila Firefox: http://br.mozdev.org/

22 Plugin Jetpack: https://jetpack.mozillalabs.com/ 
A etapa intermediária consistiu de identificar o lema no dicionário Unitex- $\mathrm{PB}^{23}$ após a determinação das etiquetas PoS usando-se o tagger MXPOST POS (Ratnaparkhi 1996) treinado no tagset do $\mathrm{Nilc}^{24}$. Seu último passo consistia de encontrar os sinônimos desta palavra em dois thesaurus o TeP $2.0^{25}$ e PAPEL ${ }^{26}$, cujo resultado era ordenado pela API de buscas do Google, cujas palavras mais frequentes ficavam no topo da lista de sinônimos, lugar de prioridade. Na Figura 43, pode ser visto a tela que mostra o sinônimo no clique da palavra "ligeiramente".

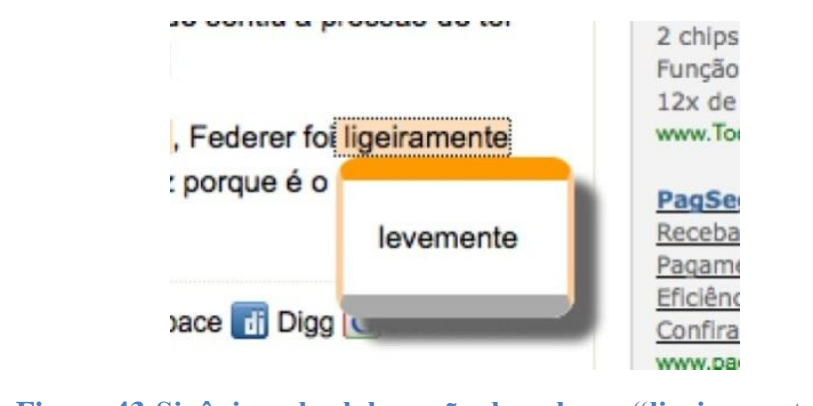

Figura 43:Sinônimo de elaboração da palavra "ligeiramente"

Neste sistema, foi conduzido um experimento com oito pessoas (grupo entre 20 e 56 anos) que não concluiram seus estudos na escola regular, dentre eles, metade do grupo acessa computadores ao menos duas horas na semana enquanto o outro grupo alega não ter contato. A avaliação consistiu em entrevistas e questionários após a leitura de um texto na ferramenta Facilita Educacional, cujos avaliadores ajudaram e estimularam o uso dos recursos de elaboração.

O texto utilizado na avaliação foi de um site de notícias esportivas cujo título é "Roger Federer vence seu quarto Aberto da Austrália". O tópico de tênis apresentou 10 palavras complexas e 8 entidades nomeadas, valores que apresentaram dificuldades ao público uma vez 37,5\% consideraram o texto difícil ou super difícil de ser compreenddo e apenas $25 \%$ dos participantes consideraram-no de fácil entendimento. Na realidade, o tema Tênis possui um vocabulário não comum a não praticante, caso da maioria das pessoas do Brasil.

Entrevistas com os usuários do sistema apontaram que a maioria deles já tinha conhecimento do significado das palavras complexas (seis deles disseram conhecer mais da metade das palavras complexas) enquanto em relação as entidades mencionadas, também seis pessoas relataram não ter conhecimento sobre essas entidades.

\footnotetext{
23 http://www.nilc.icmc.usp.br/nilc/projects/unitex-pb/web/dicionarios.html

${ }^{24} \mathrm{http}: / /$ www.nilc.icmc.usp.br/nilc/TagSet/ManualEtiquetagem.htm

${ }^{25} \mathrm{http}: / / \mathrm{www}$. nilc.icmc.usp.br/tep2/

${ }^{26} \mathrm{http}: / /$ www.linguateca.pt/PAPEL/
} 
Após a leitura do texto e a interação com o Facilita Educacional, os participantes responderam questões para medir a eficácia da aquisição de conhecimento. Os resultados novamente apontam positivamente para as definições de entidades mencionadas, pois a maioria das pessoas obteve uma pontuação melhor quando comparado ao não uso delas. Benefício este também descoberto durante as entrevista. A elaboração de palavras complexas não obteve eficácia significativa na avaliação. E, no geral, os usuários que já tinham contato com computadores relataram que ambos os tipos de elaboração ajudam no entendimento do texto. 


\section{Conclusão}

Este projeto de pesquisa considerou o problema da elaboração de textos do português para um público alvo que tem dificuldades de leitura. A elaboração textual é uma das abordagens usadas para aumentar a compreensibilidade de um texto (Rahimi, 2011), possibilitando, inclusive, a aquisição de vocabulário novo (Urano, 2000), ao contrário de outras técnicas, como a simplificação, também usada neste projeto, que melhora a inteligibilidade e reduz a complexidade do texto, fatores importantes para pessoas com baixo grau de letramento, público alvo desta pesquisa.

Considerando esse cenário, foi construído um sistema de definição de entidades mencionadas, cuja avaliação indicou que entidades mencionadas são elementos que o público em foco tem dificuldades de compreensão, e que o sistema construído, ao usar definições curtas da Wikipedia para elas ajudou na sua compreensão. A avaliação mostrou que este método de elaboração é útil tanto na opinião dos usuários, quanto na verificação da compreensão via prova aplicada, para o público em questão. Por ser uma avaliação preliminar, com um conjunto pequeno de pessoas, podemos apenas indicar uma tendência, e não concluir, do método em melhorar a compreensão de textos, que foi a primeira pergunta levantada nesta pesquisa.

Outro sistema de elaboração construído foi o de geração de perguntas elaboradas. Sua avaliação não foi com o público alvo final, mas sim com especialistas em PLN. As avaliações indicaram que as perguntas geradas apresentam tanto naturalidade e compreensibilidade em $88 \%$ dos casos e que alguns erros de geração impactam de forma negativa nessas duas variáveis, fatores esses que indicam quais problemas devem ser atacados no futuro para a melhoria deste sistema.

Este trabalho beneficiou-se de um córpus simplificado manualmente, desenvolvido no projeto PorSimples, projeto maior que abrigou a pesquisa. $\mathrm{O}$ uso de um córpus simplificado reduz a complexidade sintática dos textos, pois a simplificação efetuada transformou em ativas sentenças da voz passiva, reduziu o número de sentenças com aposição, via divisão das sentenças, e dividiu as sentenças coordenadas e subordinadas em duas ou mais sentenças mais simples o que diminui erros derivados do parser. Seu uso no sistema de classificação limitou este sistema, uma vez que o sistema considera um texto mais simples que os normais encontrados na Internet ou outros 
meios.

Contudo, esta limitação pode ser superada na construção de um simplificador que trabalhe em conjunto com este sistema de elaboração. Duas possibilidades são previstas: (1) para usuários com maior dificuldade de leitura, a elaboração ocorreria no texto simplificado, ou seja, o usuário recebe o texto original simplificado com os elementos de elaboração; e (2) para usuários com dificuldade menor de leitura, a simplificação seria apenas uma etapa intermediária, pré-requisito do sistema de geração de perguntas elaboradas, que gera as elaborações, ou seja, o usuário final recebe o mesmo texto original não modificado com os elementos de elaboração previstos. Para esta segunda opção trabalhar há a necessidade de se realizar a tarefa inversa da simplificação, o que pode ser facilitada se o sistema mantiver o processo realizado.

As principais contribuições da pesquisa incluem:

- Dois sistemas de elaboração textual: o primeiro usando definição de entidades mencionadas, e o segundo através de geração de perguntas elaboradas entre verbos e seus constituintes (argumentos);

- O teste de concordância humana de atribuição de rótulos de perguntas, uma tarefa nova que resultou desta pesquisa, com um Kappa alto de 0,78;

- O córpus de 104 textos simplificados do jornal Zero Hora com etiquetas de perguntas e evocadores verbais; e mapeamento desse córpus para etiquetas do Propbank;

- O sistema de delimitação e classificação de rótulos que pode ser aplicado tanto para a tarefa de atribuição de perguntas quanto para a de atribuição de rótulos semânticos numerados (Arg0, Arg1, etc..), dependendo das etiquetas do córpus de treinamento. A recuperação de perguntas ou de argumentos pode ser usada em sistemas de Recuperação de Informação (Aranha, 2007b).

- As regras para a elaboração de sentenças com perguntas rotuladas.

Quanto aos trabalhos futuros, o córpus etiquetado, composto por apenas 104 artigos do jornal Zero Hora pode ser aumentado. De fato, este córpus é pequeno e pertence apenas ao gênero jornalístico. Uma vez que, para a aplicação real deste sistema, é necessária a abrangência de exemplos quanto a tamanho e variedade de domínios, gêneros e tópicos para o algoritmo de aprendizado de máquina. A construção de regras para perguntas elaboradas, considerando essa nova extensão, também será necessária. Para tanto, novos atributos podem ser testados, assim como novos 
algoritmos de aprendizado de máquina, como os algoritmos semisupervisionados, que podem ser adotados para a extensão deste sistema para outros cenários.

Considerando a limitação da aplicação da técnica a apenas textos simplificados, pode ser construído um sistema que faça a ponte entre textos normais e os textos simplificados, como citado anteriormente. Para isso, seria necessário que o método de simplificação sintática estabelecesse um mapeamento entre o texto normal e o texto simplificado que ele gerou, para que a aplicação das técnicas de elaboração efetuadas nos textos simples pudesse ser mapeada aos textos normais.

Conclui-se, portanto, que sistemas automáticos de elaboração textual podem ser úteis ao público que tem dificuldades de leitura, tanto para facilitar a leitura quanto para que os usuários possam aprender mais sobre a língua, por exemplo, via aquisição de vocabulário. A criação desses recursos e ferramentas ajudou no desenvolvimento do PLN do português, uma vez que os métodos desenvolvidos podem ser aplicados e melhorados em novos cenários de pesquisa. 


\section{Referências e Bibliografia}

Abedi J., Leon S., Kao J., Bayley R., Ewers N., Herman J., Mundhenk K. (2011). Accessible Reading Assessments for Students with Disabilities: The Role of Cognitive, Grammatical, Lexical, and Textual/Visual Features. CRESST Report 785. National Center for Research on Evaluation, Standards, and Student Testing, University of California, Los Angeles. Disponível em: http://www.readingassessment.info/resources/publications/cognitivefeatures/CognitiveFeature s.pdf

Aluísio S.M., Specia L., Pardo, T.A.S., Maziero E.G, Fortes, R.P.M. (2008a): Towards Brazilian Portuguese Automatic Text Simplification Systems. In: Proceedings of The Eight ACM Symposium on Document Engineering (DocEng 2008), p. 240-248, São Paulo, Brasil.

Aluísio S.M., Specia L., Pardo, T.A.S., Maziero E.G., Caseli H.M., Fortes, R.P.M. (2008b): "A Córpus Analysis of Simple Account Texts and the Proposal of Simplification Strategies: First Steps towards Text Simplification Systems " In: Proceedings of The 26th ACM Symposium on Design of Communication (SIGDOC 2008), pp. 15-22.

Aluisio S.M., Gasperin, C. (2010): Fostering Digital Inclusion and Accessibility: The PorSimples project for Simplification of Portuguese Texts. In the Proceedings of the NAACL HLT 2010 Young Investigators Workshop on Computational Approaches to Languages of the Americas, June, 2010, Los Angeles, California, Association for Computational Linguistics, 46-53.

Amancio M.A., Duran M.S., Aluisio S.M. (2010a): Automatic Question Categorization: a New Approach for Text Elaboration. Proceedings of the Workshop in Natural Language Processing and web-based Technologies 2010, in conjunction with IBERAMIA 2010, p. 21-30.

Amancio M.A., Watanabe W., Candido Jr.A., Oliveira M., Pardo T.A.S., Fortes R.P.M., Aluísio, S.M. (2010b): Educational FACILITA: helping users to understand textual content on the Web. In the Proceedings of PROPOR 2010, 9th International Conference on Computational Processing of the Portuguese Language, Extended Activities Proceedings, 1 CD-ROM v1.

Amancio, M. A., Duran, M. S. and Aluisio, S.M. (2011) Automatic Question Categorization: a New Approach for Text Elaboration. Procesamiento del Lenguaje Natural, Revista n ${ }^{\circ}$ 46, pp 43-50.

Aranha, C.N. (2007a). O Cortex e a sua participação no HAREM. Reconhecimento de entidades mencionadas em português: Documentação e actas do HAREM , a primeira avaliação conjunta na área, Capítulo 9, p. 113-122.

Aranha, C. N. (2007b). Uma Abordagem de Pré-Processamento Automático para Mineração de Textos em Português: Sob o Enfoque da Inteligência Computacional. Dissertação de Doutorado. PUC-Rio. 
Baker, C.F., Fillmore, C.J., Lowe, J.B. (1998). The Berkley FrameNet project. In the Proceedings of COLIN/ACL, pp. 86-90, Montereal.

Baker, C. F., Charles J.F., Cronin B. (2003) The Structure of the Framenet Database, International Journal of Lexicography, Volume 16.3: 281-296.

Belder J., Moens, M. (2010). Text simplification for children. Proceedings of the SIGIR Workshop on Accessible Search Systems, pp.19-26.

Bick. E. (2000). The Parsing System Palavras, Automatic Grammatical Analysis of Portuguese in a Constraint Grammar Framework, Aarhus University Press.

Bick E. (2007). Functional aspects on Portuguese NER. Em Diana Santos e Nuno Cardoso, editores, Reconhecimento de entidades mencionadas em português: Documentação e actas do HAREM, a primeira avaliação conjunta na área, p. 145155 , Disponível

em: http://www.linguateca.pt/aval_conjunta/LivroHAREM/Cap12SantosCardoso2007-Bick.pdf.

Burstein, J., Shore, J.; Sabatini, J.; Lee, Y. ; Ventura, M. (2007): The Automated Text Adaptation Tool. Proceedings of Human Language Technologies: The Annual Conference of the North American Chapter of the Association for Computational Linguistics (NAACL-HLT). NAACL HLT Demonstration Program, pages 3-4, Rochester, New York, USA, April 2007.

Candido Jr., A., Maziero E.G., Gasperin C., Pardo T.A.S., Specia L. Aluísio, S.M.A. (2009). Supporting the adaptation of texts for poor literacy readers: a text simplification editor for brazilian portuguese. In: Proceedings of NAACL 2009 Workshop of Innovative Use of NLP for Building Educational Applications, pp. 34-42.

Cardoso, N., Santos, D. (2007). Diretivas para a identificação e classificação semântica na coleção dourada do HAREM. Relatório Técnico DI/FCUL TR-06-18, Departamento de Informática, Faculdade de Ciências da Universidade de Lisboa.

Cardoso N. (2009). REMBRANDT. Reconhecimento de Entidades Mencionadas Baseado em Relações e Análise Detalhada do Texto. Livro: Cristina Mota e Diana santos. Desafios na avaliação conjunta do reconhecimento de entidades mencionadas: O Segundo HAREM, Capítulo 11, p. 191-207.

Carletta, J. (1996). Assessing agreement on classification tasks: the kappa statistic. Computational Linguistics, 22(2), 249-254. Retrieved February 24, 2011, from http://portal.acm.org/citation.cfm?id=230386.230390.

Caseli H.M., Pereira T.F., Aluísio S. M. (2008). Editor de Anotação de Simplificação: Manual do Usuário. Technical Report NILC-TR-08-10, 17 p. Julho, São CarlosSP.

Caseli H.M., Pereira T.F., Specia L., Pardo T.A.S., Gasperin C., Aluísio S.M., (2009). Building a Brazilian Portuguese parallel córpus of original and simplified texts. In Alexander Gelbukh (ed), Advances in Computational Linguistics, Research in Computer Science, vol 41, pp. 59-70. 10th Conference on Intelligent Text Processing and Computational Linguistics (CICLing-2009), March 01-07, Mexico City. 
Chishman R. (2008) FrameCorp: Uma Proposta de Aplicação da Semântica de Frames para a Anotação de Córpus. UNISINOS. Disponível em: http://www.inf.pucrs.br/ linatural/Docs/Int_PLN_Unisinos_5.pdf

Davies J. (2006). Semantic Web Technologies: Trends and Research in Ontology-based Systems. Wiley. Disponível em: http://www.amazon.com/Semantic-WebTechnologies-Research-Ontology-based/dp/0470025964/.

Duran M.S., Amancio M.A, Aluísio S.M. (2010a) Assigning Wh-Questions to Verbal Arguments: Annotation Tools Evaluation and Córpus Building. In the Proceedings of the Seventh conference on International Language Resources and Evaluation (LREC'10). (Eds) Nicoletta Calzolari (Conference Chair), Khalid Choukri, Bente Maegaard, Joseph Mariani, Jan Odjik, Stelios Piperidis, Mike Rosner, Daniel Tapias. European Language Resources Association (ELRA), 1 CD-ROM v1. p. 1445-1451. ISBN 2-9517408-6-7

Duran, M. S.; Amancio, M. A.; Aluísio, S. M. (2010b). Assigning Wh-Questions to Verbal Arguments in a Córpus of Simplified Texts. In: International Conference on Computational Processing of Portuguese Language (PROPOR 2010), 2010, Porto Alegre. PROPOR 2010 Extended Activities Proceeding. v. 1. p. 1-16.

Fillmore, C.J. (1982). "Frame semantics" (1982). In Linguistics in the Morning Calm. Seoul, Hanshin Publishing Co., p. 111-137.

Flanagan, M. (2009). Recycling texts: human evaluation of example-based machine translation subtitles for DVD. Dublin City University. School of Applied Language and Intercultural Studies. Retrieved February 24, 2011, Disponível em: http://doras.dcu.ie/14842/.

Fleischman M, Kwon M., Hovy E. 2003. Maximum entropy models for FrameNet classification. In Proceedings of the 2003 conference on Empirical methods in natural language processing (EMNLP '03). Association for Computational Linguistics, Stroudsburg, PA, USA, 49-56.

Gasperin C., Specia L., Pereira T, Aluísio S.M. (2009) Learning When to Simplify Sentences for Natural Text Simplification. In: CSBC 2009 - XXIX Congresso da Sociedade Brasileira de Computação, 2009, Bento Gonçalves, RS. ENIA 2009 Encontro Nacional de Inteligência Artificial, 2009. p.809-818.

Gasperin, C. Maziero, E. and Aluísio, S.M. (2010) Challenging Choices for Text Simplification, In: Proceedings of PROPOR 2010, p. 40-50, António Branco, Aldebaro Klautau, Renata Vieira, Vera Lúcia Strube de Lima (Eds.): Computational Processing of the Portuguese Language, 9th International Conference, PROPOR 2010, Porto Alegre, RS, Brazil, April 27-30, 2010. Proceedings. Springer 2010, v. 6001. p. 40-50.

Gildea D., Jurafsky, D. (2002). Automatic Labeling of Semantic Roles. Computational Linguistics 28:3, 245-288.

Hall M., Frank E., Holmes G., Pfahringer B., Reutemann P, Witten I.H. (2009); The WEKA Data Mining Software: An Update; SIGKDD Explorations, Volume 11, Issue 1. 
Hauff, C. and Trieschnigg, R.B. (2010) Enhancing Access to Classic Children's Literature. In: BooksOnline'10 Workshop at CIKM 2010, 26 Oct 2010, Toronto, Canada. Microsoft Research.

INAF (2009). Instituto P. Montenegro e Ação Educativa. INAF Brasil - Indicador de Alfabetismo Funcional - 2009. Disponível em: http://www.ibope. com.br/ipm/relatorios/relatorio_inaf_2009.pdf

Jbara, Amjad Abu. (2011). Text Simplification. Disponível em: http://sitemaker.umich.edu/amjbara/files/text_simplification.pdf Data de acesso: 12 de Maio de 2011.

Johnson C.R., Fillmore C.J. Wood E.J., Ruppenhofer J., Urban M., Petruk M. R. L., Baker C. F., (2001). The FrameNet project: Tools for lexicon building. Version 0.7, Disponível em: http://www.icsi.berkeley.edu/ ${ }^{\sim}$ framenet/book.html

Karlsson F. (1990). Constraint Grammar as a Framework for Parsing Unrestricted Text. H. Karlgren, ed., Proceedings of the 13th International Conference of Computational Linguistics, Vol. 3. Helsinki 1990, p. 168-173.

Karlsson F., Voutilainen A., Heikkilä J., Anttila A. (1995). Constraint Grammar: A Language-Independent System for Parsing Unrestricted Text. Natural Language Processing, No 4. Mouton de Gruyter, Berlin and New York. ISBN 3-11-0141795.

Kazama J., Torisawa K. (2007). Exploiting wikipedia as external knowledge for named entity recognition. In Joint Conference on Empirical Methods in Natural Language Processing and Computational Natural Language Learning, pages 698707.

Kingsbury P., Palmer, M. (2002): From Treebank to PropBank. In the Proceedings of the 3rd International Conference on Language Resources and Evaluation, LREC 2002. p. 1989-1993.

Kipper K., Dang H.T, Palmer M. (2000). Class-based Construction of a Verb Lexicon. In the Proceedings of AAAI 17th National Conference on Language Resources on Artificial Intelligence. Austin, Texas, p. 691--696.

Levin B., Hovav M.R. (1996). From lexical semantics to argument realization. Manuscript. Northwestern University.

Mapleson, D.L. (2006): Post-Grammatical Processing for Discourse Segmentation. PhD Thesis. School of Computing Sciences, University of East Anglia, Norwich.

Màrquez L., Carreras S., Litkowski K. C, Stevenson S. (2008). Semantic role labeling: an introduction to the special issue. Computational Linguistics, Volume 34, Issue 2, pages $145-159$.

Max, A. (2006): Writing for Language-impaired Readers. In the Proceedings of Seventh International Conference on Intelligent Text Processing and Computational Linguistics. CICLing 2006, pp. 567-570.

Mihalcea R., Csomai A., Wikify! (2007) linking documents to encyclopedic 
knowledge. In CIKM '07: Proceedings of the sixteenth ACM conference on Conference on information and knowledge management, pages 233-242, New York, NY, US. ACM.

Milne D. Witten I.H. (2008). Learning to link with wikipedia. In: CIKM '08: Proceeding of the 17th ACM conference on Information and knowledge management, pages 509-518, New York, NY, US. ACM.

Mota C., Santos D. (2009). Desafios na avaliação conjunta do reconhecimento de entidades mencionadas: O Segundo HAREM. Disponível em: http://www.linguateca.pt/HAREM/actas/Livro-MotaSantos2008.pdf

Muniz, M. C. M. A construção de recursos lingüístico-computacionais para o português do Brasil: o projeto de Unitex-PB. Dissertação de Mestrado. Instituto de Ciências Matemáticas de São Carlos, USP. 72p. 2004.

Nadeau D., Sekine S. (2007). A survey of named entity recognition and classification. Lingvisticae Investigationes, Vol. 30, No. 1. (January 2007), pp. 3-26.

Narayanan S., Harabagiu S. (2004). Question Answering based on Semantic Structures, International Conference on Computational Linguistics (COLING 2004), Geneva, Switzerland, August 22-29. Disponível em http://www.icsi.berkeley.edu/ snarayan/837.pdf

Oliveira E., Xavier. M.A., Baptista J., Trancoso I., Oliveira L., Mamede N., Quental V., Nunes G., Teixeira G., Rino L., Vieira R., Sardinha T. B., Faria I. H., Oliveira Jr. O. (2003). Pareceres sobre Linguateca: Relatório relativo ao período 2000-2003. [http://www.linguateca.pt/documentos/Pareceres.doc].

Palmer M., Gildea D., Kingsbury P. (2005). The Proposition Bank: A Córpus Annotated with Semantic Roles, Computational Linguistics Journal, 31:1 , 71-106

Palmer, M., Gildea, D., Xue, N. (2010): Semantic Role Labeling. Synthesis Lectures on Human Language Technology Series, ed. Graeme Hirst, Mogan \& Claypoole.

Pardo, T.A.S. (2005). Métodos para análise discursiva automática: Dissertação de Doutorado. ICMC - USP. São Carlos - SP.

Pereira, T.F., Aluisio, S. M. (2008). Editor de Anotação de Simplificação: Construção. Technical Report NILC-TR-08-12, 30 p., São Carlos-SP.

Pradhan S., Hacioglu K., Krugler V., Ward W., Martin J.H., Martin D. (2005). Support Vector Learning for Semantic Argument Classification. Machine Learning, Vol. 60, No. 1, pp. 11-39, 2005

Punyakanok V., Roth D., Yih W., Zimak D., (2004) Semantic Role Labeling via Integer Linear Programming Inference. (2004). Proc. the International Conference on Computational Linguistics (COLING) - 2004, p. 1346-1352.

Rahimi, M. Y. (2011). Use of Syntactic Elaboration Techniques to Enhance Comprehensibility of EST Texts. English Language Teaching, Vol. 4, No. 1, 1117. 
Saggion H., Lapalme G. (2000). Concept identification and presentation in the context of technical text summarization, 1-10. Retrieved February 24, 2011, from http://portal.acm.org/citation.cfm?id=1567564.1567565.

Santos, D., Cardoso, N. (2006). A Golden Resource for Named Entity Recognition in Portuguese. In Renata Vieira, Paulo Quaresma, Maria da Graça Volpes Nunes, Nuno J. Mamede, Cláudia Oliveira \& Maria Carmelita Dias (eds.), 7thWorkshop on Computational Processing of Written and Spoken Language (PROPOR'2006) (Itatiaia, RJ, 13-17 de Maio de 2006), Springer, pp. 69-79.

Luís Sarmento. SIEMÊS - A Named Entity Recognizer for Portuguese Relying on Similarity Rules. In Renata Vieira; Paulo Quaresma; Maria da Graça Volpes Nunes; Nuno J. Mamede; Cláudia Oliveira; Maria Carmelita Dias (ed.), Computational Processing of the Portuguese Language: 7 th International Workshop, PROPOR 2006. Itatiaia, Brazil, May 2006 (PROPOR'2006) LNAI 3960, 13-17 de Maio de 2006, Berlin/Heidelberg: Springer Verlag, pp. 90-99 Settles B. (2004). Biomedical named entity recognition using conditional random fields and rich feature sets. In Proc. of JNLPBA-04, p. 104-107.

Siddharthan A. (2003). Syntactic Simplification and Text Cohesion. PhD thesis, University of Cambridge, UK.

Siddharthan, A. (2004). Syntactic simplification and text cohesion. IEEE Communications Magazine, 20(10), 31-31.

Shen, D. Lapata, M. (2007) Using Semantic Roles to Improve Question Answering. In the Proceedings of the 2007 Joint Conference on Empirical Methods in Natural Language Processing and Computational Natural Language Learning, pp. 12-21, Prague, June.

Snow, C. (2002). Reading for understanding: Toward an R\&D program in reading comprehension. Santa Monica, CA, 156 p. Disponível em: http://www.rand.org/pubs/monograph_reports/2005/MR1465.pdf

Specia L., Aluisi, S.M., Pardo T.A.S. (2008). Manual de Simplificação Sintática para o Português. Technical Report NILC-TR-08-06, 27 p., São Carlos-SP.

Surdeanu, M., Harabagiu, S., Williams, J., Aarseth, P. (2003). Using Predicate Arguments Structures for Information Extraction. In Proceedings of the 41st Annual Meeting of the Association for Computational Linguistics (ACL 2003), 2003, pp. 8-15.

Toutanova K., Haghighi A, Manning C.D.(2005). Joint learning improves semantic role labeling. Proceedings of the 43rd Annual Meeting of the ACL, pages 589-596, Ann Arbor, June 2005.

Turing, A. (1950): "Computing machinery and intelligence". Mind, vol. LIX, no. 236, October 1950, pp. 433-460

Urano, K. (2000). Lexical simplification and elaboration: Sentence comprehension and incidental vocabulary acquisition. Unpublished master's thesis, University of Hawai'i at Manoa, Honolulu.Available at http://www.urano-ken.com/research/thesis.pdf 
Vickrey, D., Koller, D. (2008). Sentence Simplification for Semantic Role Labeling. Proceedings of ACL-08: HLT, pages 344-352, Columbus, Ohio, USA, June 2008.

Wu F., Weld D. S. (2007). Autonomously Semantifying Wikipedia. Em Proceedings of the $16^{\text {th }}$ ACM Conference on Information and Knowledge Management (CIKM'07), Lisboa, Portugal, 7-10 de Novembro de 2007. p. 4-50.

Watanabe W.M., Candido Jr. A, Uzêda V., Fortes R. P. M., Pardo T. A. S., Aluisio S. M. (2009) 'Facilita: reading assistance for low-literacy readers. In the Proceedings of ACM SIGDOC 2009 - ACM International Conference on Design of Communication, 2009, Bloomington, IN. v. 1. p. 29 - 36.

Watanabe, W. M.; Candido JR, A.; Amancio, M. A.; Oliveira, M.; Fortes, R. P. M.; Pardo, T. A. S.; Aluísio, S. M. (2010a). Adapting web content for low literacy readers by using lexical elaboration and named entities labeling. In proceedings of W4A 2010 - International Cross-Disciplinary Conference on Web Accessibility. ACM - Association of Computing Machinery, 2010, Raleigh - NC - US. p. 1-9.

Watanabe W.M., Cândido A., Amancio, M.A., Oliveira M., Pardo, T.A.S., Fortes R.P.M., Aluísio S.M. (2010b). Adapting Web content for low-literacy readers by using lexical elaboration and named entities labeling. New Review of Hypermedia and Multimedia, v. 16, p. 303-327.

Yano, Y., Long, M. \& Ross, S. (1994). The effects of simplified and elaborated texts on foreign language reading comprehension. Language Learning, 44, 189-219.

Young, D.N. (1999): Linguistic simplification of SL reading material: Effective Instructional Practice? The Modern Language Journal, 83(3), 350-366. 


\section{Anexo A: Tabela de Verbos Auxiliares}

Neste anexo, encontra-se a tabela de verbos auxiliares para a identificação dos conjuntos verbais utilizados na identificação dos evocadores de perguntas.

\begin{tabular}{|l|l|l|}
\hline Verbo & Preposição & $\begin{array}{l}\text { Condição do } \\
\text { Verbo à } \\
\text { direita }\end{array}$ \\
\hline ser & & particípio \\
\hline estar & & particípio \\
\hline haver & & particípio \\
\hline ir & & infinitivo \\
\hline ter & & particípio \\
\hline ameaçar & & infinitivo \\
\hline conseguir & & infinitivo \\
\hline dever & & infinitivo \\
\hline ficar & de & infinitivo \\
\hline haver & de & infinitivo \\
\hline haver & que & infinitivo \\
\hline hesitar & & infinitivo \\
\hline hesitar & em & infinitivo \\
\hline necessitar & & infinitivo \\
\hline poder & & infinitivo \\
\hline precisar & & infinitivo \\
\hline procurar & & infinitivo \\
\hline querer & & infinitivo \\
\hline saber & & infinitivo \\
\hline ser & de & infinitivo \\
\hline tentar & & infinitivo \\
\hline ter & de & infinitivo \\
\hline ter & que & infinitivo \\
\hline acabar & & gerúndio \\
\hline acabar & de & infinitivo \\
\hline acabar & por & infinitivo \\
\hline andar & & gerúndio \\
\hline cessar & de & infinitivo \\
\hline chegar & a & infinitivo \\
\hline começar & a & infinitivo \\
\hline & & \\
\hline & & \\
\hline
\end{tabular}

\begin{tabular}{|l|l|l|}
\hline Verbo & Preposição & $\begin{array}{l}\text { Condição } \\
\text { do } \\
\text { Verbo à } \\
\text { direita }\end{array}$ \\
\hline começar & por & infinitivo \\
\hline continuar & & gerúndio \\
\hline continuar & a & infinitivo \\
\hline correr & a & infinitivo \\
\hline costumar & & infinitivo \\
\hline dar & para & infinitivo \\
\hline dar & de & infinitivo \\
\hline deixar & de & infinitivo \\
\hline desatar & a & infinitivo \\
\hline estar & & gerúndio \\
\hline estar & para & infinitivo \\
\hline estar & para & infinitivo \\
\hline estar & por & infinitivo \\
\hline ficar & & gerúndio \\
\hline ir & & gerúndio \\
\hline ousar & & infinitivo \\
\hline parar & de & infinitivo \\
\hline passar & a & infinitivo \\
\hline permanecer & & infinitivo \\
\hline pôr-se & a & infinitivo \\
\hline recomeçar & a & infinitivo \\
\hline sair & & gerúndio \\
\hline seguir & & gerúndio \\
\hline terminar & & gerúndio \\
\hline tornar & a & infinitivo \\
\hline vir & & gerúndio \\
\hline vir & infinitivo \\
\hline viver & gerúndio \\
\hline voltar & infinitivo \\
\hline & & \\
\hline
\end{tabular}




\section{Apêndice A: Formação de Perguntas}

A tabela de etiquetas ilustra a formação das perguntas que ocorrem geralmente por um artigo mais a pergunta em si (Tabela 14). Esta tabela permite visualizar os tipos de perguntas pela preposição ou pelo tipo de pergunta em si. Seus valores em brancos representam as perguntas que não foram levantadas, em geral, elas não fazem sentido na língua portuguesa [Por, Como] = Por como? (não existe). Mas estes valores mostram possibilidades futuras, por exemplo: $[\mathrm{Em}$, Qual $]=$ Em qual?, que poderia pertencer a frase "Em qual rua ela mora"?

Tabela 14: Tabela de formação das perguntas mais comuns

\begin{tabular}{|l|l|l|l|l|}
\hline $\begin{array}{l}\text { Papel } \\
\text { sintático }\end{array}$ & Preposição & QUE & QUEM & QUAL \\
\hline Sujeito & - & O que-Esq & Quem-Esq & $\begin{array}{l}\text { Qual- } \\
\text { Esq,Quais-Esq }\end{array}$ \\
\hline Objeto direto & - & O que-Dir & Quem-Dir & \\
\hline $\begin{array}{l}\text { Objeto } \\
\text { indireto }\end{array}$ & a & A que & A quem & \\
\hline & de & De que & De quem & \\
\hline & por & Por que & Por quem & \\
\hline & para & $\begin{array}{l}\text { Para que/Para o o } \\
\text { que }\end{array}$ & $\begin{array}{l}\text { Para quem/Para com } \\
\text { quem }\end{array}$ & \\
\hline & sobre & Sobre o que & Sobre quem & \\
\hline & contra & Contra o que & Contra quem & \\
\hline & com & Com o que & Com quem & \\
\hline & entre & Entre o que & Entre quem & \\
\hline & em & Em que & Em quem & \\
\hline & pelo & Pelo que & & \\
\hline & como & como o que & & \\
\hline & & & & \\
\hline
\end{tabular}


Tabela 15: Etiquetas que possuem sua formação específica e menos previsível

\begin{tabular}{|c|c|c|}
\hline CONCEITO & ASPECTO & PERGUNTA \\
\hline \multirow[t]{8}{*}{ TEMPO } & & Quando? \\
\hline & origem & Desde quando? \\
\hline & origem & A partir de quando? \\
\hline & frequência & Com que freqüência? \\
\hline & duração & Por quanto tempo? \\
\hline & final & Para quando? \\
\hline & final & Até quando? \\
\hline & intervalo & Em que período? \\
\hline \multirow[t]{6}{*}{ LUGAR } & & Onde? \\
\hline & origem & A partir de onde? \\
\hline & percurso & Por onde? \\
\hline & destino & Para onde? \\
\hline & destino & Até onde? \\
\hline & & Aonde? \\
\hline \multirow[t]{2}{*}{ DIREÇÃO } & destino & Para onde? \\
\hline & origem & $\begin{array}{l}\text { De onde?, de onde?- } \\
\text { filiação }\end{array}$ \\
\hline \multirow[t]{2}{*}{ CONSEQUÊNCIA } & & Com que \\
\hline & & consequiência? \\
\hline CAUSA & & Por quê? \\
\hline FINALIDADE & instrumento & Para quê? \\
\hline \multirow[t]{4}{*}{ MODO } & & Como?, Como?-verbal \\
\hline & idade & Com que idade? \\
\hline & idioma & Em que língua? \\
\hline & & Com o quê? \\
\hline \multirow[t]{8}{*}{ QUANTIDADE } & & Quanto?, Quantos? \\
\hline & & a quanto? \\
\hline & & de quanto? \\
\hline & & em quanto? \\
\hline & & por quanto? \\
\hline & & para quanto? \\
\hline & & com quanto? \\
\hline & & Ate quanto? \\
\hline
\end{tabular}




\section{Apêndice B: Manual de Avaliação do Elatex}

O Elatex é um sistema de elaboração textual que gera perguntas e respostas a partir de sentenças, via delimitação de argumentos e verbos ou sintagmas verbais, classificação em 68 tipos básicos de perguntas e elaboração destas perguntas. As perguntas geradas por esse sistema satisfazem três critérios:

(1) a resposta está contida na sentença;

(2) as perguntas são evocadas por verbos ou sintagmas verbais presentes na sentença; e

(3) as várias perguntas de uma sentença devem ser avaliadas isoladamente, sem considerar o contexto criado pela sequência de perguntas.

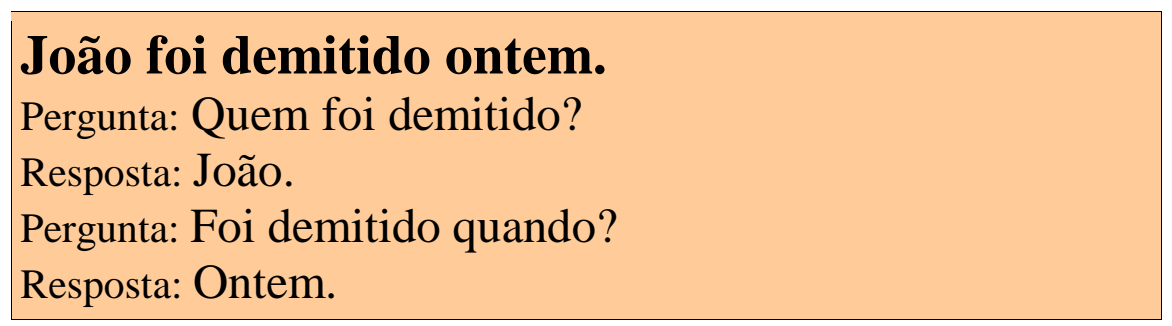

Este manual contém orientações para os avaliadores do Elatex. As perguntas geradas e suas respectivas respostas deverão ser avaliadas separadamente, por critérios diferentes.

\section{Avaliação das perguntas}

Para a avaliação de perguntas serão utilizados três critérios: 1) o grau de compreensibilidade, 2) o grau de naturalidade e 3) a ocorrência de erros.

\section{Compreensibilidade}

A avaliação do grau de compreensibilidade deverá ser expressa por um dos três conceitos abaixo:

- claramente compreensível: é fácil saber que tipo de resposta está sendo esperada.

- compreensível: desde que se conheça o contexto da sentença (texto de onde veio), é possível inferir que tipo de resposta está sendo esperada

- não compreensível: mesmo conhecendo o contexto da sentença (texto de onde veio), não é possível inferir com certeza a resposta esperada

$\mathrm{Na}$ folha de respostas, preencher o espaço correspondente à compreensibilidade com um desses números: (1), (2) ou (3).

\section{Naturalidade}

A avaliação do grau de naturalidade deverá ser expressa por um dos três conceitos abaixo:

1. Fortemente natural, isto é, como se um humano tivesse elaborado.

2. Pouco natural, mas possível de ocorrer em uma interação humana.

3. Não natural, ou seja, ninguém perguntaria assim. 
$\mathrm{Na}$ folha de respostas, preencher o espaço correspondente à naturalidade com um desses números: (1), (2) ou (3).

\section{$\underline{\text { Erros }}$}

São quatro os tipos de erros previstos para perguntas.

\section{( ) ORDEM INVERTIDA}

O avaliador pode julgar que a ordem das palavras que compõem a pergunta não está boa e ficaria melhor se fosse invertida. Nesse caso deve assinalar a opção "ordem invertida". A Figura 1 mostra a oração em amarelo com ordem indevida. A ordem correta deveria ser "O que é excelente?"

\section{Os recursos tecnológicos são excelentes. \\ Os recursos tecnológicos são o que? Excelentes. \\ Excelente é o que? Os recursos tecnológicos.}

Figura 1: Exemplo de pergunta com ordem invertida

\section{( ) NÚCLEO INADEQUADO}

O avaliador pode julgar que o núcleo da pergunta (pronome interrogativo: como, quem, quando, onde etc.) não é o adequado para fazer determinada pergunta e deveria ser substituído por outro pronome interrogativo. Nesse caso, deve assinalar a opção "núcleo inadequado". Na Figura 2, em amarelo, encontra-se o núcleo principal da pergunta gerado equivocadamente. O núcleo correto nesse caso seria "o quê?".

\section{Os recursos tecnológicos são excelentes. \\ Os recursos tecnológicos são quem? Excelentes.}

Figura 2: Exemplo de pergunta inadequada

\section{( ) PERGUNTA DESCABIDA}

$\mathrm{O}$ avaliador pode julgar que determinada pergunta é totalmente descabida, ou seja, não existiria, mesmo que eventuais erros fossem corrigidos. A Figura 3 apresenta em amarelo a pergunta que deve ser descartada, junto com sua resposta.

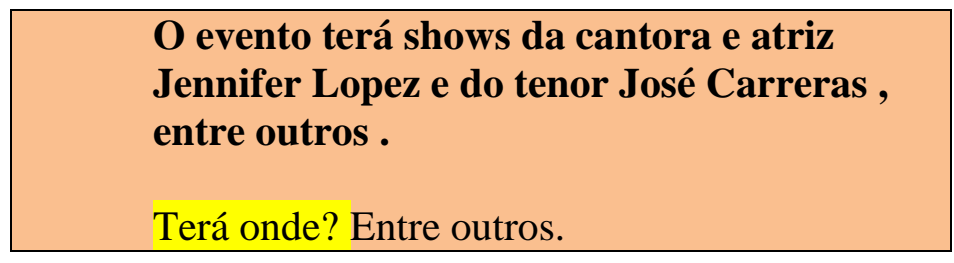

Figura 3: Exemplo de pergunta descabida, que deve ser descartada.

( ) FALTA: A pergunta tem informação a menos do que deveria. 
Na Figura 4 é exemplificado esse tipo de erro em amarelo. Seu valor deveria ser "O evento terá shows da cantora e atriz Jennifer Lopez e do tenor José Carreras , entre outros ?". O avaliador deverá anotar esse erro com a etiqueta FALTA.

\section{O evento terá shows da cantora e atriz Jennifer Lopez e do tenor José Carreras, entre outros . \\ O que terá shows da cantora e atriz Jennifer Lopez e do tenor José Carreras? O evento.}

Figura 4: Exemplo de erro delimitação na pergunta (falta)

( ) EXCESSO: A pergunta inclui palavras que não lhe pertencem.

$\mathrm{Na}$ Figura 5 é exemplificado este tipo de erro em amarelo. A pergunta correta deveria ser "Quem afirma?".

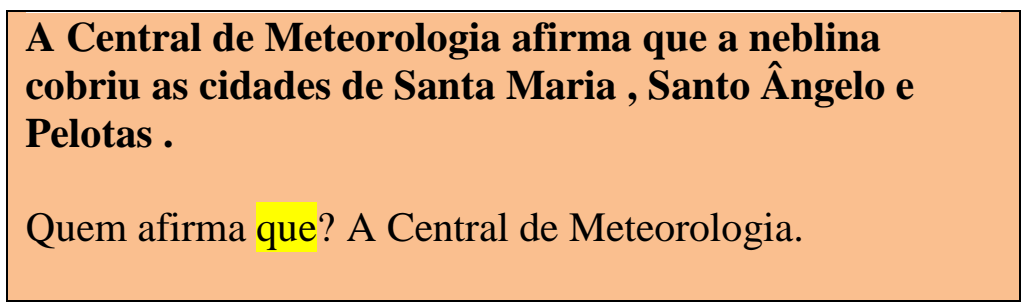

Figura 5: Exemplo de erro delimitação na pergunta (trecho extra)

\section{( ) ERRO GRAMATICAL}

$\mathrm{Na}$ geração das perguntas podem ocorrer erros, tais como: concordância de gênero, número e pessoa verbal. Na Figura 6, em amarelo, o verbo "nascer" deveria estar na terceira pessoa do singular para combinar com o pronome interrogativo "quem".

Dom Odilo Scherer nasceu em Cerro Largo .
Quem nasceram? Dom Odilo Scherer.

Figura 6: Exemplo de erro gramatical

Para registrar a ocorrência de um desses tipos de erros, o avaliador deverá assinalar com um " $X$ " o respectivo espaço na folha de respostas.

Outros erros ou observações deverão ser registrados no campo "comentários".

\section{Avaliação das respostas}

\section{A avaliação de respostas será feita somente sob o critério de ocorrência de erros. São dois os tipos de erros previstos: \\ ( ) FALTA: A resposta tem informação a menos do que deveria. \\ Na Figura 7 é exemplificado esse tipo de erro em amarelo. Seu valor deveria ser "O povo".}

O povo também chama de marcela . 
Quem chama? Povo.

Chama de que? De marcela.

Figura 7: Exemplo de erro de delimitação

( ) EXCESSO: A resposta inclui palavras que não lhe pertencem.

$\mathrm{Na}$ Figura 8 é exemplificado esse tipo de erro em amarelo. Seu valor correto deveria ser "Para o Quênia".

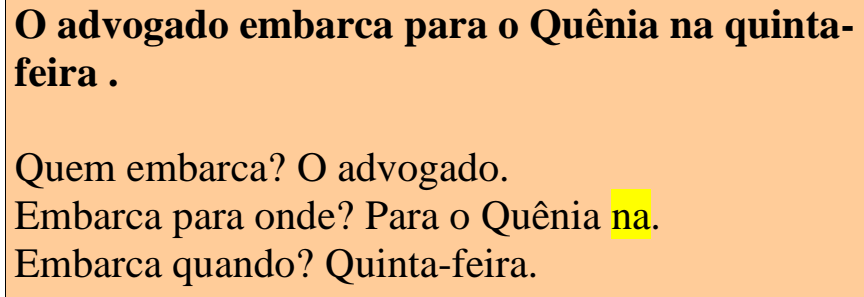

Figura 8: Exemplo de erro de excesso

Para registrar a ocorrência de um desses tipos de erros, o avaliador deverá assinalar com um " $X$ " o respectivo espaço na folha de respostas.

Erros não previstos na folha e demais observações deverão ser registrados no campo "comentários" das respectivas perguntas e respostas. 


\section{Folha de avaliacão}

As áreas marcadas por cores que são explicadas por meio de legenda na Figura 9.

\section{Compreensibilidade}

- claramente compreensível: é fácil saber que tipo de resposta está sendo esperada.

- compreensível: desde que se conheça o contexto da sentença (texto de onde veio), é possível inferir que tipo de resposta está sendo esperada

- não compreensível: mesmo conhecendo o contexto da sentença (texto de onde veio), não é possível inferir com certeza a resposta esperada

\section{Naturalidade}

- Fortemente natural, isto é, como se um humano tivesse elaborado.

- Pouco natural, mas possível de ocorrer em uma interação humana.

- Não natural, ou seja, ninguém perguntaria assim.

\section{- fsp9.s15: Isso deixa o equipamento menos visível.}

[fl_e1]

Pergunta: $\mathrm{O}$ que deixa?

Compreensibilidade ( ) 1- claramente compreensível 2- compreensível 3- não

compreensível

Naturalidade ( ) 1- fortemente natural 2-pouco natural 3- não natural

Erros: ( ) Inversão da ordem ( ) núcleo inadequado ( ) pergunta descabida

() erro gramatical () falta parte () parte em excesso

Comentários:

Resposta: Isso.

Erros: ( ) falta parte ( ) parte em excesso

Comentários:

[fl_e2]

Pergunta: Deixa quem?

Compreensibilidade ( )

Naturalidade ( )

Erros: ( ) Inversão da ordem ( ) núcleo inadequado ( ) pergunta descabida
( ) erro gramatical
( ) falta parte
( ) parte em excesso

Comentários:

Resposta: Equipamento.

Erros: ( ) falta parte ( ) parte em excesso

Comentários:

[fl_e3]

Pergunta: Deixa como?

Compreensibilidade ( )

Naturalidade ( )

Erros: ( ) Inversão da ordem ( ) núcleo inadequado ( ) pergunta descabida

() erro gramatical () falta parte () parte em excesso

Comentários:

Resposta: Menos visível. 
Erros: ( ) falta parte ( ) parte em excesso

Comentários:

Legenda das cores:

Figura 9: Folha de avaliação para cada sentença

cinza: Oração para a qual foram levantadas as perguntas

verde: Perguntas elaboradas para a oração

azul: Respostas das perguntas elaboradas

laranja: Formulário com avaliação

branco: Variáveis de controle que podem ser desprezadas durante a avaliação. 


\section{Apêndice C: Tabelas dos valores de Chi-Quadado para o cálculo da estatística entre as variáveis de qualidade de geração de sentença e os oito tipos de erros}

O teste de correlação Chi-quadrado é o mais recomendado para variáveis nominais, como as que foram adotadas na avaliação. A variável Chi-quadrado é calculada usando-se a fórmula abaixo:

$X^{2}=\sum \frac{\left(O_{i}-E_{i}\right)^{2}}{E_{i}}$

Na Tabela 16, são dados os valores de $X^{2}$ para a Compreensibilidade enquanto na Tabela 17 os da Naturalidade. Cada linha representa um avaliador, e cada coluna um tipo de erro diferente.

Tabela 16: Valores do Chi-quadrado da Compreensibilidade

\begin{tabular}{|l|l|l|l|l|l|l|l|l|}
\hline & \multicolumn{3}{|l}{ Erro na Pergunta } & \multicolumn{4}{l|}{ Erro na Resposta } \\
\cline { 2 - 9 } & Inversão & Núcleo & Descabida & Gramática & Falta & Excesso & Falta & Excesso \\
\hline A1 & 2,47 & 1,52 & 71,24 & 3,37 & 12,58 & 0,00 & 2,80 & 0,42 \\
\hline A2 & 3,17 & 20,97 & 51,33 & 11,67 & 40,67 & 0,00 & 1,35 & 1,76 \\
\hline A3 & 1,22 & 13,26 & 35,30 & 0,00 & 32,60 & 0,00 & 2,25 & 0,00 \\
\hline A4 & 7,78 & 11,36 & 44,44 & 10,12 & 16,98 & 0,00 & 2,90 & 0,49 \\
\hline A5 & 7,59 & 7,14 & 9,96 & 17,01 & 26,18 & 0,00 & 36,04 & 1,40 \\
\hline A6 & 0,59 & 10,66 & 33,27 & 0,00 & 1,79 & 0,00 & 0,00 & 0,00 \\
\hline A7 & 1,28 & 0,79 & 1,28 & 0,17 & 8,38 & 0,00 & 0,20 & 0,35 \\
\hline
\end{tabular}


Tabela 17: Valores do Chi-quadrado da Naturalidade

\begin{tabular}{|c|c|c|c|c|c|c|c|c|}
\hline & \multicolumn{6}{|c|}{ Erro na Pergunta } & \multicolumn{2}{|c|}{ Erro na Resposta } \\
\hline & Inversão & Núcleo & Descabida & Gramática & Falta & Excesso & Falta & Excesso \\
\hline A1 & 3,74 & 10,68 & 22,95 & 3,82 & 4,65 & 0,00 & 4,79 & 1,02 \\
\hline A2 & 5,51 & 20,27 & 51,33 & 11,60 & 38,94 & 0,00 & 1,21 & 1,82 \\
\hline A3 & 1,66 & 7,22 & 24,61 & 0,00 & 24,97 & 0,00 & 0,90 & 0,00 \\
\hline A4 & 10,49 & 13,85 & 47,82 & 9,28 & 3,51 & 0,00 & 3,03 & 0,39 \\
\hline A5 & 7,59 & 16,35 & 16,09 & 31,11 & 17,00 & 0,00 & 17,05 & 1,72 \\
\hline A6 & 6,16 & 5,76 & 32,83 & 0,00 & 35,09 & 0,00 & 0,00 & 0,00 \\
\hline
\end{tabular}

